\title{
Research on the Hard-Rock Breaking Mechanism of Hydraulic Drilling Impact Tunneling
}

\author{
Risheng Long, ${ }^{1,2}$ Shaoni Sun, ${ }^{3}$ and Zisheng Lian ${ }^{1,2}$ \\ ${ }^{1}$ College of Mechanical Engineering, Taiyuan University of Technology, Taiyuan, Shanxi 030024, China \\ ${ }^{2}$ Shanxi Key Laboratory of Fully Mechanized Coal Mining Equipment, Taiyuan, Shanxi 030024, China \\ ${ }^{3}$ School of Mechanical Engineering and Automation, Northeastern University, Shenyang, Liaoning 110004, China
}

Correspondence should be addressed to Risheng Long; etomi@163.com

Received 19 May 2015; Revised 21 July 2015; Accepted 26 July 2015

Academic Editor: Francesco Franco

Copyright (C) 2015 Risheng Long et al. This is an open access article distributed under the Creative Commons Attribution License, which permits unrestricted use, distribution, and reproduction in any medium, provided the original work is properly cited.

In order to realize the rapid hard-rock tunneling in a safe, highly effective, and economic manner, the hydraulic drilling impact hard-rock tunneling (HDIHT) technology and method were introduced based on the theories of rock mechanics and hydraulic impact. The key parameters, including drilling radius and impact distance, were researched to reveal the stress behavior during HDIHT process. The Von Mises equivalent stress and its principal stress components were analyzed, and the breaking mechanism of HDIHT was also discussed. The simulation results show that, to ensure the effectiveness of "secondary breaking" caused by drilling hole free surfaces, the impact distance should not exceed $200 \mathrm{~mm}$, and the optimal drilling radius was about $35 \mathrm{~mm}$.

\section{Introduction}

Hard-rock rapid tunneling, especially for the rock whose hardness exceeds f10 (rock Platts ruggedness coefficient), is a worldwide technical issue, whether for underground tunneling or construction. So far, drill and blast tunneling (DBT) and heavy-duty roadheader are still the main methods for hard-rock tunneling in coal mine. However, lots of auxiliary equipment and persons needed at working face, great damage to the surrounding rocks, and overtunneling and insufficient tunneling of final sections are the major problems of DBT method. Heavy-duty roadheader also has its disadvantages which are as follows: lower economic cutting hardness $(\leq \mathrm{f} 8)$, nethermore tunneling efficiency, higher cutter consumption rate, and so forth. Although the hard-rock tunnels $(\geq \mathrm{f} 10)$ are not more than 5 percent of the general amount of annual tunneling, it is still a crucial restriction factor for the highly efficient production and management of coal mine. Therefore, it is urgent to seek a novel, safe, and highly effective approach (including theories, technology, and equipment) for the hard-rock rapid tunneling, with no explosion.

Hydraulic drilling impact hard-rock tunneling (HDIHT) may be just the potential method we are looking for. Based on the theories of rock mechanics, when hammer impacts hard rock directly, its impact energy will be converted into the compressive wave in the depths of rock at the impact moment, and a broken pit is formed instantly. If some holes existed in working face, the compressive impact wave will be transformed into the tensile stress after the reflection at free surfaces. Owing to the fact that the tensile strength of rock is only three to five percent of its compressive strength, the rock near the holes may be broken again under the secondary breaking effect of "compression-tension" transformation [1, 2]. Thus, in the proposed HDIHT process, many holes should be drilled in advance to increase free surface area, and then a hydraulic breaker with large impact energy was used to impact and crush hard rock directly.

Many numerical simulation methods, including mechanics of continuous medium (MCM), mechanics of noncontinuous medium (MNCM), and coupling analysis of continuous discrete (CACD), have been conducted to reveal the breaking and failure behavior of brittle rock. In 1995, Munjiza et al. [3,4] introduced the damage mechanics and fracture mechanics into the finite element method (FEM) and proposed the combined finite-discrete element method (CF/DEM) to simulate the brittle fracture and failure. Based 


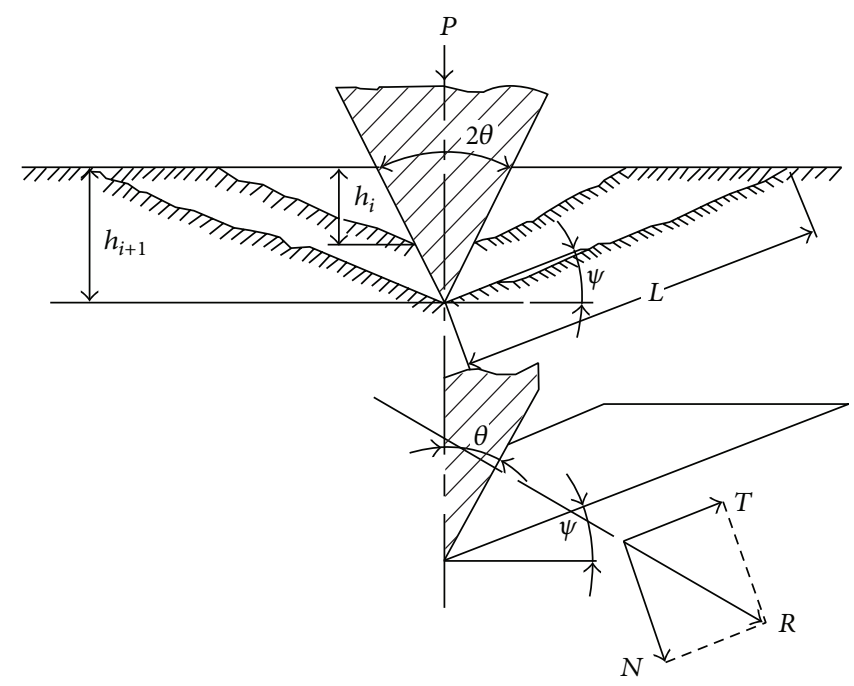

FIGURE 1: Sketch of the rock intrusion process of wedge shaped blade.

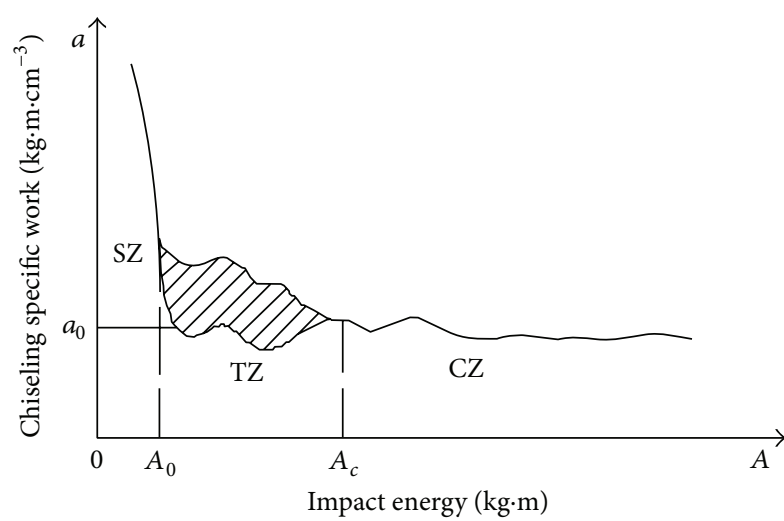

FIgURE 2: $\alpha$ - $A$ curve during impact breaking process.

on the MCM approach and deep understanding of rock's heterogeneity, Tang and his team [5-7] proposed a realistic failure process analysis model $\left(\mathrm{RFPA}^{2 \mathrm{D}}, \mathrm{RFPA}^{3 \mathrm{D}}\right)$, which had been widely used around the world. Jing et al. [8] presented a numerical model for coupled hydromechanical processes in fractured hard rocks using the discontinuous deformation analysis (DDA) method, but their emphasis was placed on the physical behaviour of the coupled stress/deformation and fluid flow interaction in rock fractures. Zhang et al. [9] used a modified discontinuous deformation algorithm to simulate the failure behavior of jointed rock. Using particle simulation method, Xia and Zhou [10] investigated the failure process of brittle rock under triaxial compression through both experimental and numerical approaches. Based on the statistical continuum damage mechanics theory and the finite element method (FEM), Li et al. [11] developed a statistical meso-damage mechanical method (SMDMM) to model the transscale progressive failure process of rock. Furthermore, many simulations were also carried out by Min and other researchers to study the failure process of brittle rock [1218]. However, the researches about the hard-rock breaking mechanism of HDIHT method and technology have never been reported yet.

In this work, based on the relevant rock mechanics theories and "element birth and death" technique, the key parameters, including drilling radius (dr) and impact distance (di), were researched to explore the hard-rock stress behavior during HDIHT process through APDL programming. The Von Mises equivalent stress and its principal stress components were analyzed in detail, and the breaking mechanism of HDIHT was also discussed.

\section{Theoretical Analysis and Calculation}

On the basis of the relevant theories of rock static intrusion $[1,2]$, Paul simplified the rock intrusion of wedge shaped blade into the sketch shown in Figure 1. Suppose $R$ was the stress component of load $P$ along the vertical edge-surface direction; it could be decomposed into the shear force $(T)$ and normal force $(N)$ on the shear fracture surface. Based on Mohr-Coulomb failure theory, when shear stress $\tau$ exceeded cohesion $C$ and internal friction $\mu \sigma$, shear-breaking would occur. The failure condition was given by

$$
\tau-\mu \sigma=C
$$

Assuming the load of the $i$ th impact was $P_{i}^{*}$, the penetration depth of the $i$ th impact was $H_{i}^{*}$, and the edge angle was $2 \theta$ (see Figure 1), there must be a relationship between the $(i+1)$ th load and its stress:

$$
\begin{aligned}
& R=\frac{P_{i+1}^{*}}{2 \sin \theta}, \\
& L=\frac{h_{i+1}^{*}}{\sin \psi},
\end{aligned}
$$




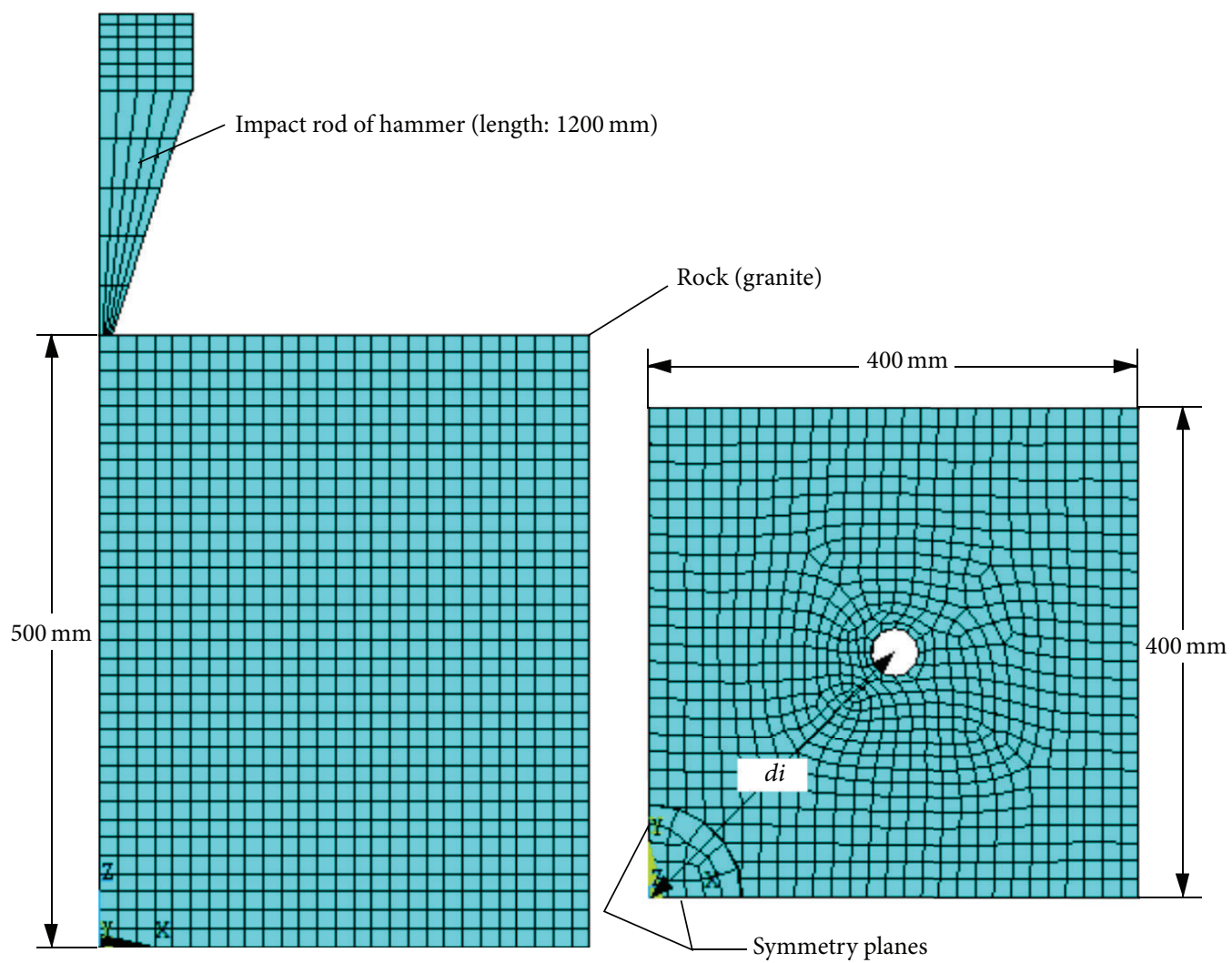

FIGURE 3: Sketch of FE model used in the simulations.

where $L$ was the length of shear plane and $\psi$ was the shear plane angle. Using edge length as the unit, $\tau$ and $\sigma$ could be given by

$$
\begin{gathered}
\tau=\frac{T}{L}=\frac{R}{L} \cos (\psi+\theta), \\
\sigma=\frac{N}{L}=\frac{R}{L} \sin (\psi+\theta) .
\end{gathered}
$$

Substituting (3) and (4) into (1), then (1) could be rewritten as

$$
\begin{gathered}
\tau-\mu \sigma=\frac{P_{i+1}^{*}}{h_{i+1}^{*} 2 \sin \theta}[\sin \psi \cos (\psi+\theta) \\
-\mu \sin \psi \sin (\psi+\theta)] .
\end{gathered}
$$

The internal friction angle $\phi$ was used to represent the internal friction coefficient; that is,

$$
\mu=\operatorname{tg} \phi=\frac{\sin \phi}{\cos \phi} .
$$

Equation (5) could be further written as

$$
\begin{gathered}
\tau-\mu \sigma=\frac{P_{i+1}^{*}}{h_{i+1}^{*}} \cdot \frac{1}{2 \sin \theta \cos \phi}[\sin \psi \cos (\psi+\theta) \cos \phi \\
-\sin \psi \sin (\psi+\theta) \sin \phi]=\frac{P_{i+1}^{*}}{2 h_{i+1}^{*}} \\
. \frac{\sin \psi \cos (\psi+\theta+\phi)}{\sin \theta \cos \phi},
\end{gathered}
$$

where $\tau-\mu \sigma$ was a function of $\psi$. Setting the first derivative of (7) equals zero, it was easy to be found that when

$$
\psi=\frac{\pi}{4}-\frac{\theta+\phi}{2}
$$

The value of $\tau-\mu \sigma$ reached its maximum. Therefore, the shear-breaking surface would first appear in the plane of the slope of $\psi$. When $\theta+\Phi<90^{\circ}$, shear-breaking might occur; while $\theta+\Phi>90^{\circ}$, the rock was in a fully compressed state; the leap-forward invasion would not happen. Substituting (8) into (7), (7) could be finally written as

$$
\begin{aligned}
\tau & -\mu \sigma \\
& =\frac{P_{i+1}^{*}}{h_{i+1}^{*}} \frac{\sin (\pi / 4-(\theta+\phi) / 2) \cos (\pi / 4+(\theta+\phi) / 2)}{2 \sin \theta \cos \phi} \\
& =C .
\end{aligned}
$$




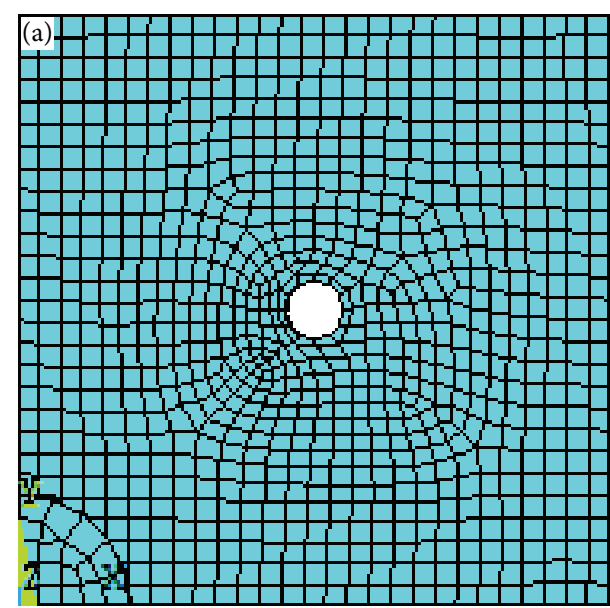

(a) $\mathrm{dr}=20 \mathrm{~mm}, \mathrm{di}=200 \mathrm{~mm}$

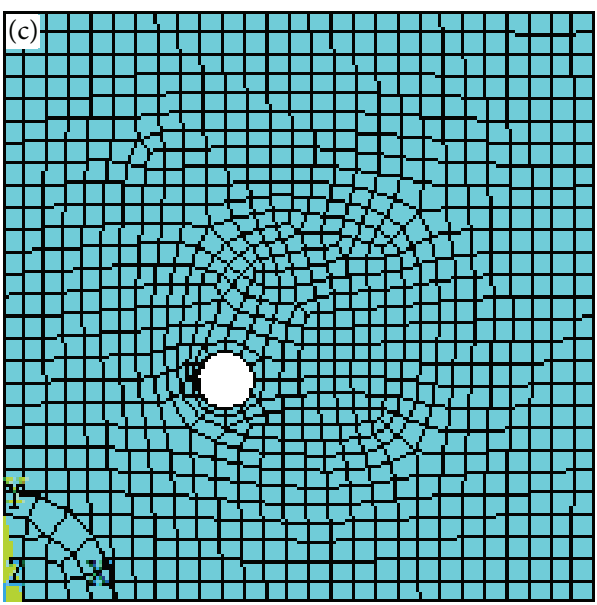

(c) $\mathrm{dr}=20 \mathrm{~mm}, \mathrm{di}=150 \mathrm{~mm}$

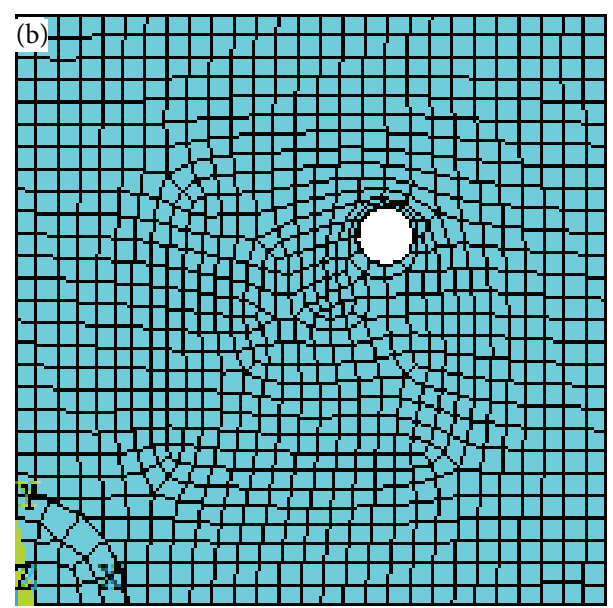

(b) $\mathrm{dr}=20 \mathrm{~mm}, \mathrm{di}=250 \mathrm{~mm}$

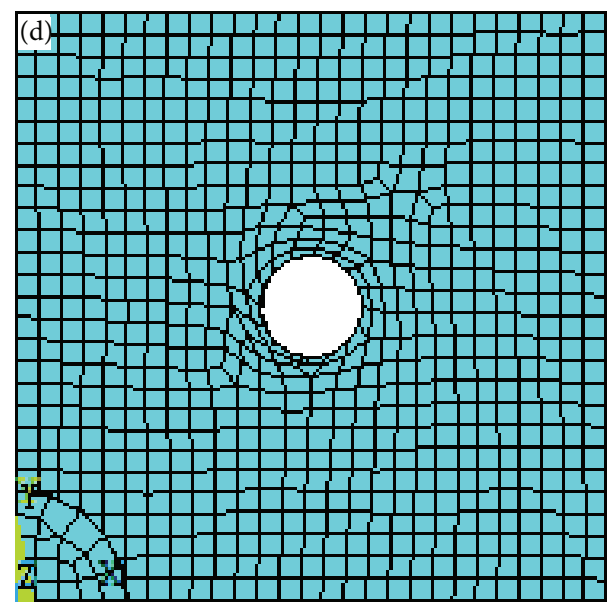

(d) $\mathrm{dr}=35 \mathrm{~mm}, \mathrm{di}=200 \mathrm{~mm}$

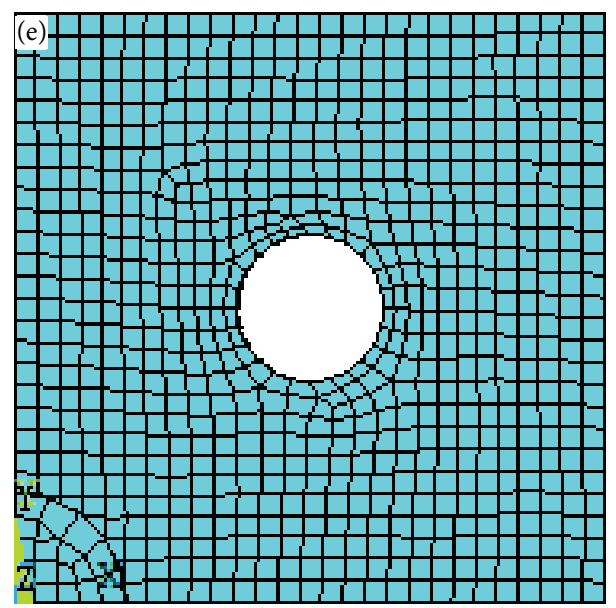

(e) $\mathrm{dr}=50 \mathrm{~mm}, \mathrm{di}=200 \mathrm{~mm}$

FIgURE 4: Comparison of different FE models.

Solving the above formula, the ratio of $P_{i+1}^{*}$ to $h_{i+1}^{*}$ could be given by

$$
\frac{P_{i+1}^{*}}{h_{i+1}^{*}}=\frac{4 C \cdot \sin \theta \cdot(1-\sin \phi)}{1-\sin (\theta+\phi)}=K
$$

That is, the ratio of each impact's load to its invasion depth was a constant. In addition, according to the correlation between impact energy and chiseling specific work (CSW, $\alpha$ ), the $\alpha$-A curve of impact breaking process could be divided into three zones, that is, scaring zone (SZ), transient zone 

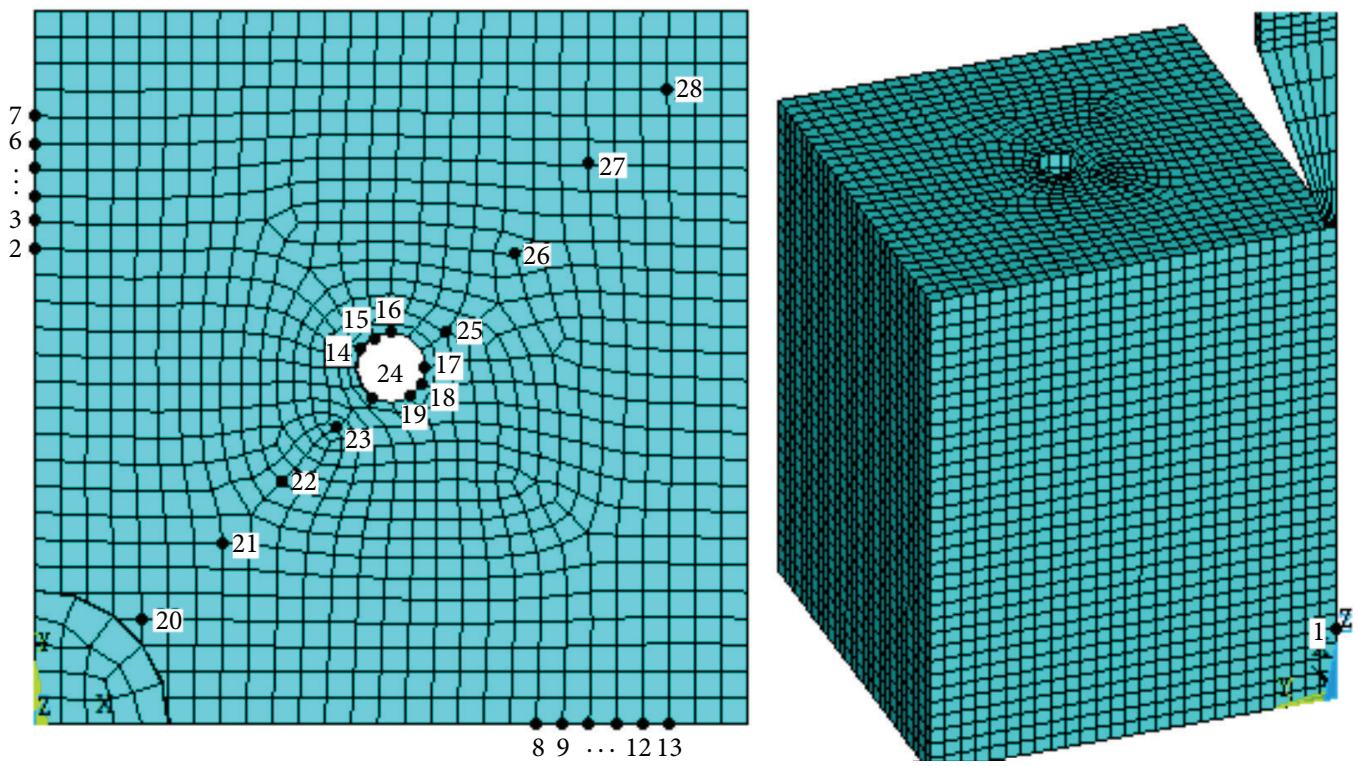

FIGURE 5: Sketch of node distribution in FE model.

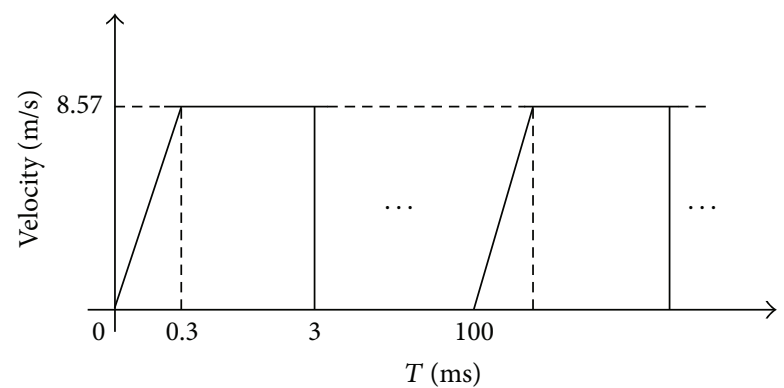

FIGURE 6: Velocity-time loading curve of impact rod in the simulations.

(TZ), and crushed zone (CZ). When impact energy was quite small, the $\alpha$-A curve would fall into its left side, which was SZ. In this region, the impact power was too small to form a broken pit, and the dropped rock powder was very fine, for the CSW was quite large. The shaded region in $\alpha$ - $A$ curve was TZ. In this domain, the impact breaking data and behavior were unpredictable. As impact energy was larger than $A_{c}$, the $\alpha-A$ curve would eventually enter a relatively stable region, $\mathrm{CZ}$.

With regard to the relationship between broken rock volume $\left(V_{\text {break }}\right)$ and impact energy $(A)$, the following empirical formula was widely used and expressed as follows [1]:

$$
V_{\text {break }}=C_{1}\left(A-A_{0}\right)^{a}
$$

where $A_{0}=0, a=1, C_{1}=1 / \alpha$, in units of $\mathrm{kg}^{-1} \cdot \mathrm{m}^{-1} \cdot \mathrm{cm}^{3}$.

Supposing the impact energy of hydraulic impact hammer is $7500 \mathrm{~J}$, rod diameter, $150 \mathrm{~mm}$, and the CSW of granite,
$26 \mathrm{~kg} \cdot \mathrm{m} \cdot \mathrm{cm}^{-3}$, the crushed granite volume of each impact could be calculated as follows:

$$
\begin{aligned}
V_{\text {break }} & =\frac{A}{\alpha}=\frac{7500(\mathrm{~N} \cdot \mathrm{m})}{26\left(\mathrm{~kg} \cdot \mathrm{m} / \mathrm{cm}^{3}\right)}=\frac{7500}{26 \times 10 / 10^{-6}} \mathrm{~m}^{3} \\
& =2.885 \times 10^{-5} \mathrm{~m}^{3} .
\end{aligned}
$$

Based on the crushed granite volume of each impact, if hammer impacted a fixed point repeatedly, the final radius of broken pit $\left(r_{\text {pit }}\right)$ should meet the following:

$$
\begin{aligned}
\pi r_{\mathrm{pit}}^{2} \cdot \frac{h}{3} & =2.885 \times 10^{-5} \times n_{\mathrm{imp}}, \\
\frac{r_{\mathrm{pit}}}{h_{\mathrm{pit}}} & =0.375
\end{aligned}
$$

where $n_{\text {imp }}$ was the impact times at a fixed point, $h_{\text {pit }}$ was the depth of broken pit, and 0.375 was a constant, decided and given by the end-shape of impact rod. Therefore, in theory, hydraulic impact tunneling was feasible. 


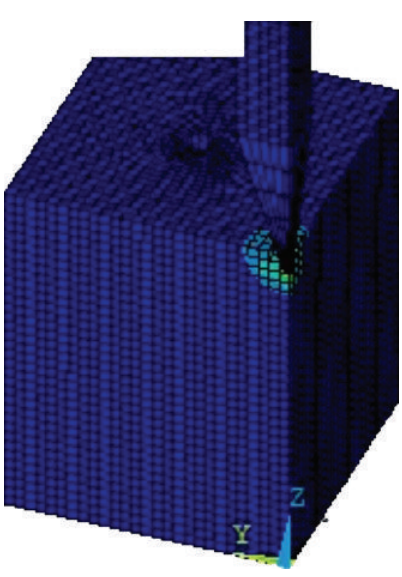

(a) The 0.003 th s

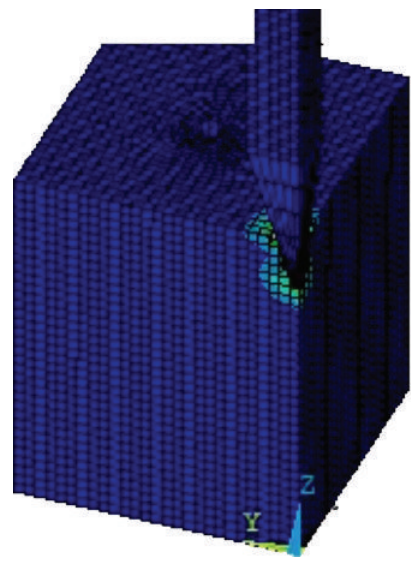

(b) The 0.203th s

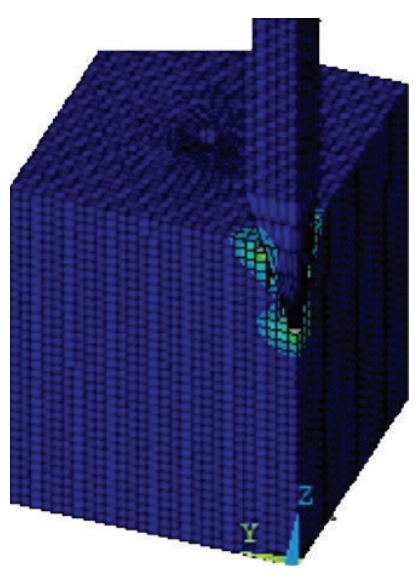

(c) The 0.403th s
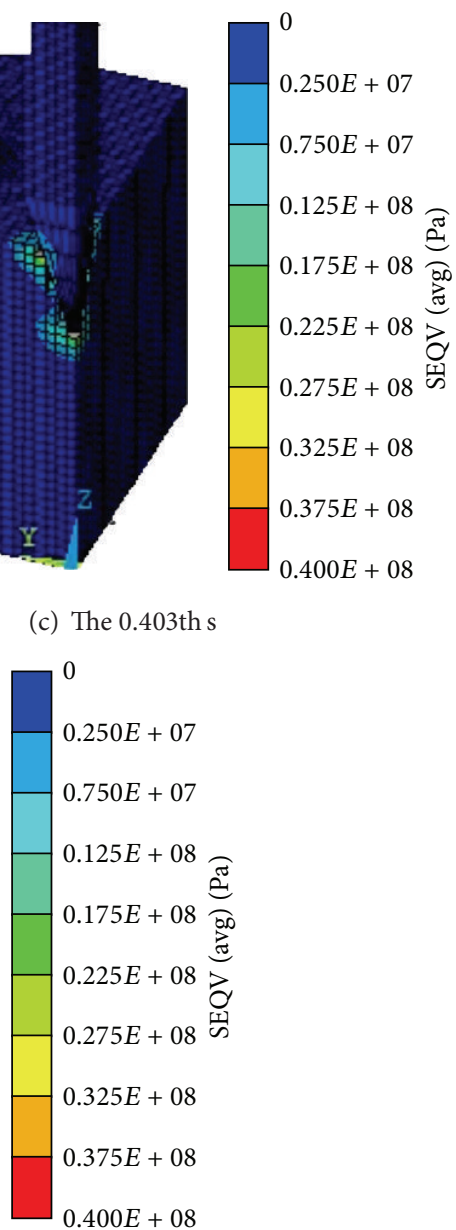

(d) The 0.603th s

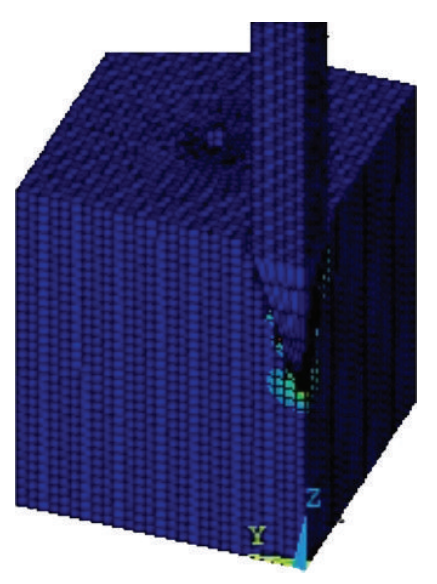

(e) The 0.803th s

Figure 7: The Von Mises equivalent stress contours of model A at different time.

\section{Finite Element Modeling and Configuration}

Taking the granite, whose Platts ruggedness coefficient varied from $\mathrm{f} 10$ to $\mathrm{f} 15$, as the research object, the mechanical and physical properties parameters were listed as follows: elastic modulus, $3.58 \times 10^{4} \mathrm{MPa}$; Poisson's ratio, 0.28 ; ratio of tensile strength to compressive strength, 0.03. For almost all crushed granite was powdery detritus in actual impact breaking process, and the objective of this work was mainly focused on the stress variation behavior of broken pit, drilling holes, and their surrounding area, the crack generation and propagation of granite during HDIHT process would not be considered. Thus, the following assumptions could be made:

(1) Based on the continuous homogeneous medium theory and the characteristics of granite, the isotropic bilinear kinematics hardening model was used. But the joint development and tectonic changes of granite was not taken into account in the simulations.

(2) In virtue of ANSYS/LS-DYNA module, the "surface to surface" contact type of ESTS algorithm was chosen, and the "element birth and death" technique was realized through APDL programming.

(3) The compressive and shear strength were used as the failure criterion of granite elements. Program could automatically calculates the stress status of each cell after one load step or substep. For the cells, whose Von Mises equivalent stress exceeded the compressive or shear strength of granite, they would be deemed invalid and would be removed from the model immediately. In the meantime, system would also automatically redefine the contact relationship between rod-end and broken pit.

(4) To consider the effect of surrounding rocks in actual impact breaking process, the side and bottom surfaces of FE model were all set as the unlimited boundaries.

The main parameters of hydraulic hammer were listed in Table 1. In order to reduce the computational workload, as depicted in Figure 3, FE model with the rock size of $400 \mathrm{~mm} \times$ $400 \mathrm{~mm} \times 500 \mathrm{~mm}$ (length $\times$ width $\times$ thickness) was only 

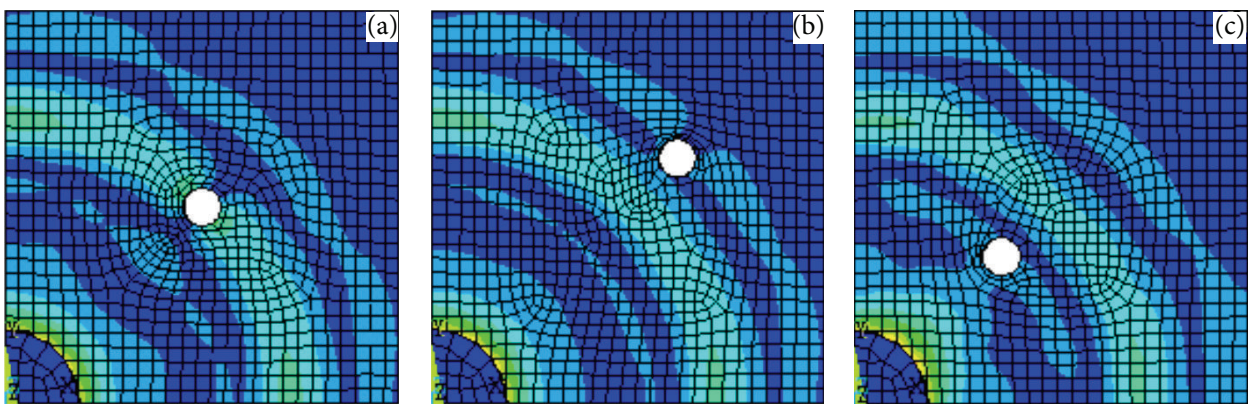

Time $=0.002 \mathrm{~s}$
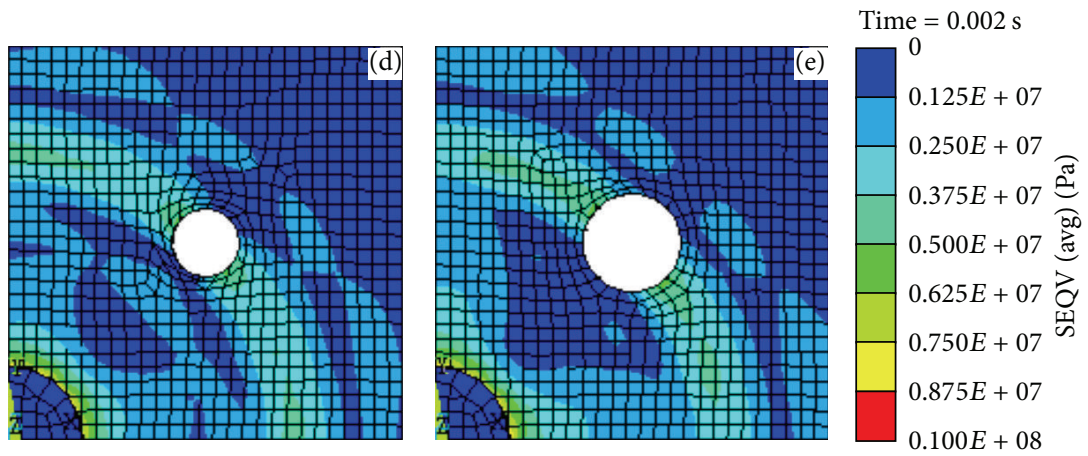

Figure 8: The Von Mises equivalent stress top-view contours of different models at the 0.002th s.
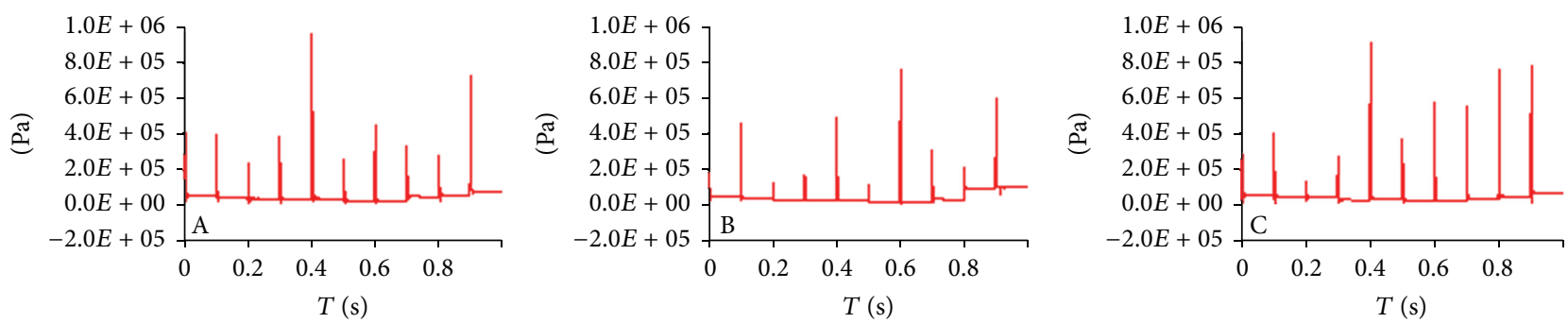

(a) The Von Mises equivalent stress curves
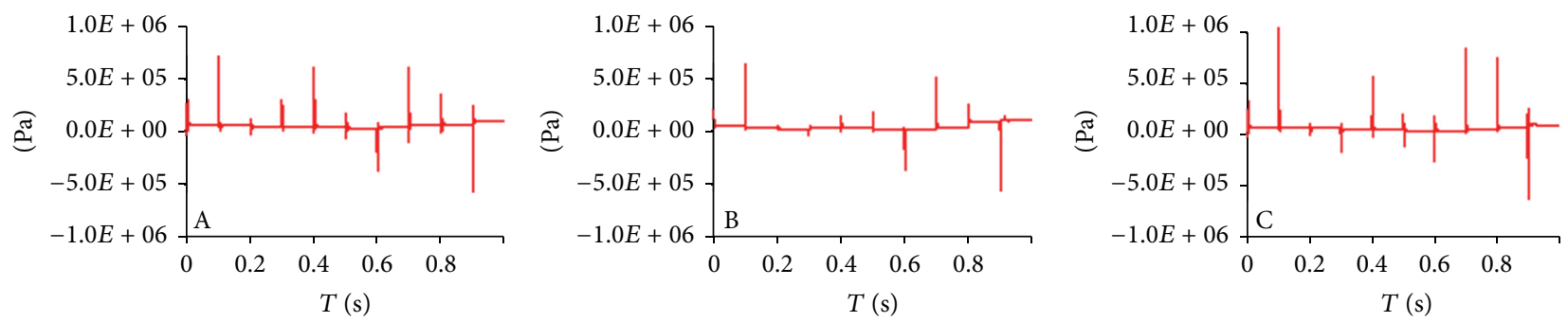

(b) The 1st principal stress curves
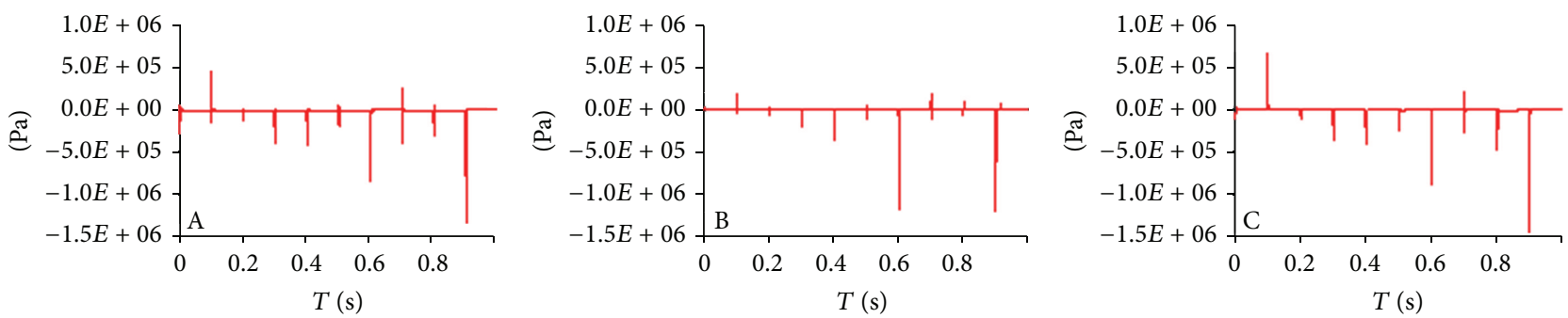

(c) The 3rd principal stress curves

FiguRE 9: Stress variation curves of bottom node in models A, B, and C. 

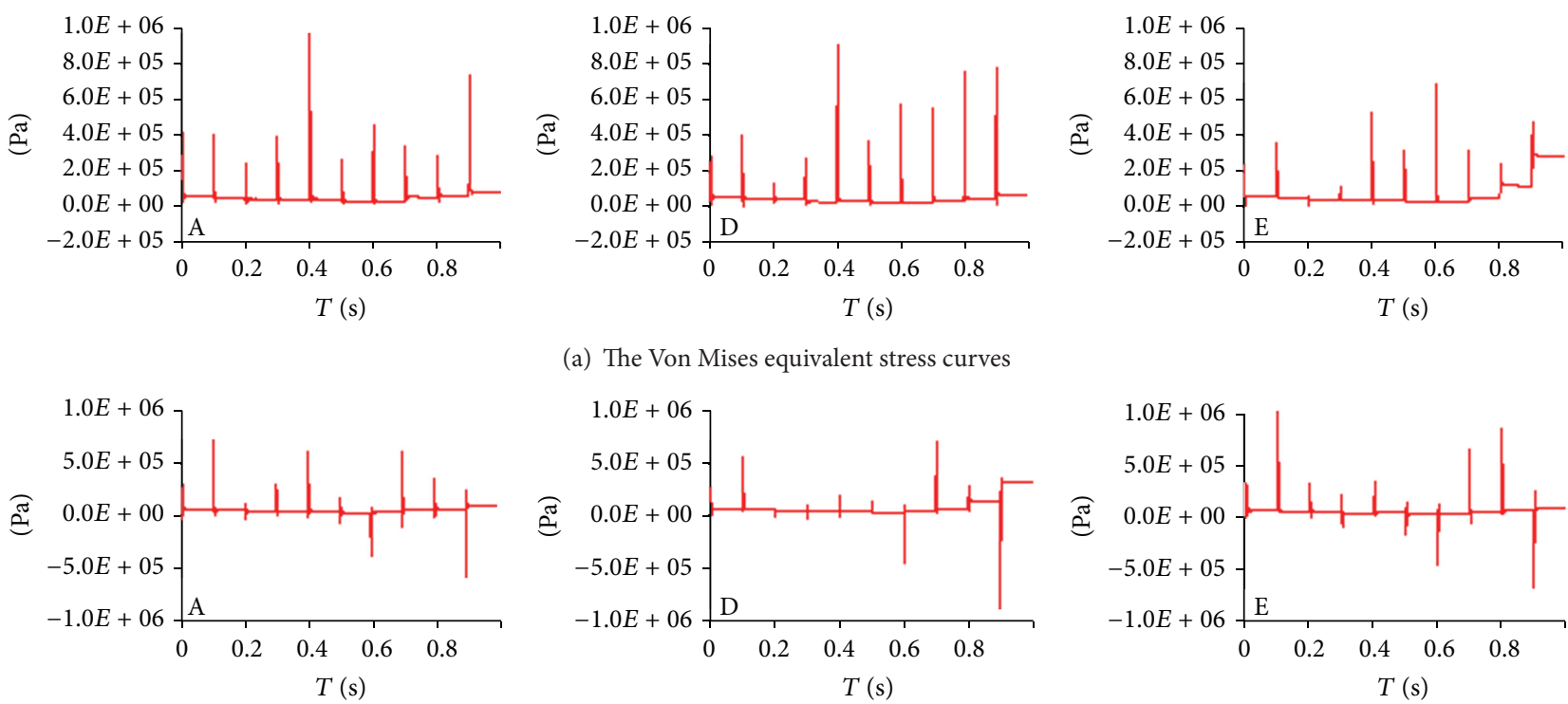

(a) The Von Mises equivalent stress curves
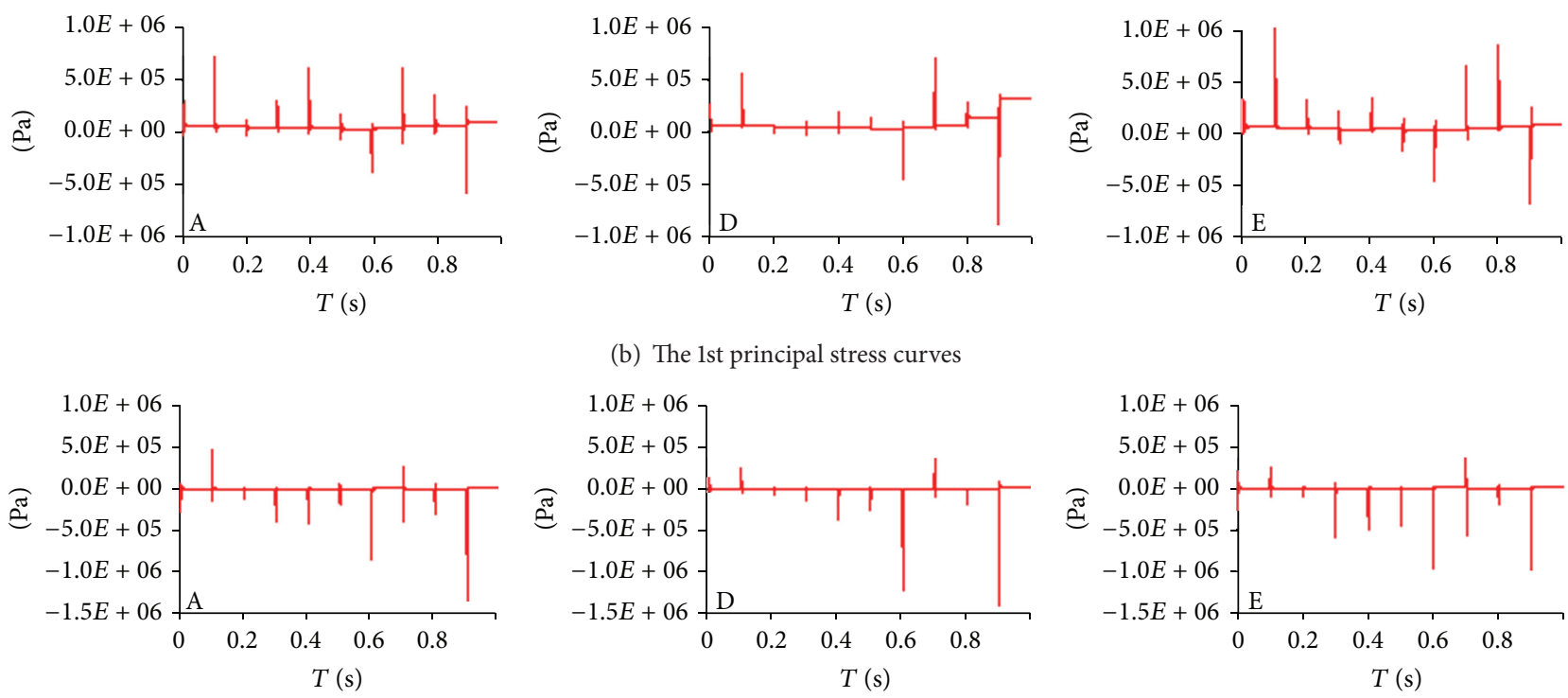

(c) The 3rd principal stress curves

FIGURE 10: Stress variation curves of bottom node in models A, D, and E.

TABLE 1: Main parameters of hydraulic hammer with large impact energy.

\begin{tabular}{lc}
\hline Parameter name & Value \\
\hline Impact energy & $7500 \mathrm{~J}$ \\
Piston weight of hammer & $200 \mathrm{~kg}$ \\
Rod diameter & $150 \mathrm{~mm}$ \\
Piston energy transfer efficiency & $98 \%$ \\
Elastic modulus of rod material & $1.02 E 11 \mathrm{~Pa}$ \\
Density of rod material & $7800 \mathrm{~kg} \cdot \mathrm{m}^{-3}$ \\
Impact frequency & $10 \mathrm{~Hz}$ \\
Rod weight & $200 \mathrm{~kg}$ \\
Rod length & $1200 \mathrm{~mm}$ \\
Rod tip diameter & $20 \mathrm{~mm}$ \\
Rod tip length & $200 \mathrm{~mm}$ \\
Poisson's ratio of rod material & 0.3 \\
\hline
\end{tabular}

a quarter of the actual one and the symmetry boundary conditions were applied on its symmetry planes.

There were five different models developed to explore the stress variation behavior during HDIHT process (see
Figure 4), including model $\mathrm{A}(\mathrm{dr}=20 \mathrm{~mm}, \mathrm{di}=200 \mathrm{~mm})$, model B $(\mathrm{dr}=20 \mathrm{~mm}, \mathrm{di}=250 \mathrm{~mm})$, model C $(\mathrm{dr}=20 \mathrm{~mm}$, di $=150 \mathrm{~mm})$, model $\mathrm{D}(\mathrm{dr}=35 \mathrm{~mm}, \mathrm{di}=200 \mathrm{~mm})$, and model $\mathrm{E}(\mathrm{dr}=50 \mathrm{~mm}, \mathrm{di}=200 \mathrm{~mm})$. As shown in Figure 5, there were 28 typical nodes researched in each model, including bottom node (node 1), nodes along the diagonal (nodes 20 to 28), nodes around drilling hole (nodes 14 to 19), and nodes along sideline (nodes 8 to 13 ).

The impact frequency of rod was $10 \mathrm{~Hz}$, and its loading curve was demonstrated in Figure 6, which lasted one second. In accordance with the impact energy and energy transfer efficiency $\eta_{S}$ (between the piston of hammer and rod) listed in Table 1, the velocity of rod $\left(v_{\text {rod }}\right)$ should meet $7500 \times 98 \%=$ $200 \times v_{\text {rod }}^{2} / 2$; namely, $v_{\text {rod }}=8.57 \mathrm{~m} \cdot \mathrm{s}^{-1}$. Furthermore, to ensure the efficiency of HDIHT method, a pressing force would be applied on the rod to offset its rebound after each impact and keep it in contact with broken pit all the time. The value of pressing force could be calculated by [1]

$$
F=2 f M V_{P}=0.015 N_{f} \sqrt{G A},
$$

where $N_{f}$ was the impact frequency of hammer (BPM), $G$ was the weight of hammer's piston (kg), and $A$ was the impact 

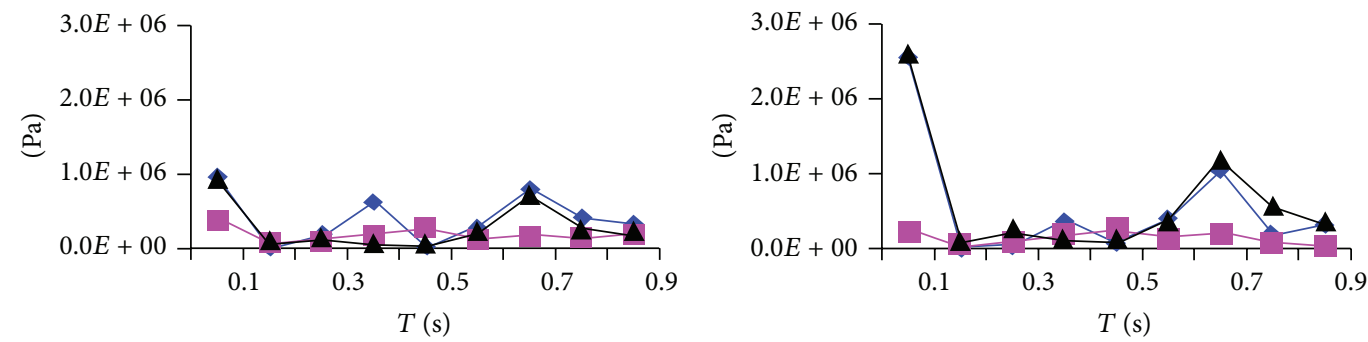

$$
\begin{aligned}
& \multimap \mathrm{A} \\
& -\mathrm{B} \\
& \leftarrow \mathrm{C}
\end{aligned}
$$

$$
\begin{aligned}
& \rightarrow \mathrm{A} \\
& -\mathrm{B}
\end{aligned}
$$

(a) Node 28
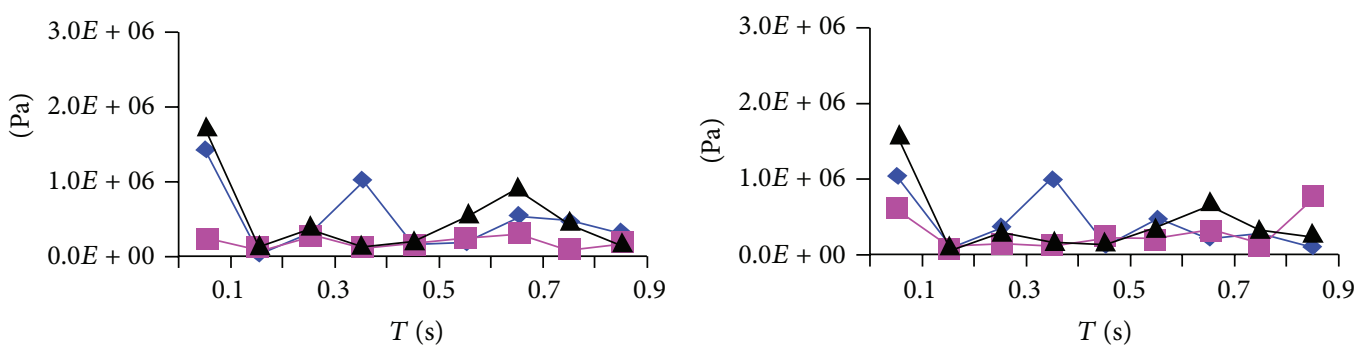

$$
\begin{aligned}
& \multimap \mathrm{A} \\
& -\mathrm{B} \\
& \leftarrow \mathrm{C}
\end{aligned}
$$

$$
\begin{aligned}
& \multimap \mathrm{A} \\
& -\mathrm{B} \\
& \leftarrow \mathrm{C}
\end{aligned}
$$

(c) Node 26

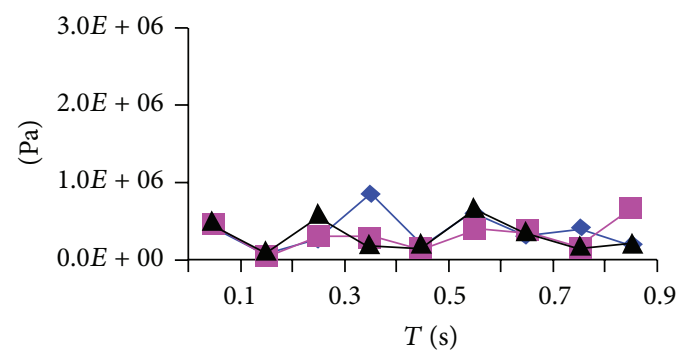

(d) Node 25

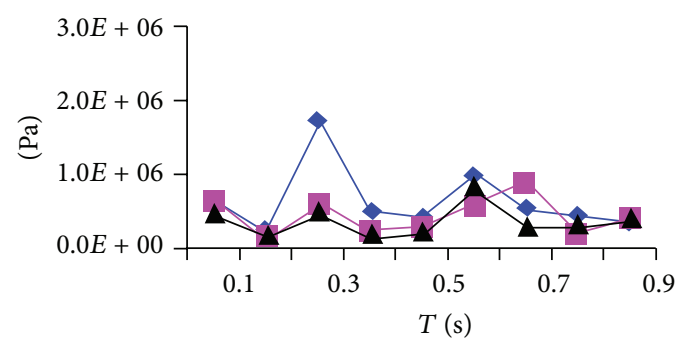

$$
\begin{aligned}
& \rightarrow \mathrm{A} \\
& \rightarrow \mathrm{B}
\end{aligned}
$$$$
\rightarrow \mathrm{A}
$$$$
\rightarrow-B
$$

(e) Node 24

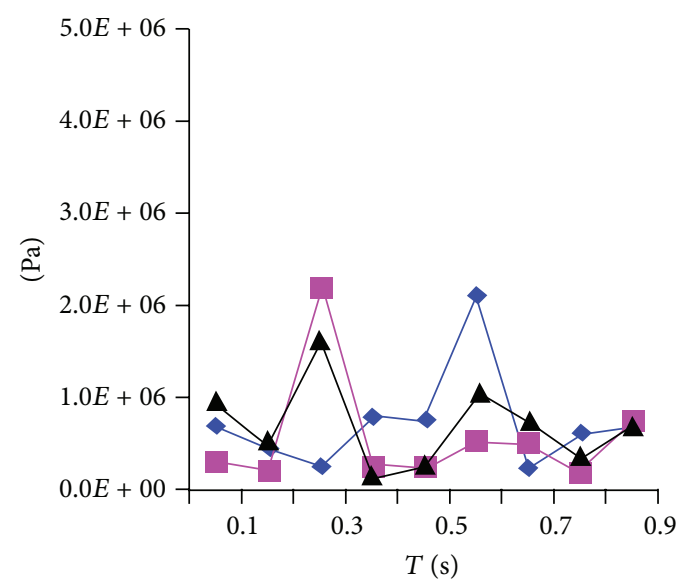

(f) Node 23

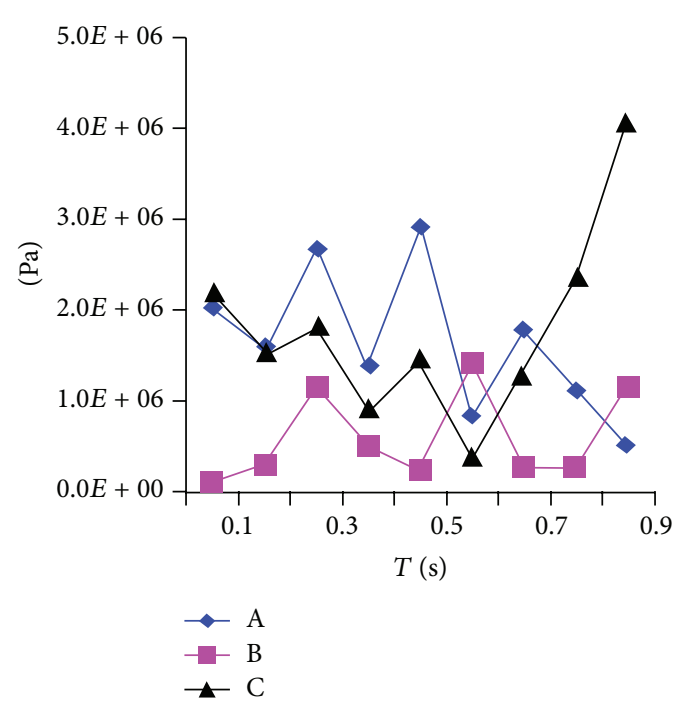

(g) Node 22

Figure 11: Continued. 


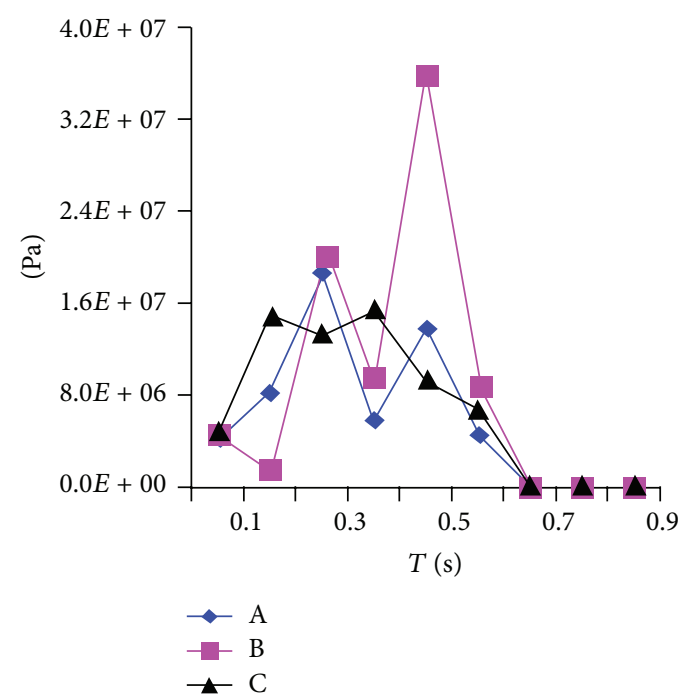

(i) Node 20

FIGURE 11: The Von Mises equivalent stress peak-curves of nodes along the diagonal in models A, B, and C.

energy $(\mathrm{kg} \cdot \mathrm{m})$. Thus, the final pressing force should not be less than

$$
F=0.015 \times 600 \times \sqrt{200 \times 750} \times 10=34850 N .
$$

\section{Simulation Results and Discussion}

4.1. Von Mises Equivalent Stress Contours. Figure 7 showed the Von Mises equivalent stress contours of model A at different time. Obviously, the rod could be penetrated deep into the granite gradually. In the meantime, the elements in broken pit were "killed" and removed, for their stresses had exceeded the compressive or shear strength of granite. It was consistent with the conclusion of theoretical calculation.

Figure 8 depicted the Von Mises stress top-view contours of different models at the 0.002th s. As demonstrated in the figure, when $\mathrm{dr}$ was fixed $(20 \mathrm{~mm})$, there was a significant stress concentration phenomenon around the hole in model $\mathrm{A}$, and the maximum Von Mises stress of hole-nodes (14 to 19 ; see Figure 5) in model A was $2.69 \mathrm{MPa}$. Instead, as di was larger or less than $200 \mathrm{~mm}$, the stress concentration phenomena around the holes both were weakened and became no longer obvious. In this case, the maximum Von Mises stresses of hole-nodes in models B and C were 1.72 MPa and $2.29 \mathrm{MPa}$, respectively. Likewise, for models $\mathrm{A}, \mathrm{D}$, and E, when di was constant $(200 \mathrm{~mm})$, there were significant stress concentration phenomena around the hole for all three models. The maximum Von Mises stress of hole-nodes in model $\mathrm{D}$ was $3.14 \mathrm{MPa}$ and that of hole-nodes in model $\mathrm{E}$ was 3.24 MPa. Once the stress reached or exceeded the tensile strength of granite, which was only three to five percent of its compressive strength, it might result in the secondary crushing of the rock near the hole.

Therefore, the following results could be gained: (1) in this work, the impact distance of $200 \mathrm{~mm}$ might be the critical point of HDIHT process; (2) when di kept constant, with the increase of drilling radius, the Von Mises stress of hole-nodes would ascend simultaneously. That is, the bigger the drilling radius was, the larger the maximum Von Mises stress of holenodes was.

4.2. Stress Behavior of Bottom Node (Node 1). In terms of the three principal components of the Von Mises equivalent stress, because of the symmetry of FE model, only the 1st principal stress and the 3rd principal stress were discussed in the simulations. The location of bottom node (see Figure 5) was just below the drill rod and could directly reflect the stress behavior of the rock under impact rod. Figure 9 revealed the stress variation curves of bottom node in models $\mathrm{A}$, $\mathrm{B}$, and $\mathrm{C}$, including the Von Mises equivalent stress, the 1st principal stress, and the 3rd principal stress. Obviously, when $\mathrm{dr}$ was fixed $(20 \mathrm{~mm})$, among those three models, the stress of bottom node in model $\mathrm{C}$ was the largest, while that in model B was the smallest, whether for the Von Mises equivalent, the 1st principal stress, or the 3rd principal stress. Likewise, Figure 10 demonstrated the stress variation curves of bottom node in models A, D, and E. It was evident that when di kept constant (200 $\mathrm{mm})$, among those three models, the Von Mises equivalent stress of bottom node in model $\mathrm{E}$ was the smallest, while that in model $\mathrm{D}$ was the largest. The 1st principal stress of bottom node in model $\mathrm{E}$ was relatively large, but its $3 \mathrm{rd}$ principal stress was quite small.

Comparing Figure 9 with Figure 10, the following was evident. (1) For the 1st principal stress and the 3rd principal stress of bottom node, there were obvious "compress-tensile stress" transformation phenomena, which could be attributed to the existence of drilling hole free surface. (2) When dr remained unchanged, the stresses of bottom node in model $\mathrm{C}$ were distinctly larger than those in models A and B, regardless 


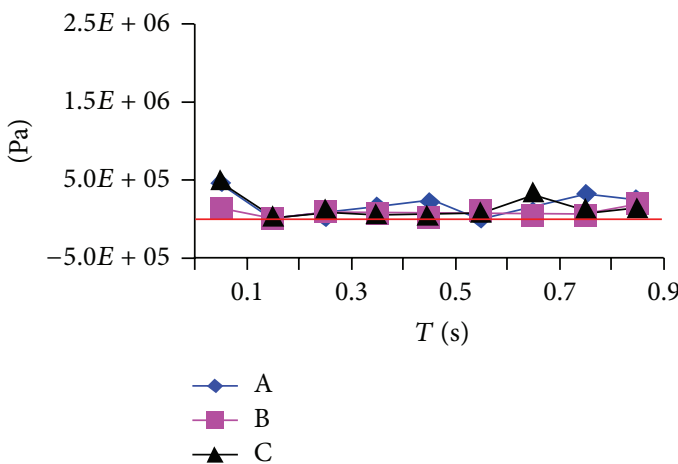

(a) Node 28

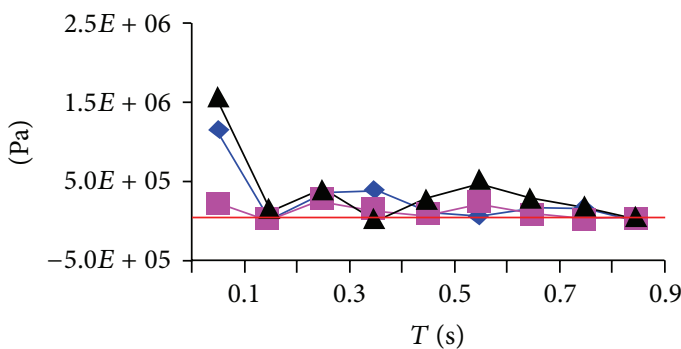

$$
\begin{aligned}
& \rightarrow \mathrm{A} \\
& -\mathrm{B} \\
& \leftarrow \mathrm{C}
\end{aligned}
$$

(c) Node 26

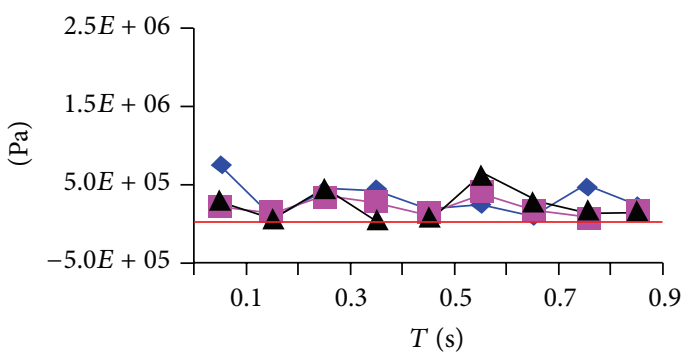

$$
\begin{aligned}
& \multimap \mathrm{A} \\
& -\mathrm{B} \\
& \leftarrow \mathrm{C}
\end{aligned}
$$

(e) Node 24

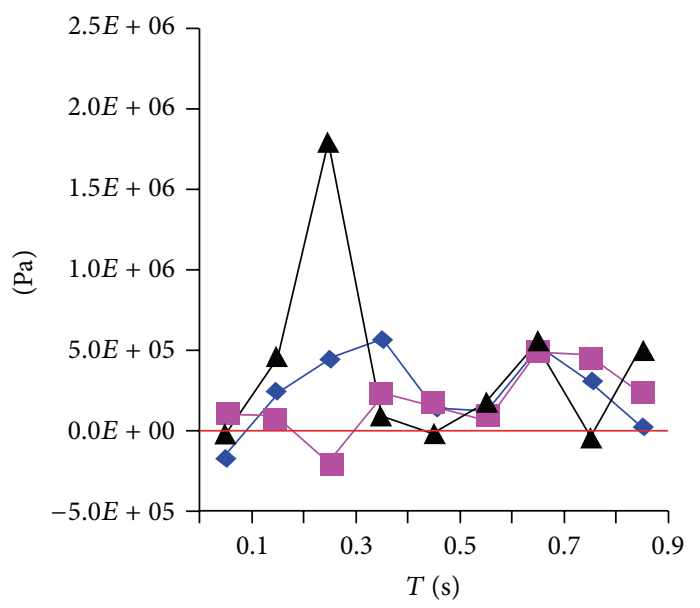

$$
\begin{aligned}
& \rightarrow \mathrm{A} \\
& \rightarrow-\mathrm{B} \\
& -\mathrm{C}
\end{aligned}
$$

(g) Node 22

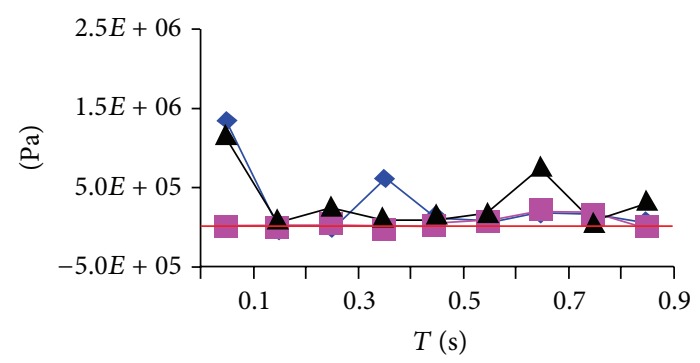

$$
\begin{aligned}
& \leftarrow \mathrm{A} \\
& -\mathrm{B} \\
& \leftarrow \mathrm{C}
\end{aligned}
$$

(b) Node 27

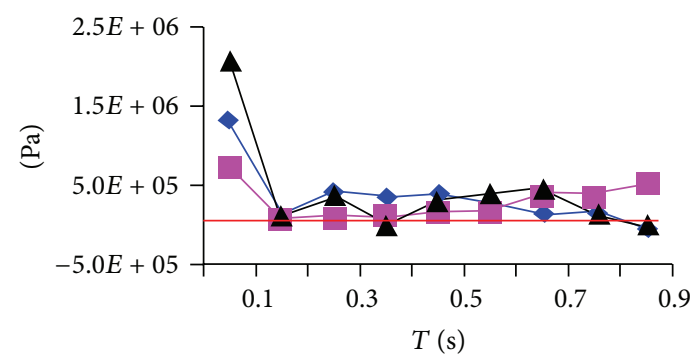

$$
\begin{aligned}
& \rightarrow \mathrm{A} \\
& \rightarrow \mathrm{B} \\
& \leftarrow \mathrm{C}
\end{aligned}
$$

(d) Node 25

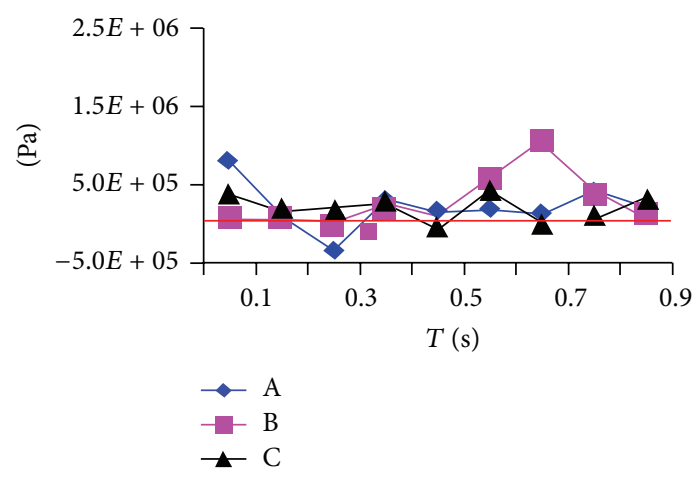

(f) Node 23

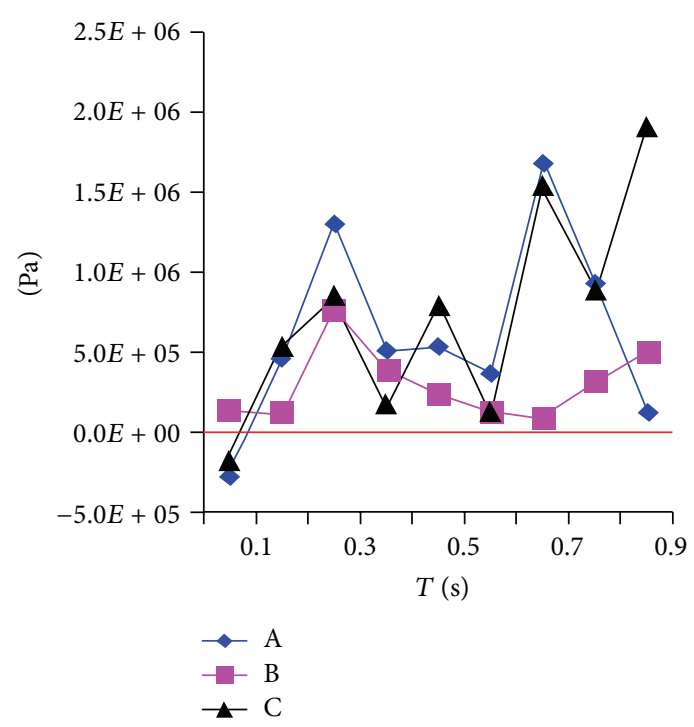

(h) Node 21

Figure 12: Continued. 


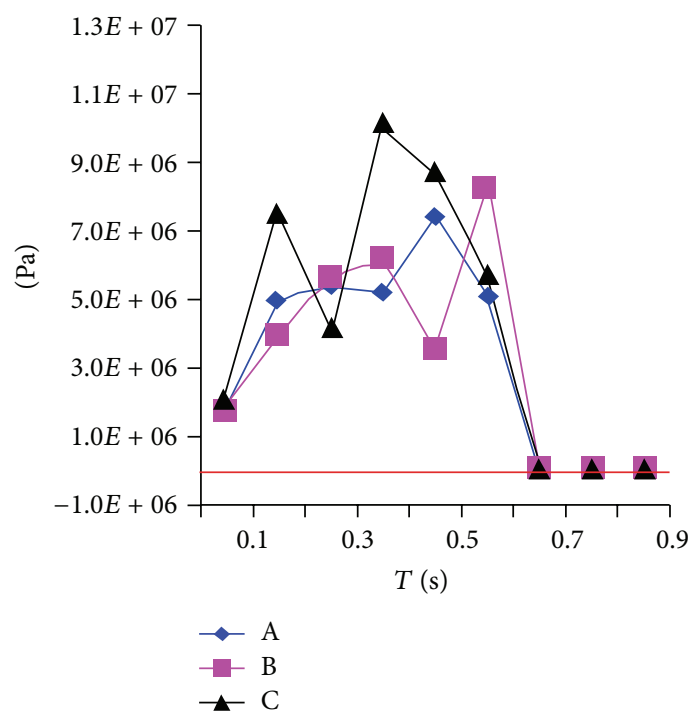

(i) Node 20

FIGURE 12: The 1st principal stress peak-curves of nodes along the diagonal in models A, B, and C.

of the Von Mises equivalent stress, the 1st principal stress, or the 3rd principal stress. That is, the smaller the di was, the larger the stress of bottom node was. For a certain working face, if the hole spacing was too small, it meant that there were more holes which had to be drilled per unit area and we must spend more time in drilling, which was sometimes impossible to accept. (3) When di kept constant, the stresses of bottom node in model $\mathrm{D}$ were slightly larger than those in models $\mathrm{A}$ and $\mathrm{E}$, indicating that there was a critical drilling radius. In this work, the drilling radius of $35 \mathrm{~mm}$ might be a good choice.

4.3. Stress Behavior of Nodes along the Diagonal (Nodes 20 to 28). Note that, to better reveal the stress variation regularities during HDIHT process, the curves in the following figures were all peak stress curves. Figures 11-13 displayed the stress variation curves of nodes along the diagonal (see Figure 5) in models A, B, and C, including the Von Mises equivalent stress, the 1st principal stress, and the 3rd principal stress. From Figures 11-13, it was easy to find that node 20 was killed at the 0.7 th $\mathrm{s}$, and its stress kept zero from the 0.7 th $\mathrm{s}$ to the end. In addition, the stresses of node 20 were much larger than other nodes, whether for the Von Mises equivalent stress, the 1st principal stress, or the 3rd principal stress. This was because node 20 was the closest node to impact rod. Specifically, the maximum Von Mises equivalent stress of node 20 in model $\mathrm{B}$ was quite larger than that in models $\mathrm{A}$ and $\mathrm{C}$, about $35.89 \mathrm{MPa}$. Its 1st principal stress in model $\mathrm{C}$ was larger than that in models $\mathrm{A}$ and $\mathrm{B}$, which was equal to 10.16 $\mathrm{MPa}$ and expressed as the tensile stress, while its 3rd principal stress in model $\mathrm{B}$ was larger than that in models $\mathrm{A}$ and $\mathrm{C}$, about $39.43 \mathrm{MPa}$, and shown as compressive stress. In terms of node 21, it was evident that the effect of impact distance on the stresses of those nodes along the diagonal in model B was the smallest, whether for the Von Mises equivalent stress, the 1st principal stress, or the 3rd principal stress. Therefore, larger impact distance could significantly weaken the effect of drilling hole free surface.

Moreover, in the case of node 24, although it located on the edge of drilling hole, no distinct "compress-tensile stress transformation" occurred, regardless of the 1st principal stress or the 3rd principal stress. As for those nodes far away from impact place, their stresses were quite smaller than the stresses of nodes 21 and 20 and had less influence on the final breaking performance of HDIHT technology. Thus, they would not be discussed in the following work.

Figures 14-16 depicted the stress variation curves of nodes along diagonal in models $\mathrm{A}, \mathrm{D}$, and $\mathrm{E}$. As demonstrated in the figures, when di kept constant, regardless of the Von Mises equivalent stress, the 1st principal stress, or the $3 \mathrm{rd}$ principal stress, the stresses of node 20 in model $\mathrm{D}$ were undoubtedly the largest among models $\mathrm{A}, \mathrm{D}$, and $\mathrm{E}$ wherein the maximum 1st principal stress of node 20 in model $D$ was $8.83 \mathrm{MPa}$, while the maximum $3 \mathrm{rd}$ principal stress of node 20 in model D equaled $38.99 \mathrm{MPa}$. In terms of node 24 , no obvious "compress-tensile stress transformation" occurred too.

By comparing Figures 11-16, the following conclusions could be drawn. (1) For node 24, no obvious "compresstensile stress transformation" occurred in all models. (2) The 1st principal stress of nodes along diagonal in all models is expressed as the tensile stresses, which was very important for the hard-rock breaking process. (3) When dr kept constant, the maximum Von Mises equivalent stress and the maximum 1st principal stress of those nodes in model $B$ were quite smaller than those in models $\mathrm{A}$ and $\mathrm{C}$. The difference of the stress variations between models $\mathrm{A}$ and $\mathrm{C}$ was not clear. However, smaller impact distance meant to spend more time 

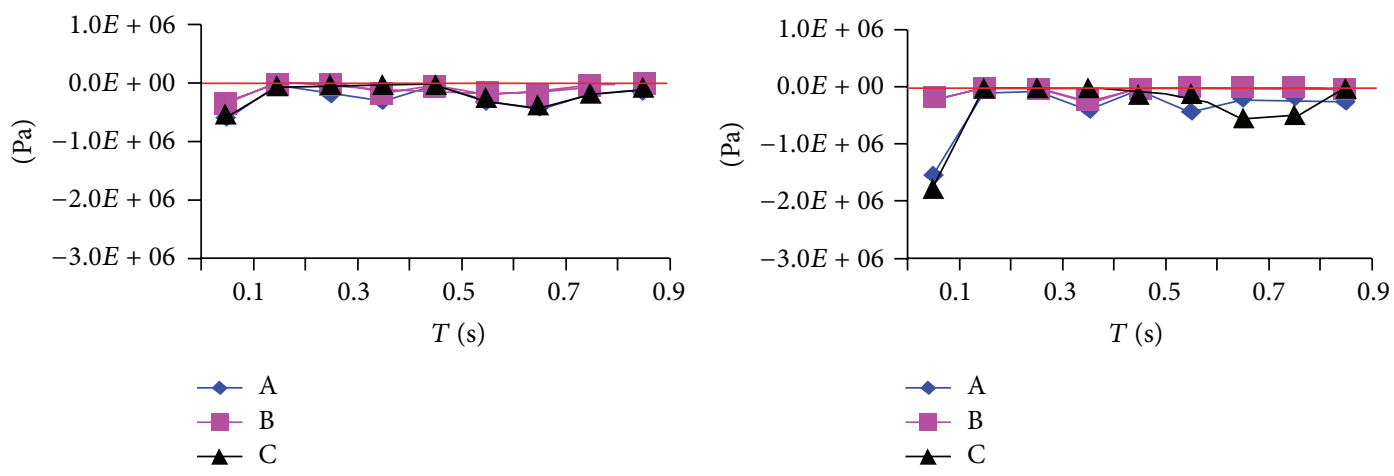

(a) Node 28

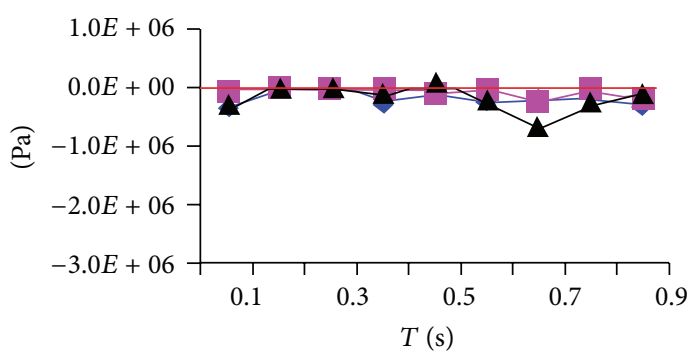

(b) Node 27

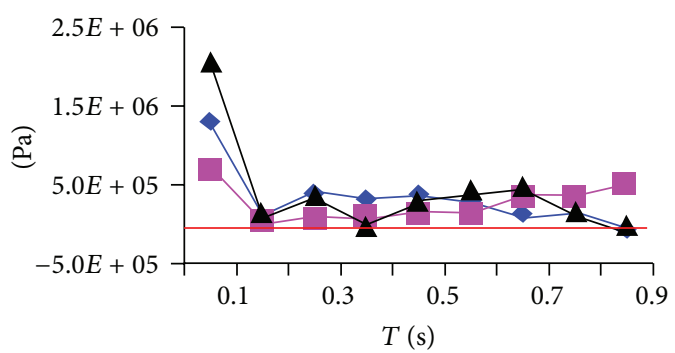

$$
\begin{aligned}
& \multimap \mathrm{A} \\
& -\mathrm{B} \\
& \leftarrow \mathrm{C}
\end{aligned}
$$$$
\begin{aligned}
& \longrightarrow \mathrm{A} \\
& \rightarrow \mathrm{B}
\end{aligned}
$$$$
\leftarrow \mathrm{C}
$$

(c) Node 26
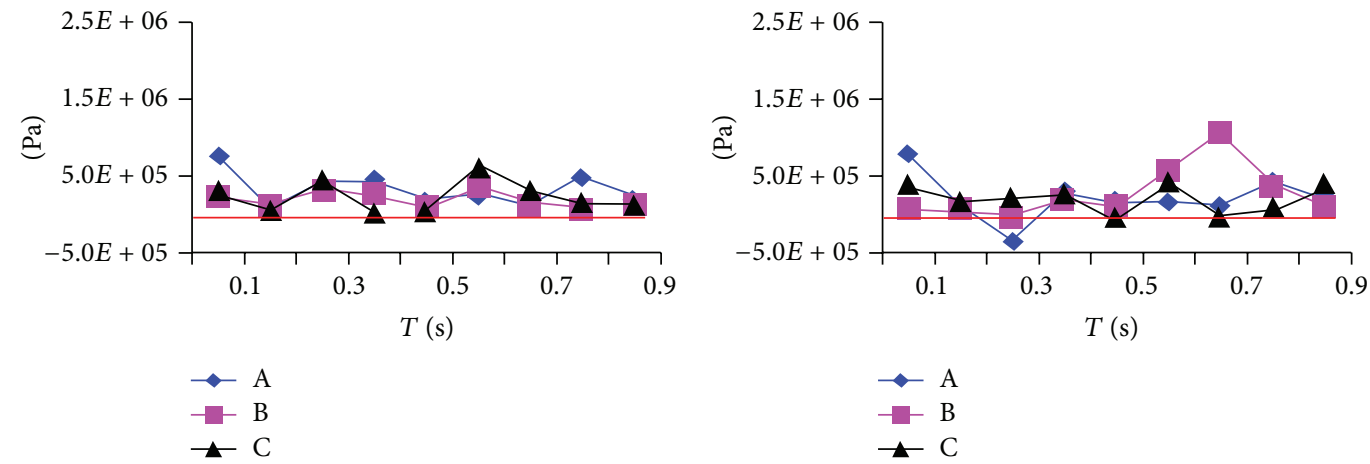

(e) Node 24
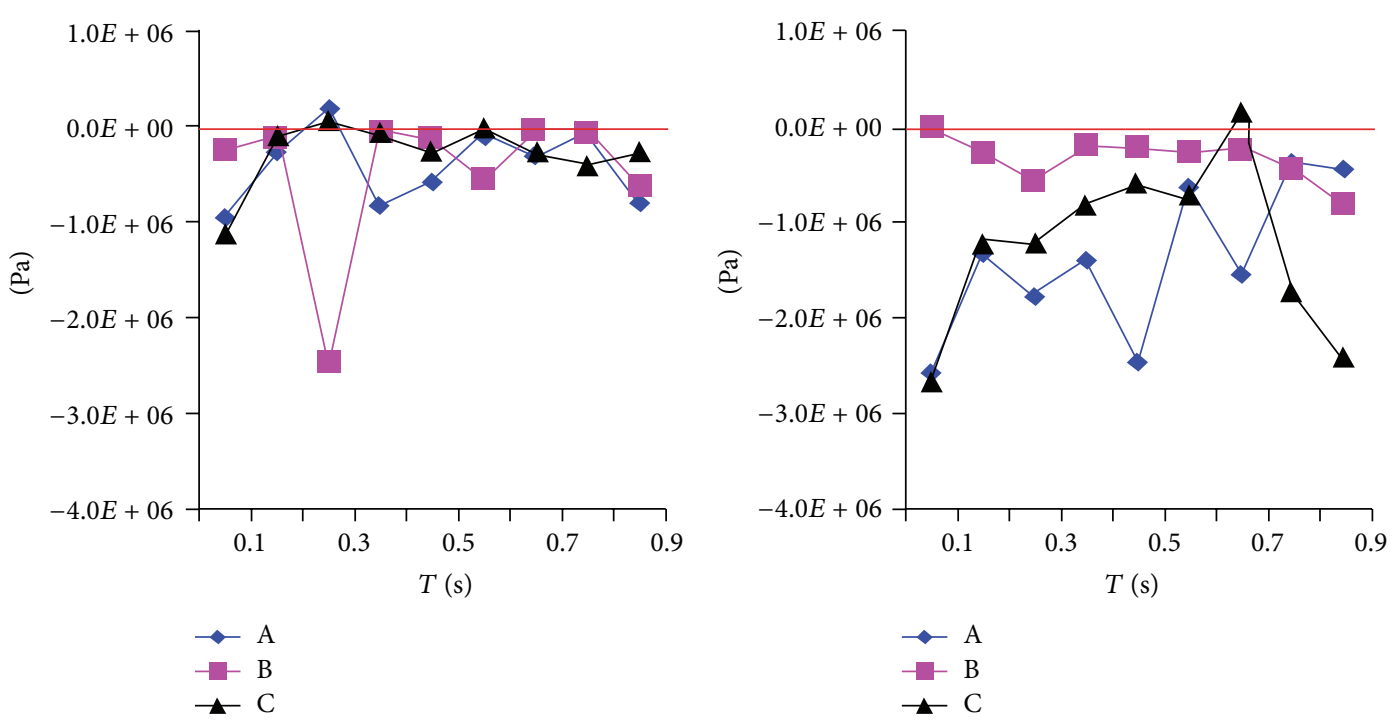

(g) Node 22

(h) Node 21

FIGURE 13: Continued. 


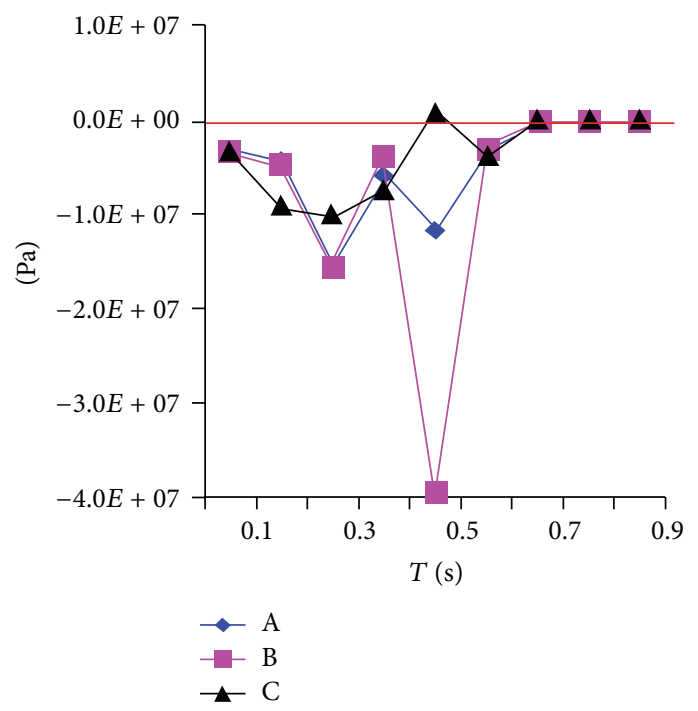

(i) Node 20

Figure 13: The 3rd principal stress peak-curves of nodes along the diagonal in models A, B, and C.

in drilling. Taking into account the practicability, the impact distance between $150 \mathrm{~mm}$ and $200 \mathrm{~mm}$ was the best choice. (4) When di kept constant, it was obvious that the stresses of those nodes in model $\mathrm{D}$ were undoubtedly the largest among models A, D, and E, whether for the Von Mises equivalent stress, the 1st principal stress, or the 3rd principal stress. In other words, the drilling radius of $35 \mathrm{~mm}$ was the optimal choice in this work.

4.4. Stress Behavior of Nodes around Drilling Hole (Nodes 14 to 19). Figures 17-19 showed the stress variation curves of nodes around drilling hole (see Figure 5) in models A, B, and C, including the Von Mises equivalent stress, the 1st principal stress, and the 3rd principal stress. By comparing the curves of different nodes, for the symmetry of model, it was obvious that the stress behavior of nodes 14, 15, and 16 was similar to that of nodes 19,18 , and 17 , respectively, whether for the Von Mises equivalent stress, the 1st principal stress, or the 3rd principal stress.

Specifically, as presented in Figure 17, when dr was constant, the Von Mises equivalent stress of node 14 in different models was sorted as A $>C>B$, which was similar to that of node 19. Likewise, the Von Mises equivalent stress of node 15 in different models was sorted as $\mathrm{C}>\mathrm{B} \geq \mathrm{A}$ and was similar to that of node 18 . The Von Mises equivalent stress of node 16 in different models was sorted as $\mathrm{C}>\mathrm{A} \geq \mathrm{B}$, which was similar to that of node 17. In addition, all the 1st principal stresses were expressed as the tensile stresses, while all the 3rd principal stresses were shown as the compressive stresses.

Figures 20-22 displayed the stress variation curves of nodes around drilling hole (see Figure 5) in models A, D, and $\mathrm{E}$. As depicted in the figures, when di was fixed, the Von Mises equivalent stress of node 14 in different models was sorted as $\mathrm{E}>\mathrm{D}>\mathrm{A}$, which was similar to that of node 19 .
The Von Mises equivalent stress of node 15 in different models was sorted as E > D > A and was similar to that of node 18. Likewise, the Von Mises equivalent stress of node 16 in different models was sorted as $\mathrm{E}>\mathrm{D} \geq \mathrm{A}$, which was similar to that of node 17 .

Obviously, as shown in Figures 18 and 19, all the 1st principal stress was expressed as the tensile stress, while all the 3rd principal stress was shown as the compressive stress. There were "compress-tensile stress transformation" phenomena in all models, especially for nodes 14 and 19, but the degree of transformation was quite weak.

By comparing Figures 17-22, the following results could be obtained. (1) For models A, B, and C, there were two evident stress peaks at the 0.25 th s and 0.55 th $\mathrm{s}$, respectively, whether for the Von Mises equivalent stress or the 3rd principal stress. The peak time of the 1st principal stress was hard to distinguish. (2) The maximum Von Mises equivalent stress of node 19 in model A was the largest and equaled 2.69 $\mathrm{MPa}$, while that of node 14 in model $\mathrm{B}$ was the smallest and equaled $1.72 \mathrm{MPa}$. The maximum 1st principal stresses of nodes around drilling hole in models $\mathrm{A}, \mathrm{B}$, and $\mathrm{C}$ were 1.91 $\mathrm{MPa}$ (node 19), 1.85 MPa (node 14), and 1.55 MPa (node 16), respectively. The maximum $3 \mathrm{rd}$ principal stresses of nodes around drilling hole in models $\mathrm{A}, \mathrm{B}$, and $\mathrm{C}$ were 2.87 MPa (node 19), 0.97 MPa (node 18), and 2.43 MPa (node 16), respectively. Thus, the impact distance of $200 \mathrm{~mm}$ might be a critical point in this work. (3) In terms of models A, D, and $\mathrm{E}$, there was only one evident stress peak for both the 1st principal stress and the 3 rd principal stress. But the peak time of the 1st principal stress was the 0.55 th s, while the peak time of the 3rd principal stress was the 0.25 th s. (4) The maximum Von Mises equivalent stresses of nodes in models A, D, and E were 2.69 MPa (node 19), 3.14 MPa (node 14), and 3.24 MPa (node 14), respectively; the maximum 1st principal stresses of 

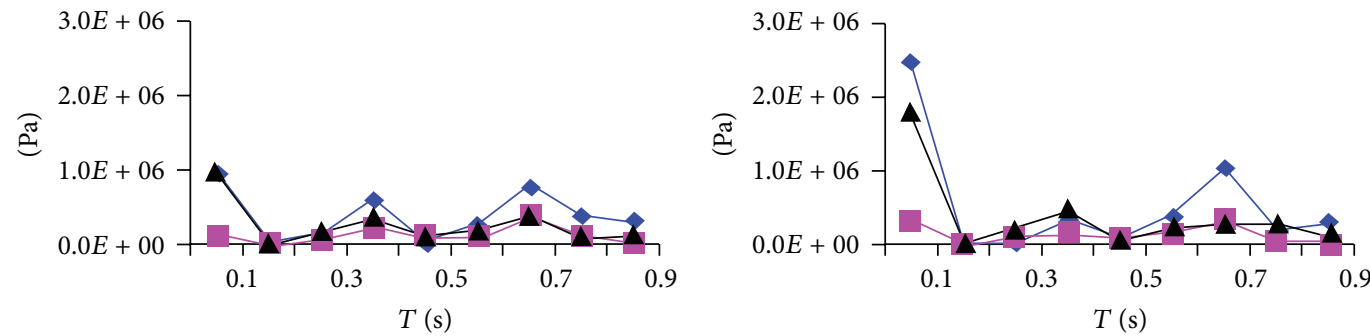

$$
\begin{aligned}
& \multimap \mathrm{A} \\
& \rightarrow \mathrm{D} \\
& \rightarrow \mathrm{E}
\end{aligned}
$$$$
\begin{aligned}
& \rightarrow \mathrm{A} \\
& -\mathrm{D} \\
& \rightarrow \mathrm{E}
\end{aligned}
$$

(a) Node 28
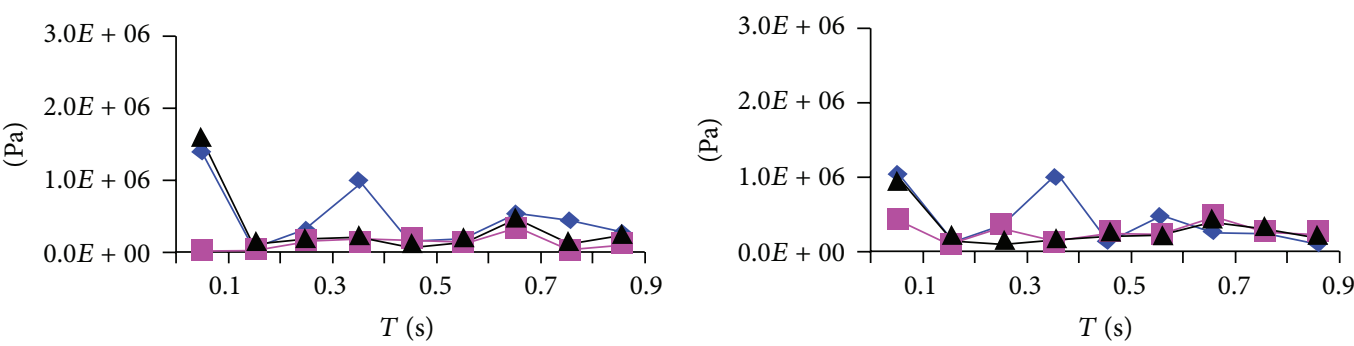

$$
\begin{aligned}
& \multimap \mathrm{A} \\
& -\mathrm{D} \\
& \leftarrow \mathrm{E}
\end{aligned}
$$$$
\begin{aligned}
& \rightarrow \mathrm{A} \\
& \rightarrow \mathrm{D} \\
& -\mathrm{E}
\end{aligned}
$$

(c) Node 26
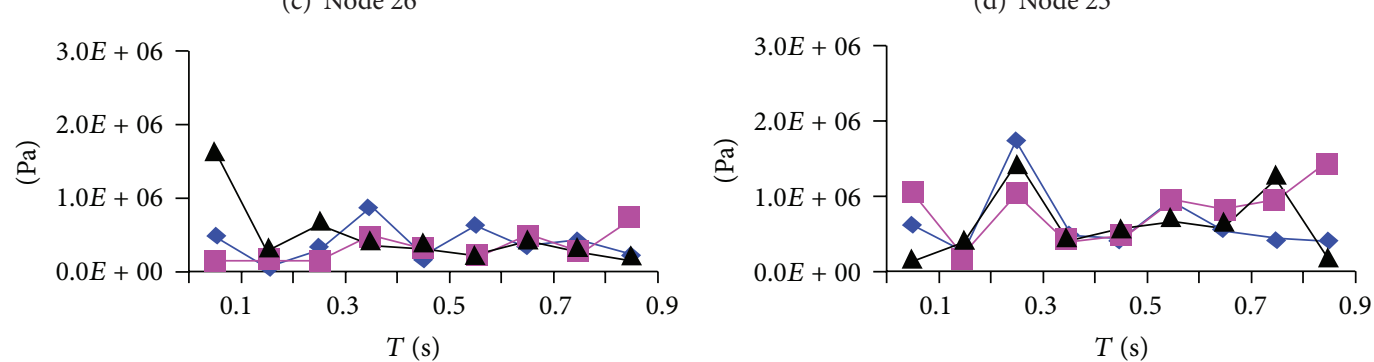

$$
\begin{aligned}
& \multimap \mathrm{A} \\
& -\mathrm{D}
\end{aligned}
$$$$
\begin{aligned}
& \multimap \mathrm{A} \\
& -\mathrm{D} \\
& -\mathrm{E}
\end{aligned}
$$

(e) Node 24

(f) Node 23
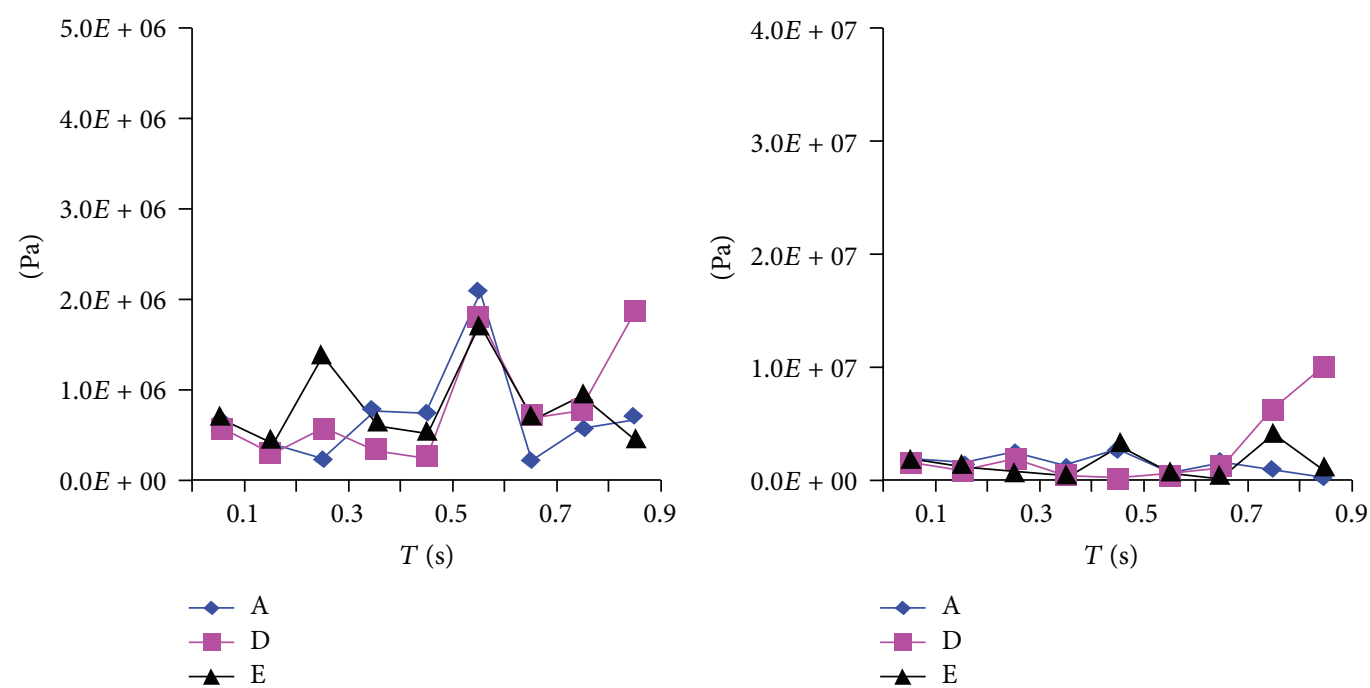

(g) Node 22

(h) Node 21

FIGURE 14: Continued. 


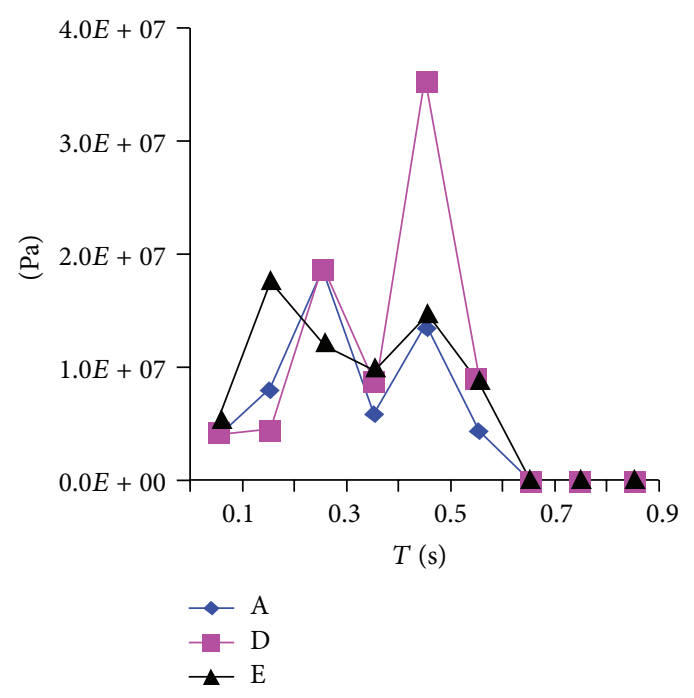

(i) Node 20

Figure 14: The Von Mises equivalent stress peak-curves of nodes along the diagonal in models A, D, and E.

nodes were 1.91 MPa, 2.48 MPa, and 2.49 MPa, respectively; the maximum 3 rd principal stresses of nodes were $2.87 \mathrm{MPa}$, 3.38 $\mathrm{MPa}$, and $3.52 \mathrm{MPa}$, respectively. Therefore, the drilling radius of $50 \mathrm{~mm}$ might be the optimal choice in this work.

4.5. Stress Behavior of Nodes along Sideline (Nodes 8 to 13). Figures 23-25 exhibited the stress variation curves of nodes along sideline (see Figure 5) in models A, B, and C, including the Von Mises equivalent stress, the 1st principal stress, and the 3rd principal stress. As shown in the figures, when dr kept constant, it was easy to find that, for those nodes near the impact rod (nodes 8 to 10), their stresses had distinct variation regularities, regardless of the Von Mises equivalent stress, the 1 st principal stress, or the 3rd principal stress. In terms of those nodes far away from impact rod (nodes 11 to 13), their stresses variations were in a state of disorder, and there were no obvious regularities, especially for nodes 12 and 13 .

Figures 26-28 displayed the stress behavior of nodes along sideline (see Figure 5) in models A, D, and E. As exhibited in the figures, when di was constant, all nodes had distinct variation regularities, regardless of the Von Mises equivalent stress or the 1st principal stress. The 3rd principal stresses were also in the state of disorder, having no clear regularities, regardless of the nodes near the impact rod, like nodes 8 to 10, or those nodes far away from impact rod, like nodes 11 to 13 . In addition, for a certain node, its 3rd principal stress was evidently smaller than its 1st principal stress.

From Figures 24 to 25 and Figures 27 to 28, it could be found that all the 1st principal stress was expressed as the tensile stress, while all the 3rd principal stress was shown as the compressive stress. For a certain node, its 3 rd principal stress was evidently smaller than its 1st principal stress. Therefore, in the case of those nodes along sideline, the 1st principal stresses were the main reasons of potential secondary breaking.

By comparing Figures 23-28, the following conclusions could be made. (1) Obvious "compress-tensile stress transformation" occurred at node 8, especially for the 1st principal stress curves. (2) As for models A, B, and C, the Von Mises equivalent stress of those nodes near the impact rod, there were two evident stress peaks at the 0.05 th $\mathrm{s}$ and the 0.55 th $\mathrm{s}$, respectively. The peak time of the 1st principal stress and the 3rd principal stress was hard to determine. (3) In terms of models A, D, and E, there was only one evident stress peak for both the Von Mises equivalent stress and the 1st principal stress at the 0.55 th $\mathrm{s}$. The peak time of the $3 \mathrm{rd}$ principal stress was uncertain. (4) Generally, the stresses of those nodes far away from the impact rod (nodes 11 to 13) were quite small and in the state of disorder, while the stresses of those nodes near the impact rod (nodes 8 to 10) were relatively bigger and had clear variation regularities, regardless of the Von Mises equivalent stress, the 1st principal stress, or the 3rd principal stress.

\section{Experiment Results}

To verify the feasibility of HDIHT method and explore its impact breaking mechanism, a hydraulic hammer (GT130, Giant hydraulic Tech., China) with $7500 \mathrm{~J}$ impact energy was used in the field experiments at Baitaizi township granite stone pit, Jinzhou, Liaoning Province, China, and all the items were conducted at the environmental temperature of $-15^{\circ} \mathrm{C}$.

Due to the restriction of experimental equipment, the effect of different drilling radius on hydraulic impact breaking process was not researched, which could be done in the future. As depicted in Figure 29, there were many holes drilled prior to the hydraulic impact breaking process. 


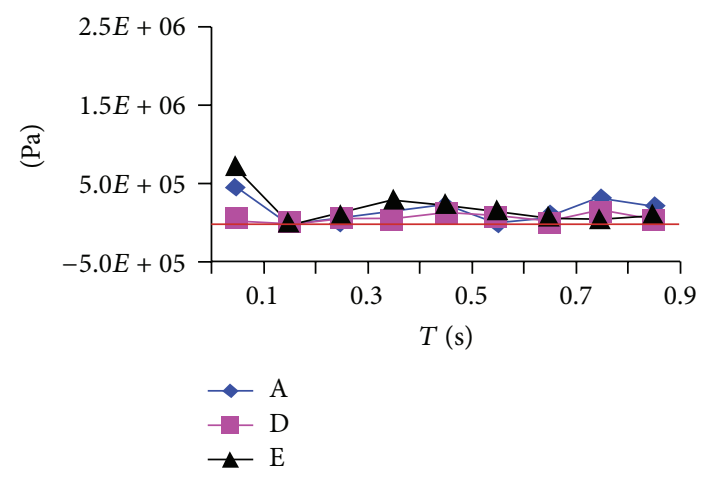

(a) Node 28

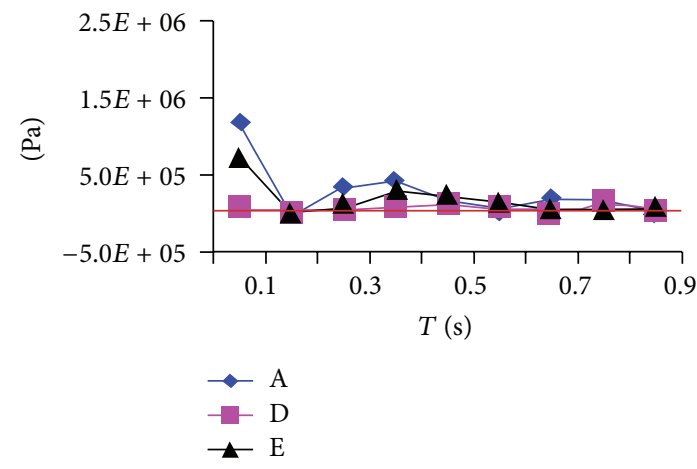

(c) Node 26

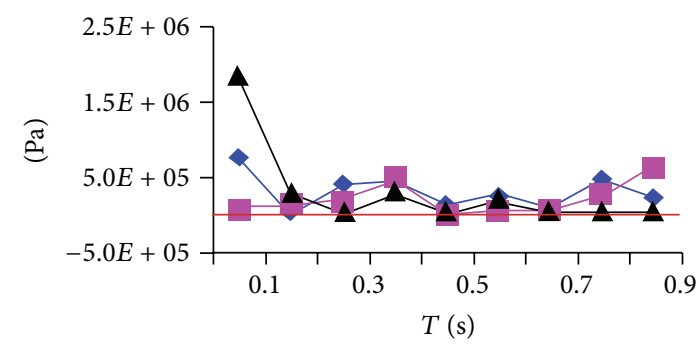

$$
\begin{aligned}
& \rightarrow \mathrm{A} \\
& -\mathrm{D} \\
& \rightarrow \mathrm{E}
\end{aligned}
$$

(e) Node 24

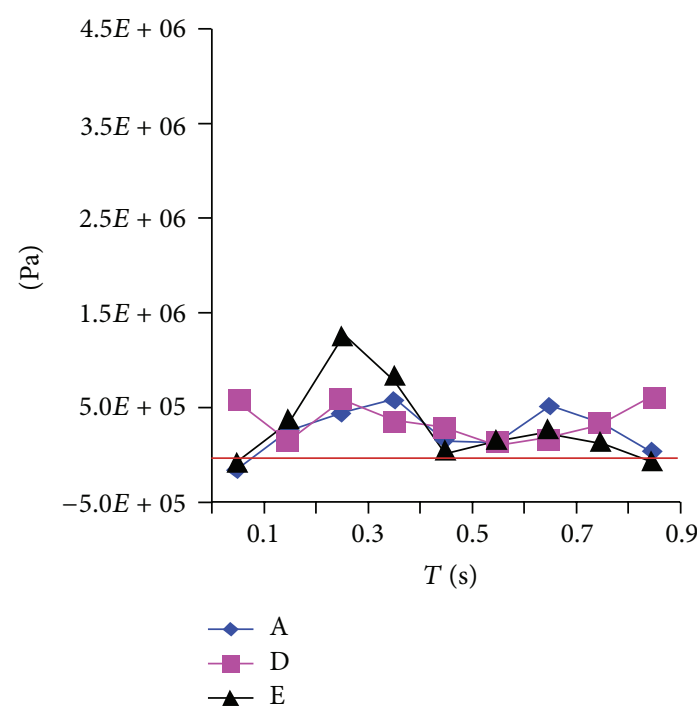

(g) Node 22

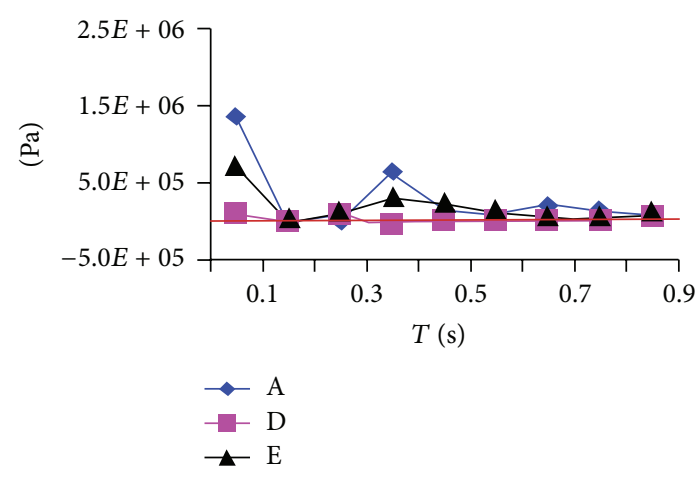

(b) Node 27

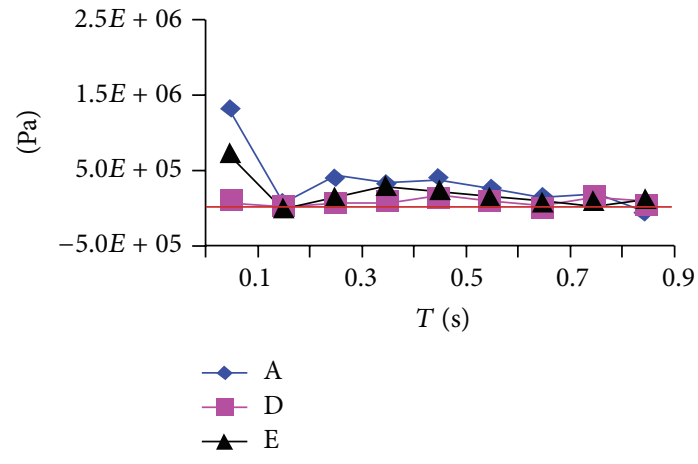

(d) Node 25

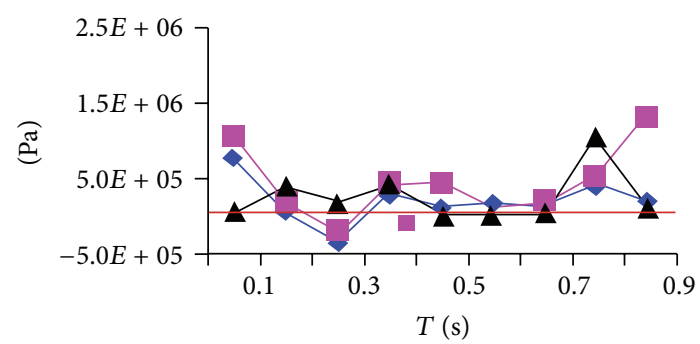

$$
\begin{aligned}
& \rightarrow \mathrm{A} \\
& \rightarrow \mathrm{D} \\
& \leftarrow \mathrm{E}
\end{aligned}
$$

(f) Node 23

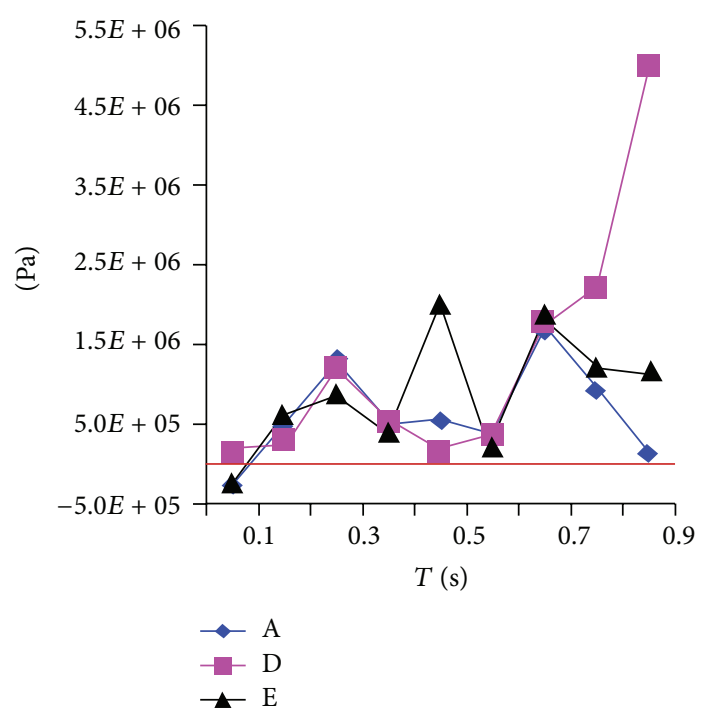

(h) Node 21

FIgURE 15: Continued. 


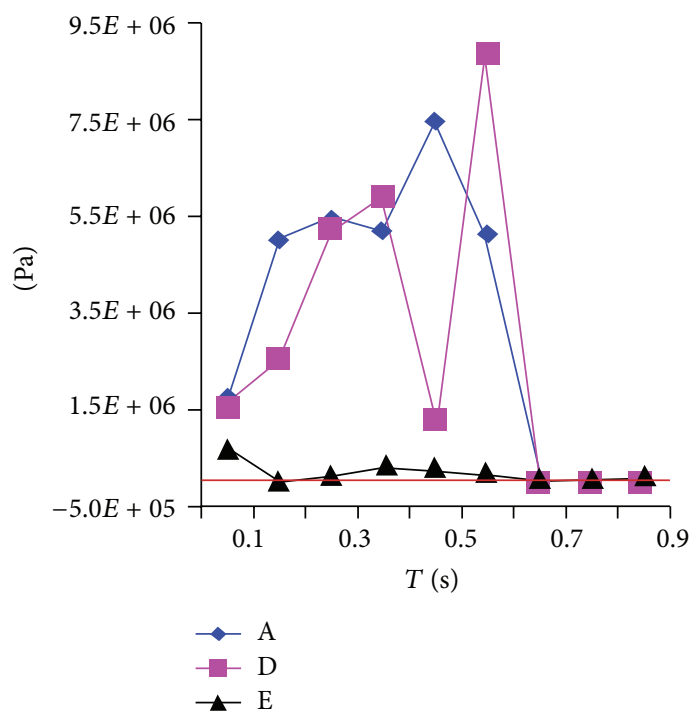

(i) Node 20

FIGURE 15: The 1st principal stress peak-curves of nodes along the diagonal in models A, D, and E.

The distribution of drilling holes was expressed in Figure 29(a), whilst the parameters of drilling were listed as follows: drilling radius, $21 \mathrm{~mm}$, and drilling depth, $1000 \mathrm{~mm}$.

Figure 30 demonstrated the actual impact breaking conditions, and the following results could be obtained. (1) When impact distance equaled $240 \mathrm{~mm}$ or $282 \mathrm{~mm}$, the existence of drilling holes had less effect on the actual breaking process and the breaking efficiency was very low. In this case, all dropped rocks were detritus or powder, without chunks. (2) As impact distance was $174 \mathrm{~mm}$, the breaking effect was evidently improved. Besides the dropped powder, there were also some chunks; the maximum length of chunks was about $100 \mathrm{~mm}$. (3) When hammer impacted the granite around a hole at a circle of $300 \mathrm{~mm}$ (see Figure 30(b)), that is, di was $150 \mathrm{~mm}$, the breaking efficiency could be significantly enhanced, which was in agreement with the critical value of impact distance in the simulations.

\section{Discussion of the Hard-Rock Breaking Mechanism}

Based on the rock mechanics theories and actual experiment results, the hard-rock breaking mechanism of HDIHT technology could be summarized and demonstrated in Figure 31. As shown in the figure, when hammer impacted hard rock directly, its impact energy would be converted into the compressive wave in the depths of rock at the impact moment, and a broken pit was formed in an instant when impact energy was larger than $A_{c}$ (see Figure 2). If there were some holes in working face, the compressive impact wave might be transformed into the tensile stress after the reflection at free surfaces. Thus, the nodes around drilling hole were under the joint action of those two kinds of stresses at the same time, that is, compressive stress and tensile stress, which would cause the rock shear fracture if the tensile stress was big enough. For the tensile strength of rock was only three to five percent of its compressive strength, the "compression-tension" transformation would finally lead to the secondary breaking of the rock near the holes. In the HDIHT experiments, there was another phenomenon at the impact moment, that is, the discharging of the dust in holes, which was caused by the action of compressive stress wave during the impact process.

When rod chiseled into a certain depth, the contact area between impact rod and broken pit increased sharply, which directly led to the significant increasing of work resistance. It would not only lower the contact static pressure of rodend caused by pressing force but also remarkably reduce the dynamic impact pressure of impact moment. As a result, the impact energy, which is mainly used for overcoming the specific chiseling work of hard rock, could not be fully delivered to the rod-end, and it would finally weaken the efficiency of the subsequent impacting. Furthermore, in the impact breaking process, the crushed rock powder and debris were hard to be rapidly discharged from the gap between impact rod and broken pit (see Figure 30(a)). The rock powder remaining in the broken pit would act as a cushion between rod-end and rock and inevitably absorb partial energy. In the end, when the rest of impact energy was not enough to overcome the compression strength of granite, the subsequent impacts would become meaningless, which meant the impact position should be changed.

As the crucial factors of HDIHT technology, drilling radius and impact distance had great influence on the final breaking efficiency, but they should be combined with the tunneling process beat. If impact distance was too small, as revealed in the simulations, it was undoubtedly helpful 

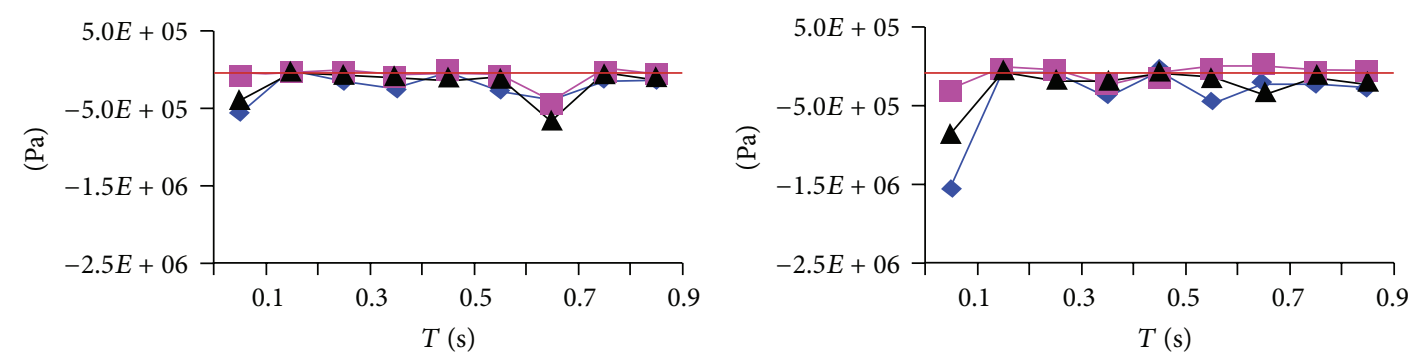

$$
\begin{aligned}
& \multimap \mathrm{A} \\
& -\mathrm{D} \\
& \leftarrow \mathrm{E}
\end{aligned}
$$

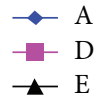

(a) Node 28

(b) Node 27
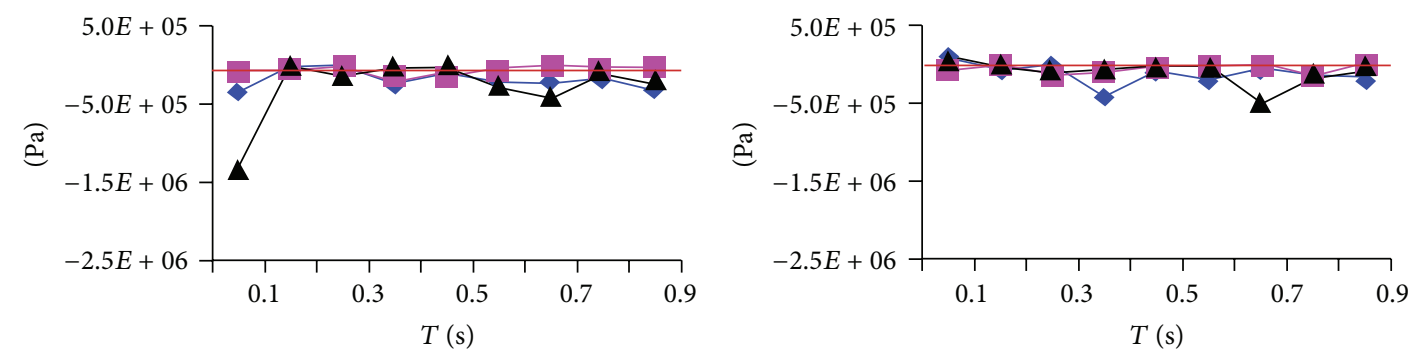

$$
\begin{aligned}
& \multimap \mathrm{A} \\
& -\mathrm{D} \\
& \leftarrow \mathrm{E}
\end{aligned}
$$$$
\rightarrow \mathrm{A}
$$$$
\rightarrow-D
$$

(c) Node 26

(d) Node 25
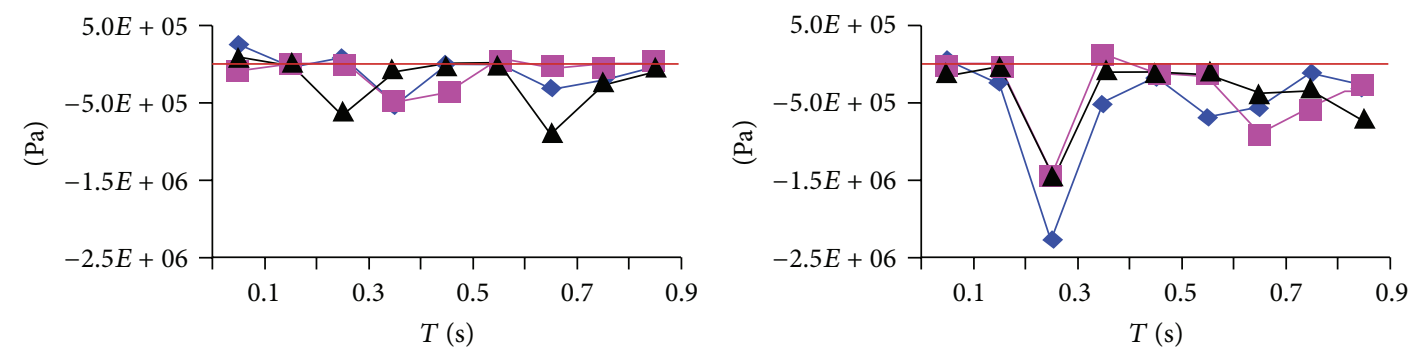

$$
\begin{aligned}
& \multimap \mathrm{A} \\
& -\mathrm{D} \\
& \leftarrow \mathrm{E}
\end{aligned}
$$$$
\begin{aligned}
& \multimap \mathrm{A} \\
& -\mathrm{D} \\
& \leftarrow \mathrm{E}
\end{aligned}
$$

(e) Node 24

(f) Node 23
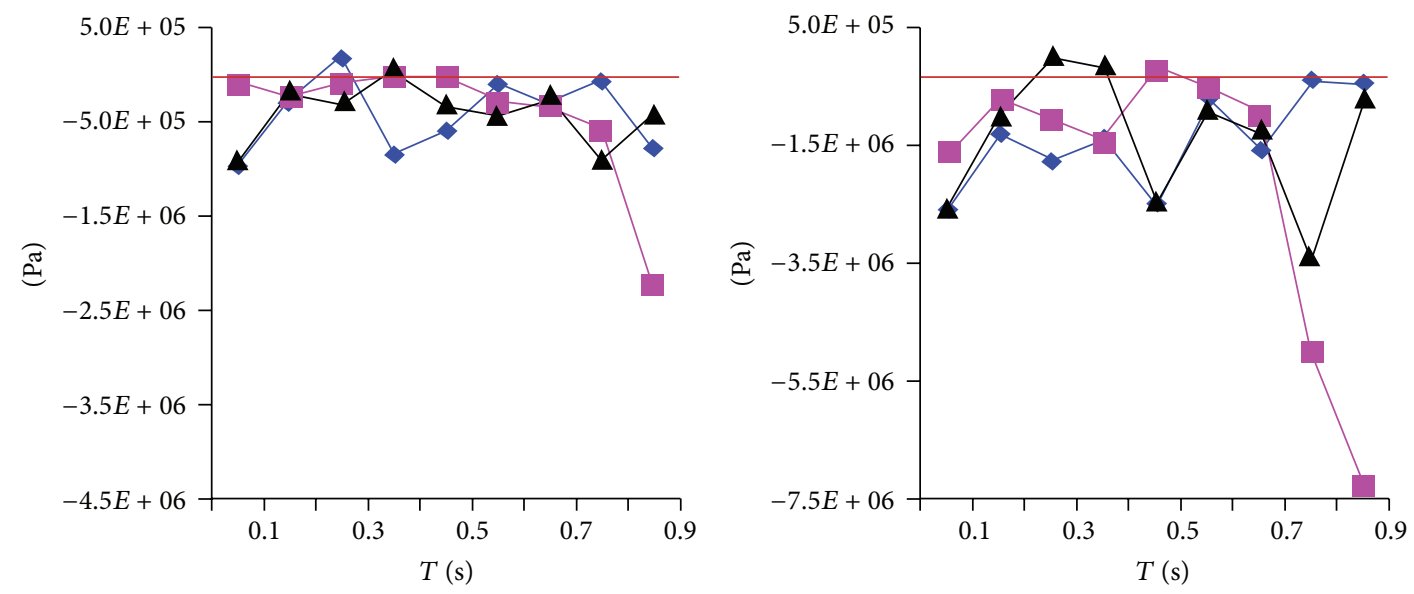

$$
\begin{aligned}
& \multimap \mathrm{A} \\
& -\mathrm{D} \\
& \leftarrow \mathrm{E}
\end{aligned}
$$$$
\begin{aligned}
& \multimap \mathrm{A} \\
& \rightarrow \mathrm{D} \\
& -\mathrm{E}
\end{aligned}
$$

(g) Node 22

(h) Node 21

FIGURE 16: Continued. 


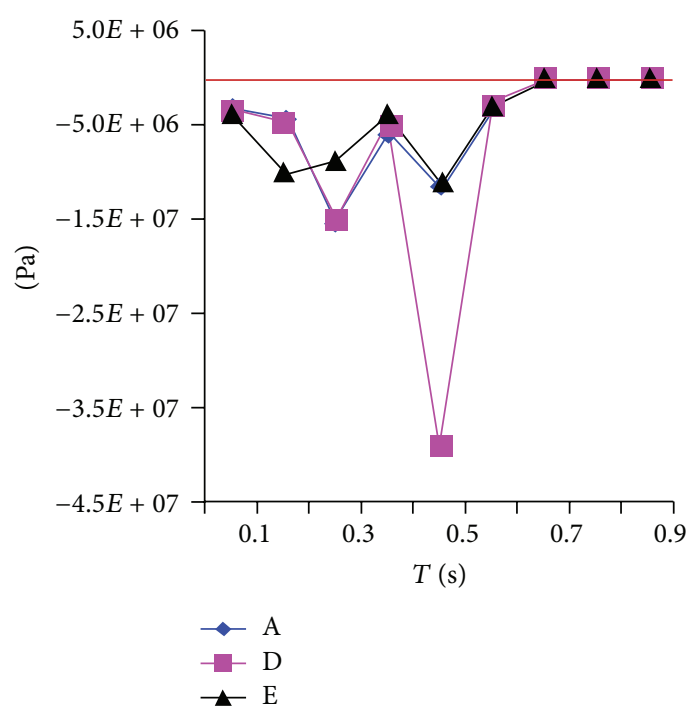

(i) Node 20

FIGURE 16: The 3rd principal stress peak-curves of nodes along the diagonal in models A, D, and E.

to improve the impact breaking efficiency. However, it also meant we had to spend more time in drilling for there were more holes which had to be drilled. Therefore, we must choose an acceptable drilling spacing, from the viewpoints of economy and process. Likewise, as for drilling radius, it was evident that the bigger the drilling radius was, the higher the impact breaking efficiency was. But bigger drilling radius commonly meant more time we had to spend in drilling.

Therefore, there must be a critical point, whether for drilling radius or impact distance. In this work, for granite, the drilling radius of $35 \mathrm{~mm}$ and the impact distance of $150 \mathrm{~mm}$ were the optimal combination of parameters for HDIHT technology.

\section{Conclusions}

HDIHT is a novel technology and method proposed to solve the rapid tunneling problem in hard rock. Based on "element birth and death" technique, through APDL programming, the key parameters, including drilling radius and impact distance, were researched to explore the stress behavior during HDIHT process. The breaking mechanism was also discussed, and the following conclusions could be drawn:

(1) There was obvious stress concentration phenomenon around the hole when impact distance equaled $200 \mathrm{~mm}$. It was not only the signal of "compresstensile stress transformation" of drilling hole free surface but also the direct reason of the high efficiency of HDIHT method, for it would finally lead to the "secondary breaking effect" of the rock near the hole.

(2) Impact distance was not the smaller the better. For granite, the impact effect distance of hammer was a constant and was decided by impact energy of hammer, CSW of rock, diameter of rod, rod material, and so forth. In this work, $200 \mathrm{~mm}$ might be an optimal choice. If impact distance was too large, it would decrease the effect of drilling hole free surfaces on the HDIHT efficiency.

(3) As for drilling radius, the bigger the drilling radius was, the larger the stress was. However, for the stress difference between models D and $\mathrm{E}$ was not distinct; taking the drilling difficulty and price into account, $35 \mathrm{~mm}$ was an optimal choice.

The simulation results and the discussion about the breaking mechanism of hard rock could provide a basis for the further research and application of HDIHT technology.

\section{Nomenclature}

dr: $\quad$ Drilling radius $(\mathrm{mm})$

di: $\quad$ Distance of impact $(\mathrm{mm})$

A: $\quad$ Impact power/energy (J)

$N$ : $\quad$ Direction stress on shear fracture surface $(\mathrm{N})$

$N_{f}: \quad$ Impact frequency of $\operatorname{rod}(\mathrm{BPM})$

$n_{\text {imp }}: \quad$ Impact times at single point

L: $\quad$ Length of shear plane (m)

C: $\quad$ Material cohesion

$K: \quad$ Intrusive coefficient

R: $\quad$ Stress component of load $P$ along the vertical edge-surface direction $(\mathrm{N})$

T: $\quad$ Shear stress (N)

$P_{i}^{*}: \quad$ Load of the $i$ th leap $(\mathrm{N})$

$H_{i}^{*}$ : $\quad$ Penetration depth of the $i$ th leap (m)

$R_{\text {pressure }}$ : Ultimate compressive strength ( $\left.\mathrm{Pa}\right)$ 


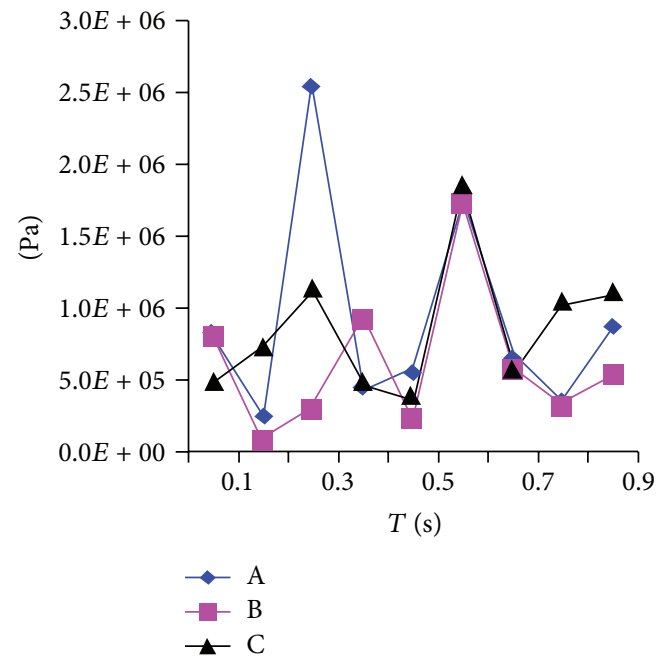

(a) Node 14
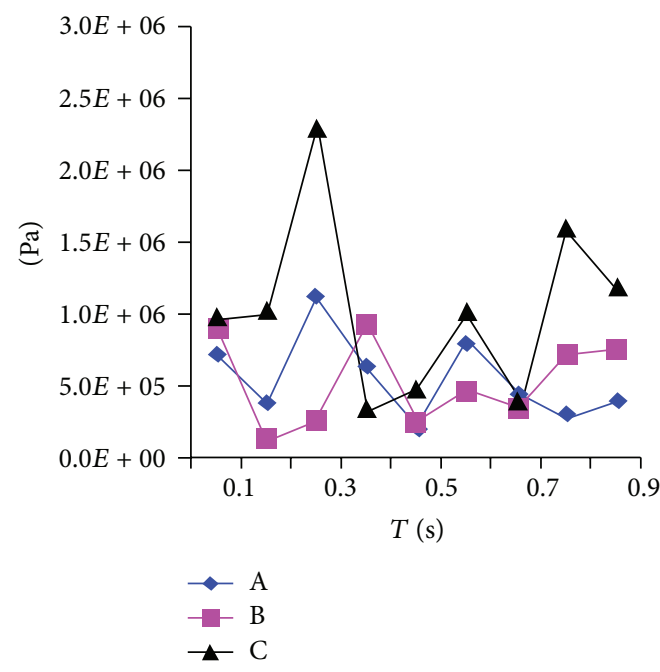

(c) Node 16

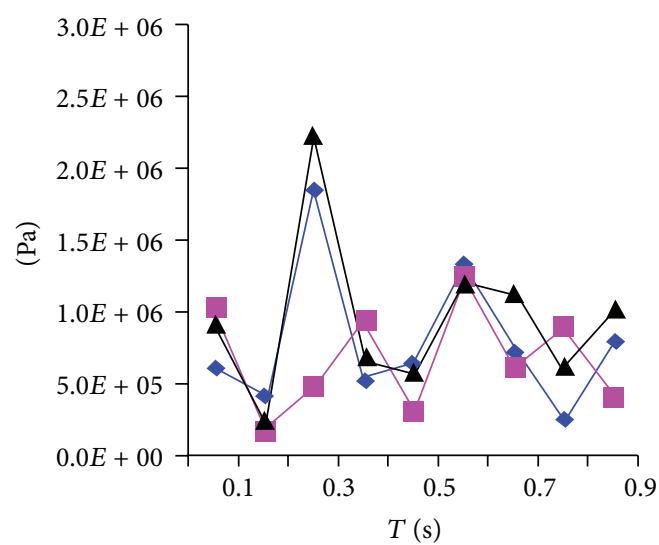

$$
\begin{aligned}
& \multimap \mathrm{A} \\
& \rightarrow \mathrm{B} \\
& \leftarrow \mathrm{C}
\end{aligned}
$$

(e) Node 18

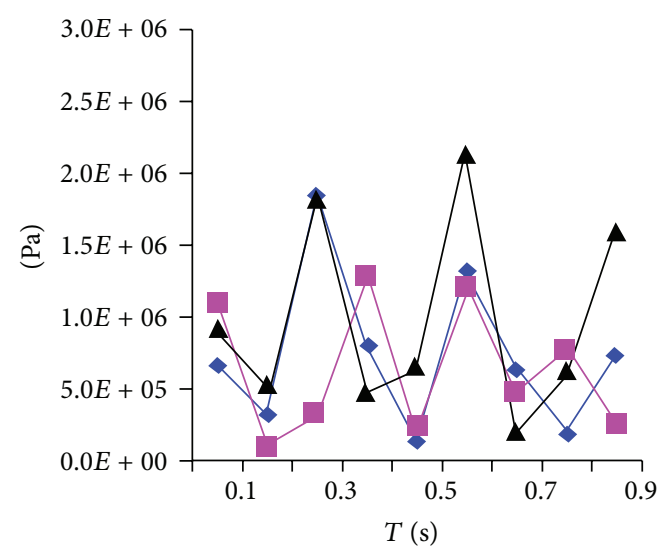

$$
\begin{aligned}
& \rightarrow \mathrm{A} \\
& -\mathrm{B}
\end{aligned}
$$

(b) Node 15

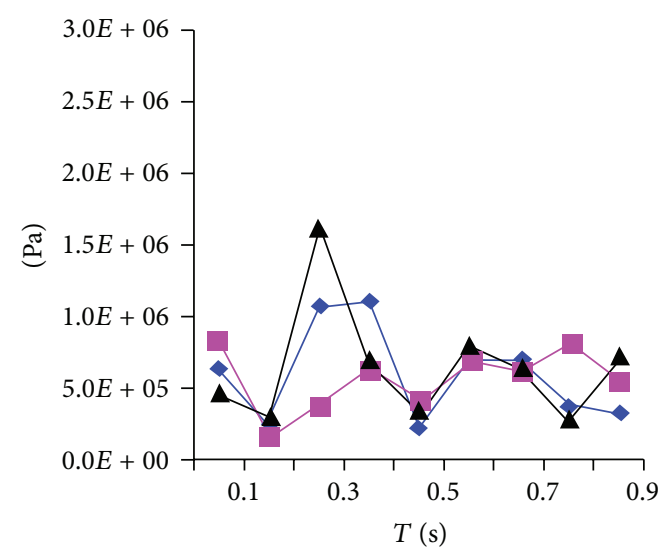

$$
\begin{aligned}
& \multimap \mathrm{A} \\
& -\mathrm{B} \\
& \leftarrow \mathrm{C}
\end{aligned}
$$

(d) Node 17

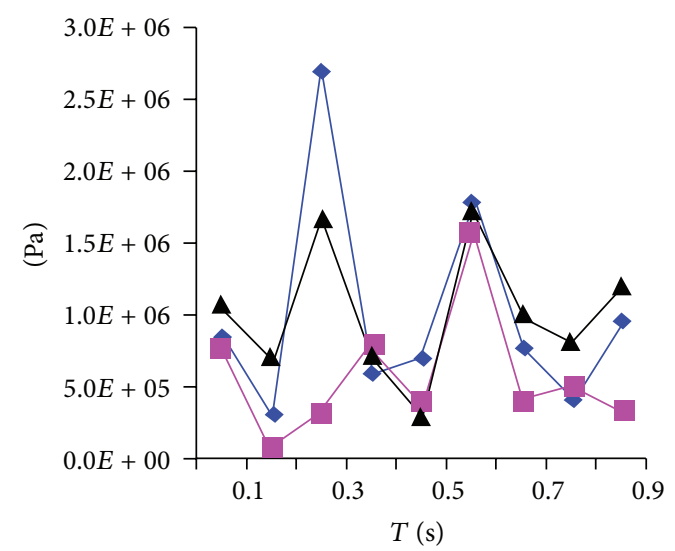

$$
\begin{aligned}
& \multimap \mathrm{A} \\
& -\mathrm{B} \\
& \leftarrow \mathrm{C}
\end{aligned}
$$

(f) Node 19

Figure 17: The Von Mises equivalent stress peak-curves of nodes around drilling hole in models A, B, and C. 


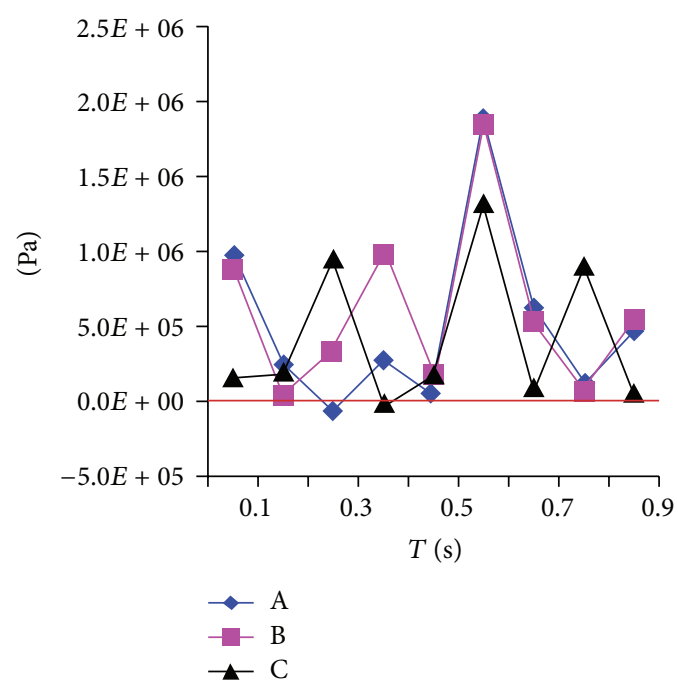

(a) Node 14

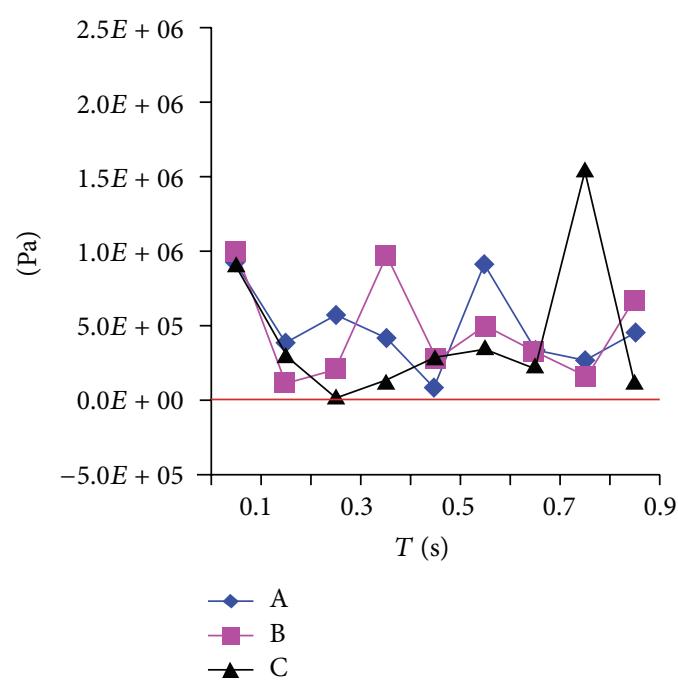

(c) Node 16

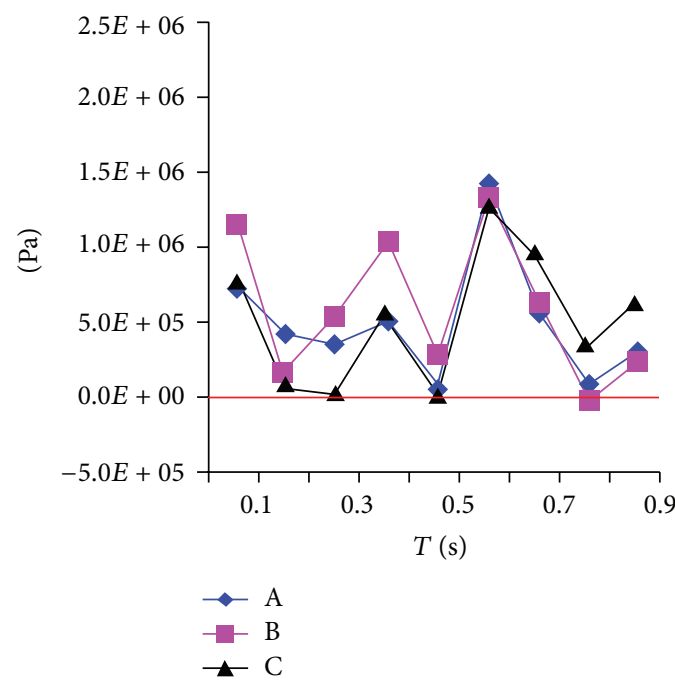

(e) Node 18

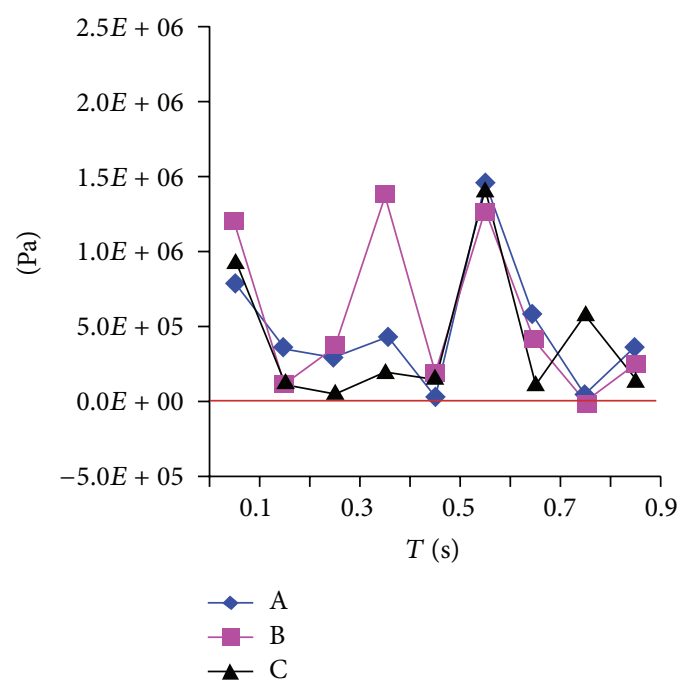

(b) Node 15

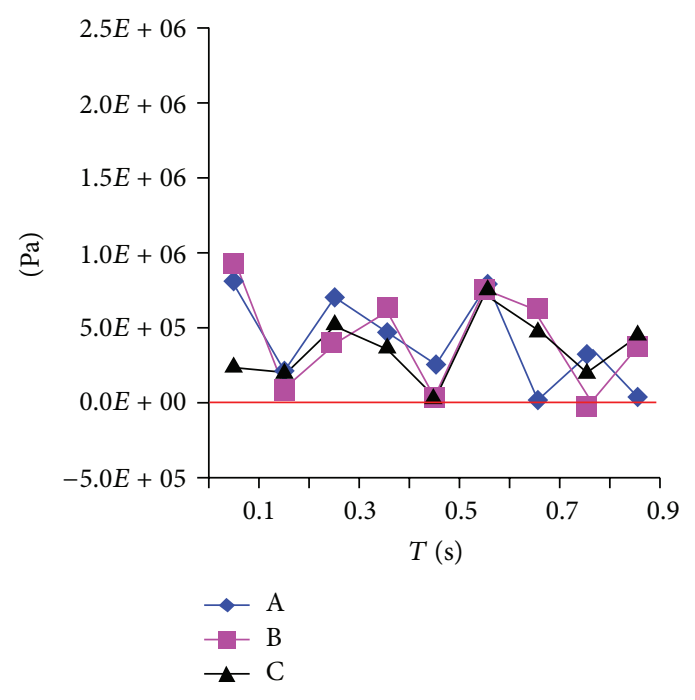

(d) Node 17

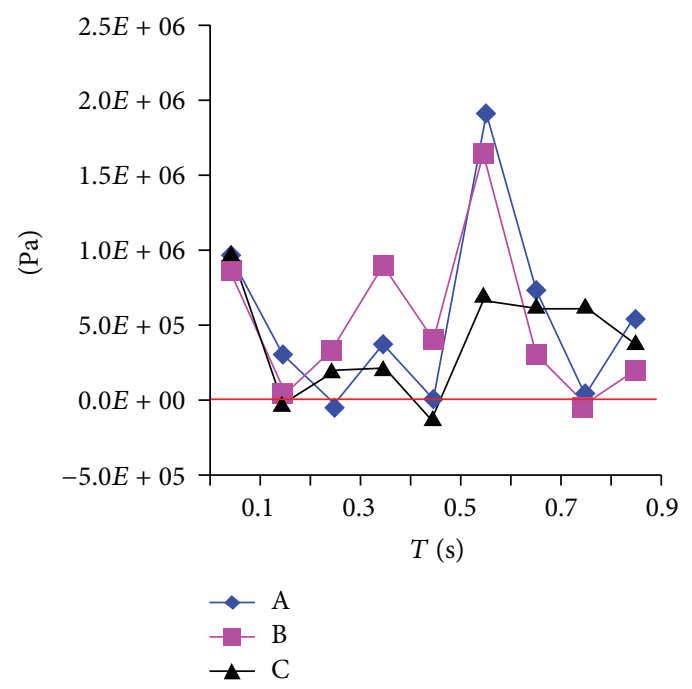

(f) Node 19

FIGURE 18: The 1st principal stress peak-curves of nodes around drilling hole in models A, B, and C. 

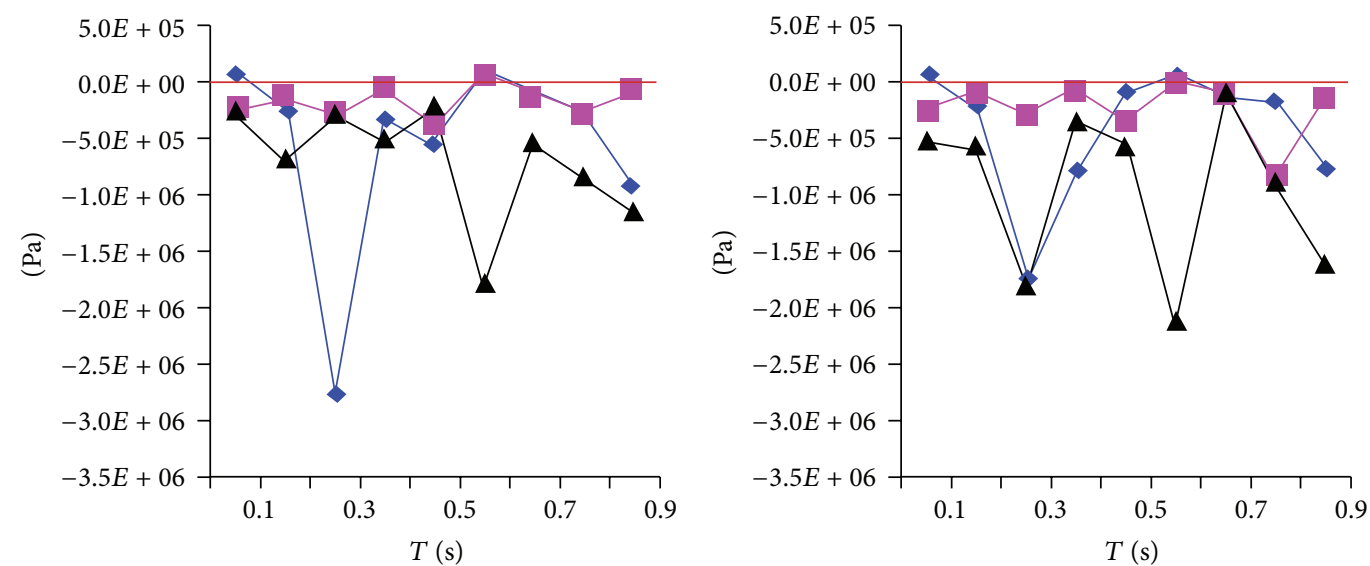

$$
\begin{aligned}
& \rightarrow \mathrm{A} \\
& -\mathrm{B} \\
& \leftarrow \mathrm{C}
\end{aligned}
$$$$
\begin{aligned}
& \rightarrow \mathrm{A} \\
& \rightarrow \mathrm{B} \\
& \leftarrow \mathrm{C}
\end{aligned}
$$

(a) Node 14

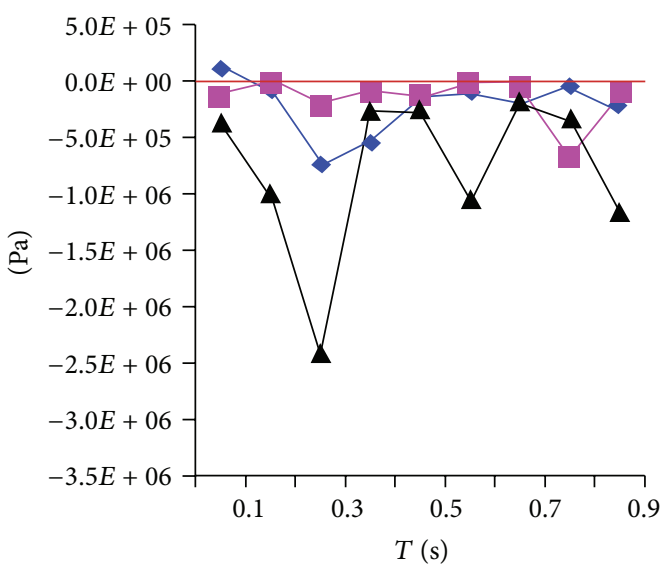

(b) Node 15

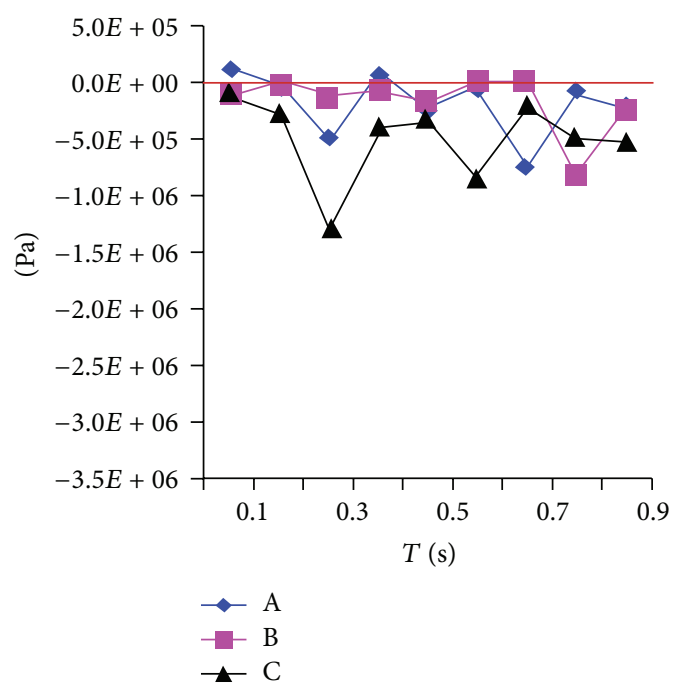

(c) Node 16

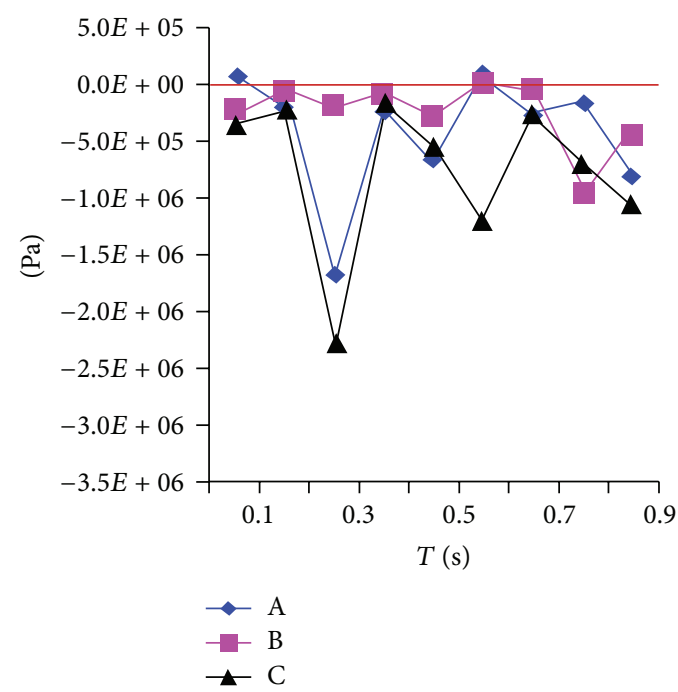

(d) Node 17

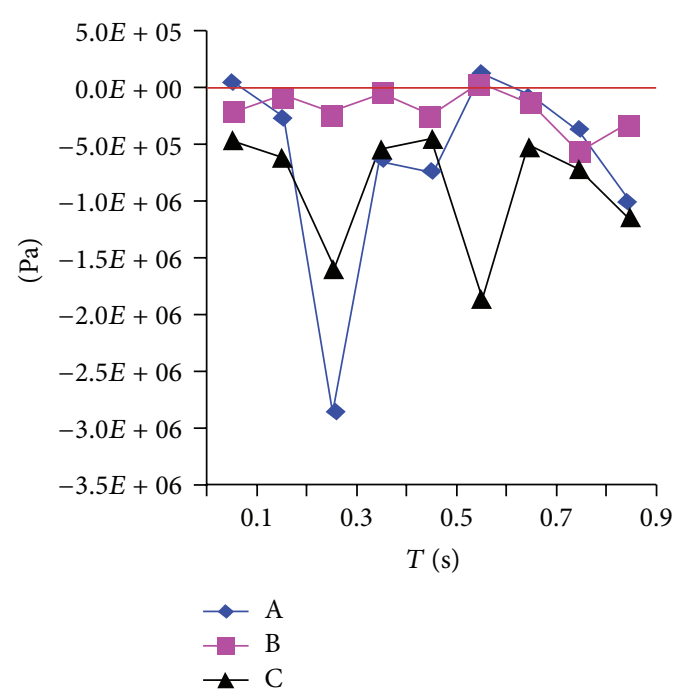

(e) Node 18

(f) Node 19

FIgURE 19: The 3rd principal stress peak-curves of nodes around drilling hole in models A, B, and C. 

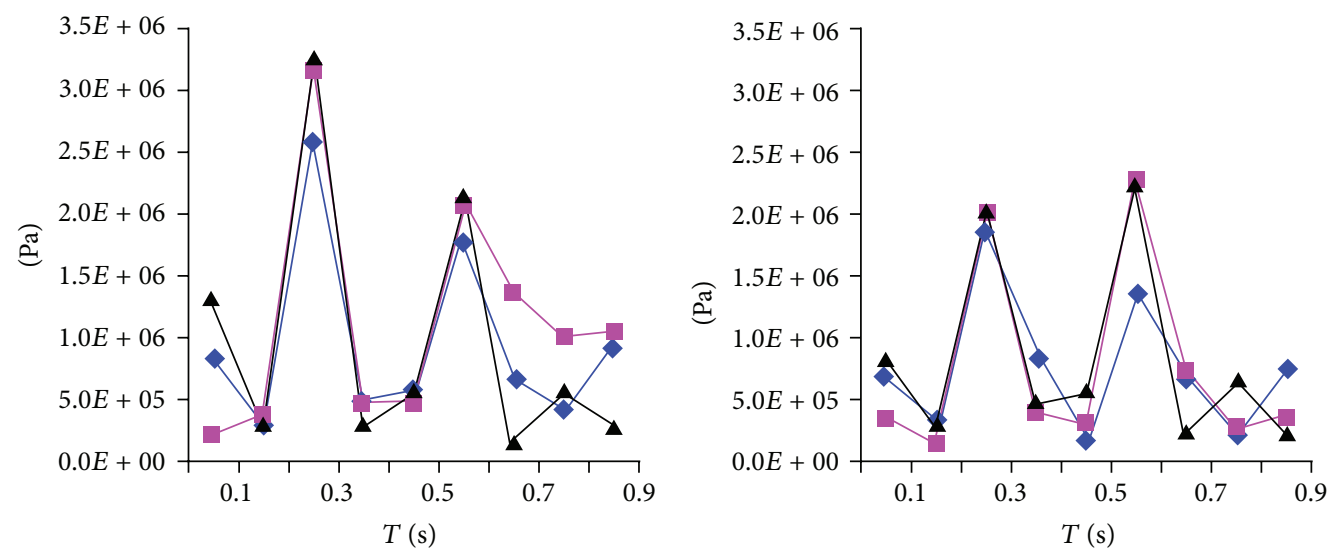

$$
\begin{aligned}
& \rightarrow \mathrm{A} \\
& \rightarrow \mathrm{D} \\
& \rightarrow \mathrm{E}
\end{aligned}
$$$$
\begin{aligned}
& \leftarrow \text { A } \\
& -\mathrm{D} \\
& \leftarrow \mathrm{E}
\end{aligned}
$$

(a) Node 14

(b) Node 15
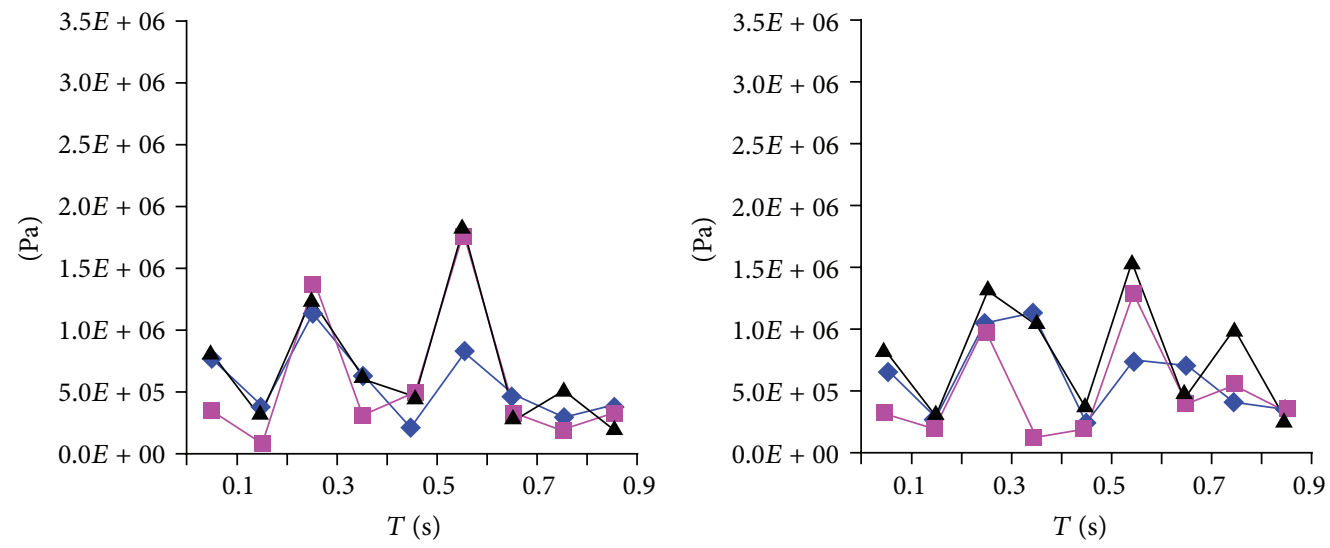

$$
\begin{aligned}
& \multimap \mathrm{A} \\
& -\mathrm{D} \\
& \leftarrow \mathrm{E}
\end{aligned}
$$$$
\begin{aligned}
& \multimap \mathrm{A} \\
& -\mathrm{D} \\
& \leftarrow \mathrm{E}
\end{aligned}
$$

(c) Node 16

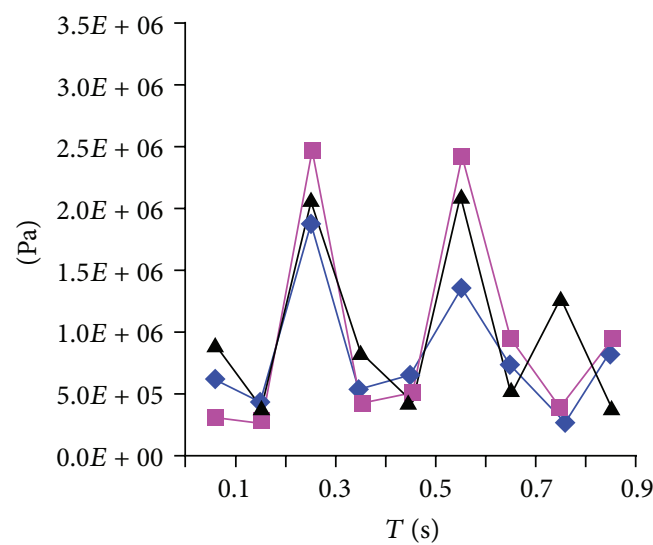

(d) Node 17

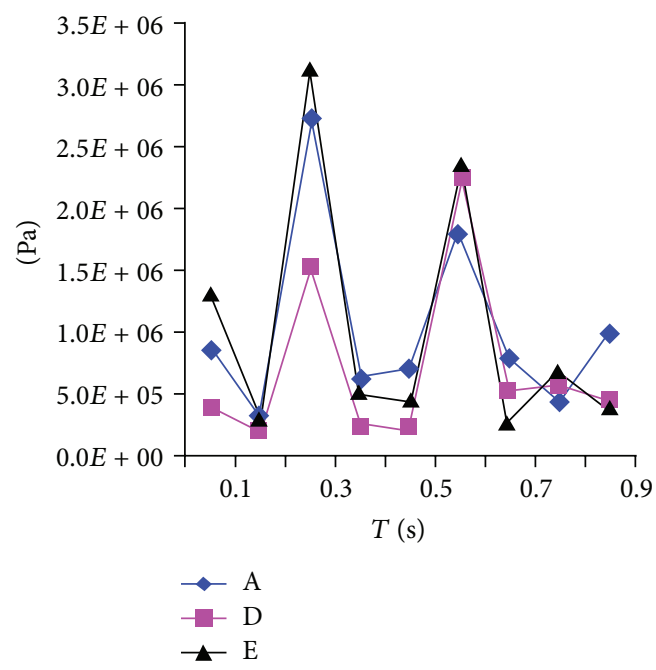

(e) Node 18

(f) Node 19

Figure 20: The Von Mises equivalent stress peak-curves of nodes around drilling hole in models A, D, and E. 


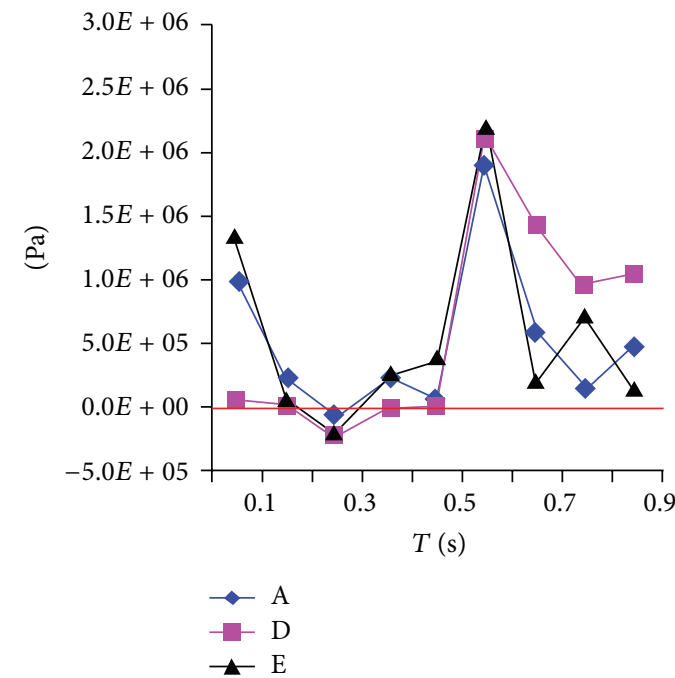

(a) Node 14
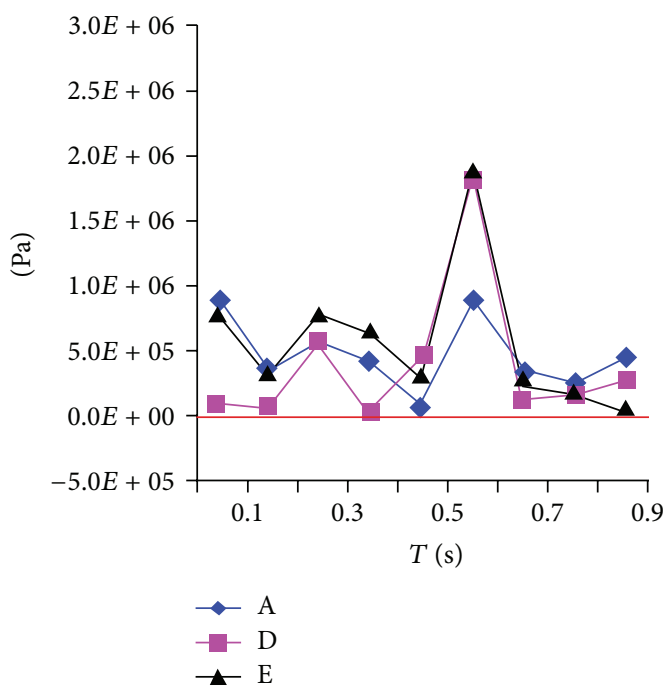

(c) Node 16

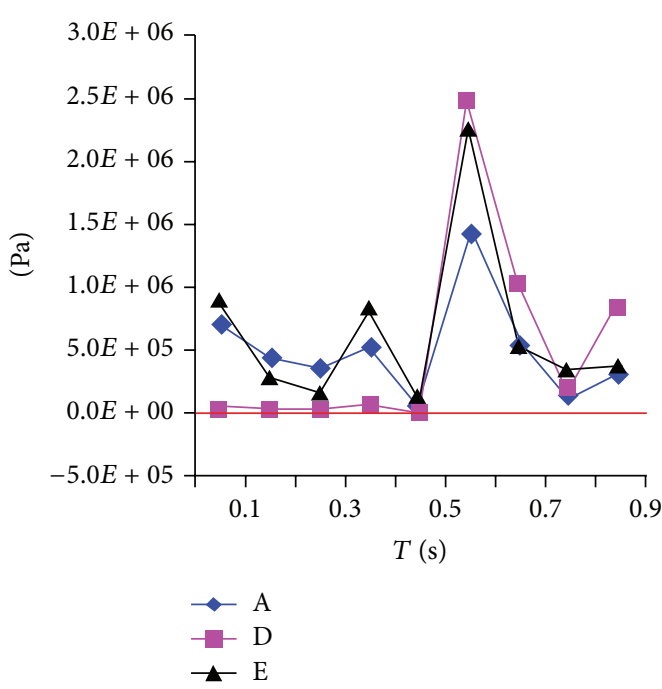

(e) Node 18

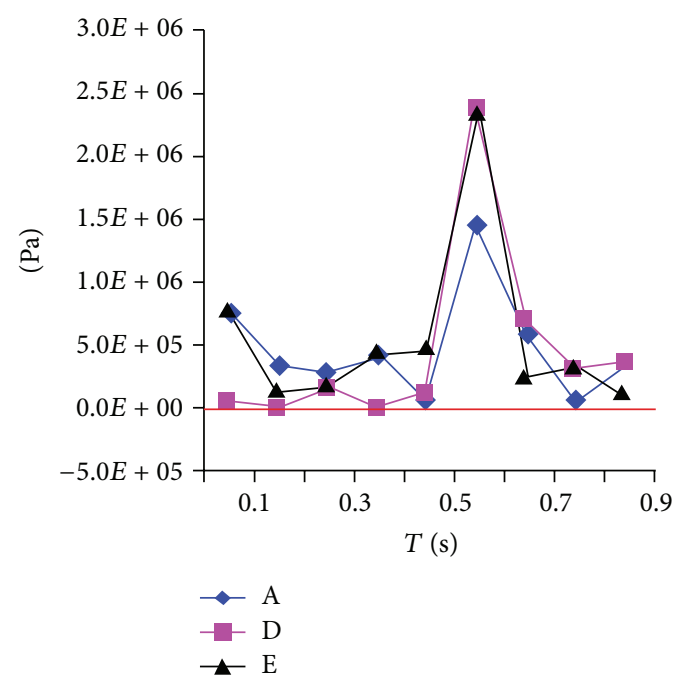

(b) Node 15

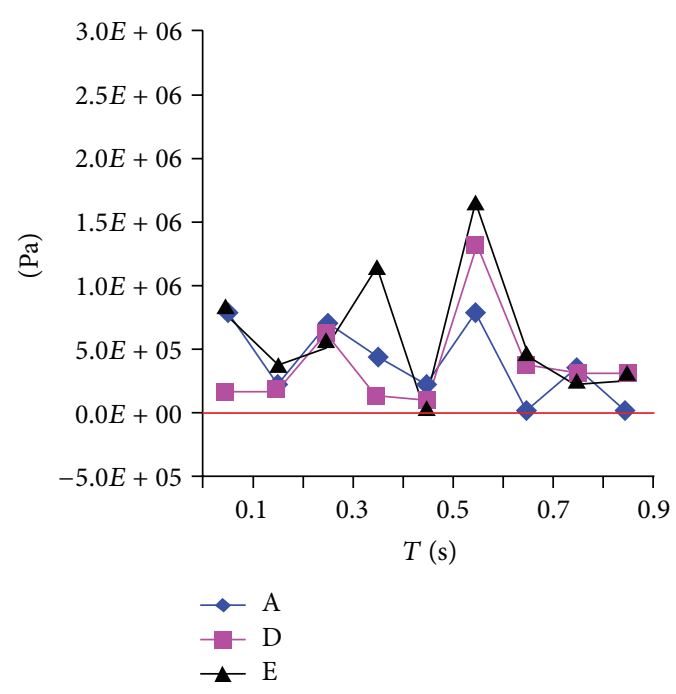

(d) Node 17

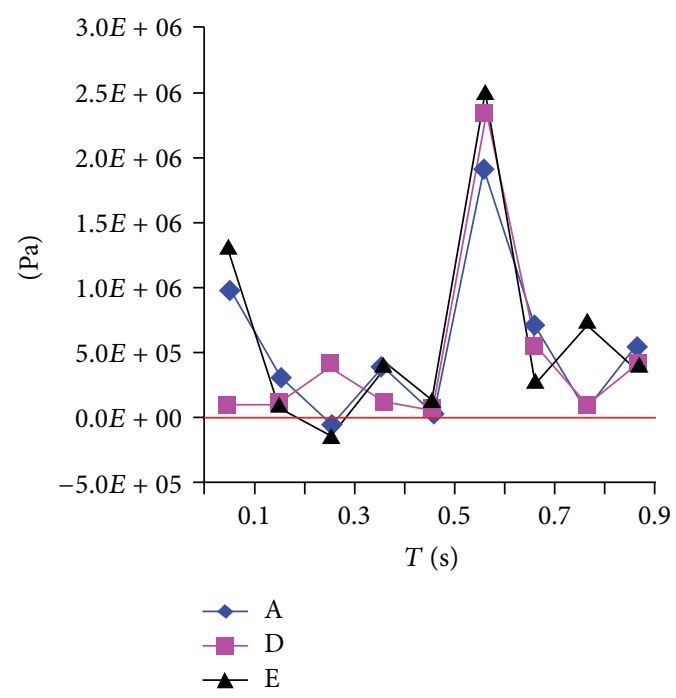

(f) Node 19

FIGURE 21: The 1st principal stress peak-curves of nodes around drilling hole in models A, D, and E. 

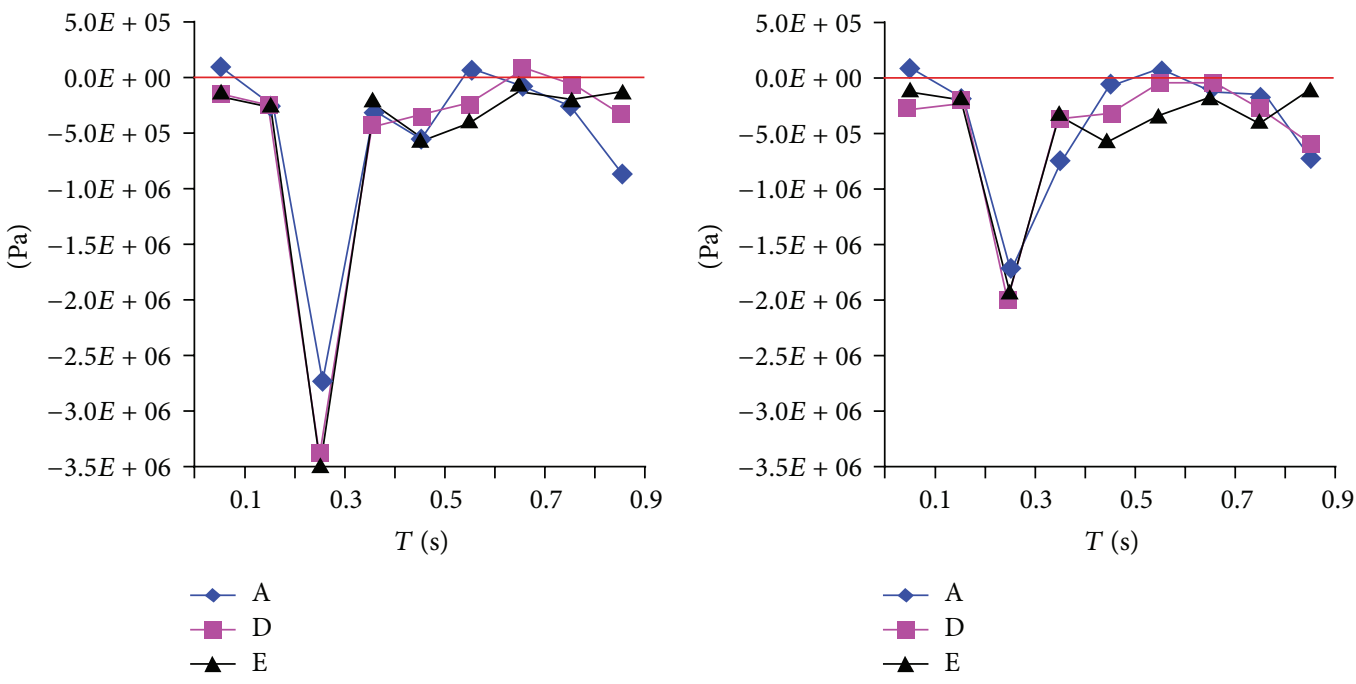

(a) Node 14

(b) Node 15
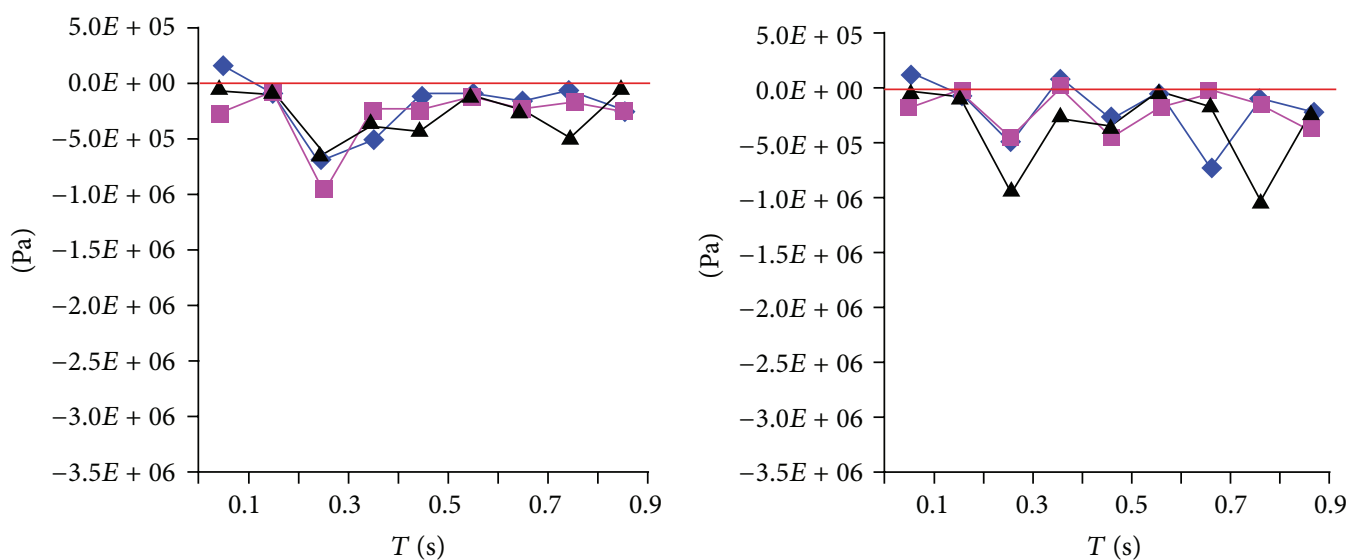

$$
\begin{aligned}
& \rightarrow \mathrm{A} \\
& -\mathrm{D} \\
& \leftarrow \mathrm{E}
\end{aligned}
$$$$
\begin{aligned}
& \rightarrow \mathrm{A} \\
& \rightarrow \mathrm{D} \\
& \leftarrow \mathrm{E}
\end{aligned}
$$

(c) Node 16

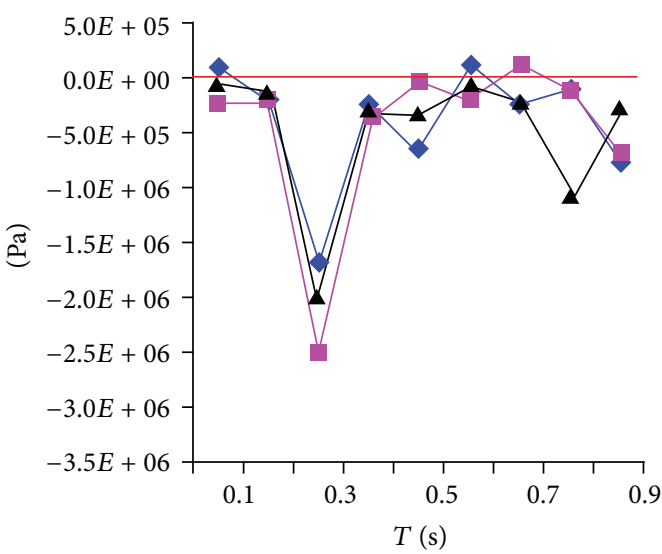

(d) Node 17

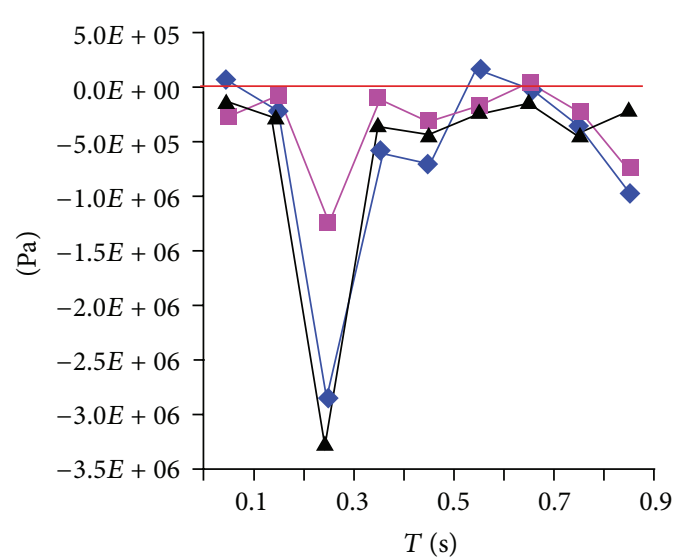

$$
\begin{aligned}
& \multimap \mathrm{A} \\
& -\mathrm{D} \\
& \leftarrow \mathrm{E}
\end{aligned}
$$

(e) Node 18

$$
\begin{aligned}
& \multimap \mathrm{A} \\
& -\mathrm{D} \\
& \leftarrow \mathrm{E}
\end{aligned}
$$

(f) Node 19

FIGURE 22: The 3rd principal stress peak-curves of nodes around drilling hole in models A, D, and E. 

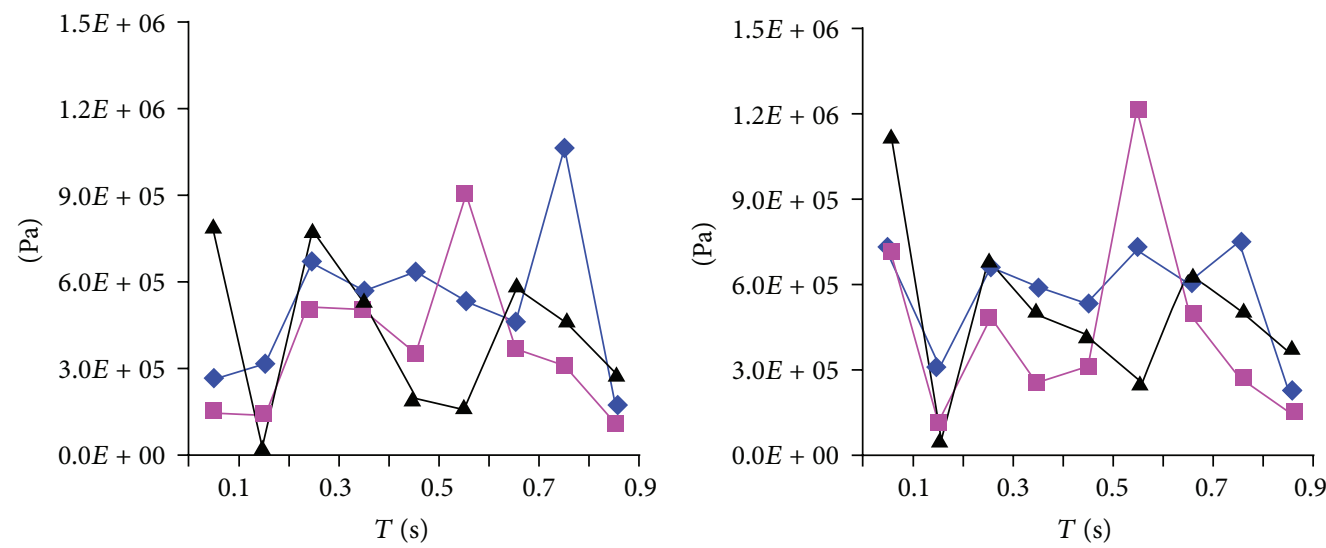

$$
\begin{aligned}
& \rightarrow \mathrm{A} \\
& -\mathrm{B} \\
& \leftarrow \mathrm{C}
\end{aligned}
$$$$
\begin{aligned}
& \leftarrow \mathrm{A} \\
& -\mathrm{B} \\
& \leftarrow \mathrm{C}
\end{aligned}
$$

(a) Node 13

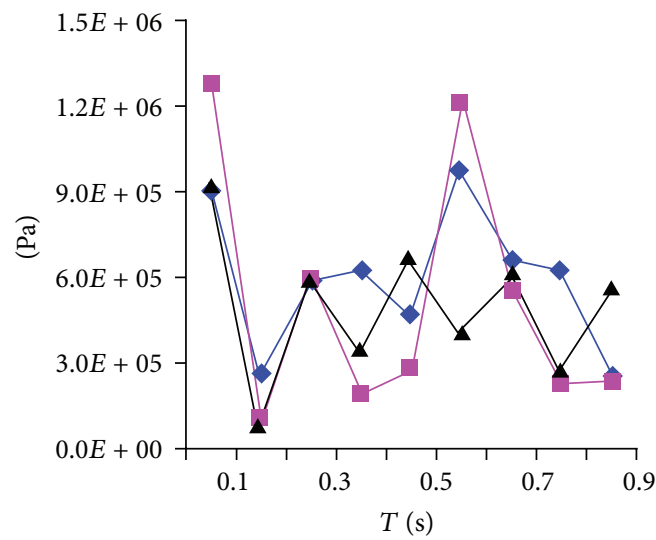

(b) Node 12

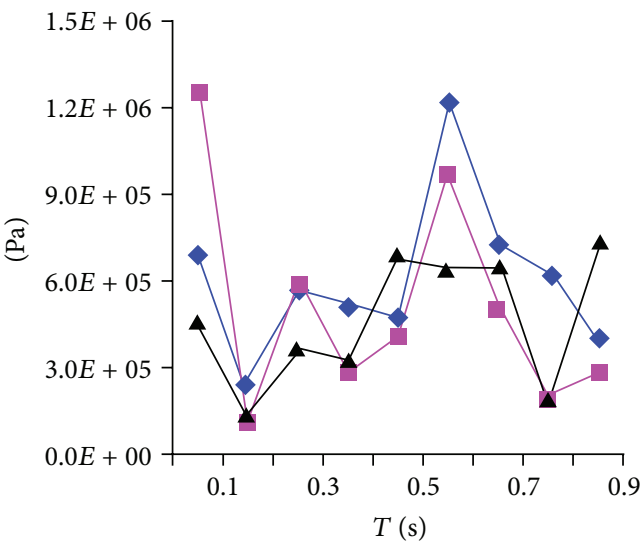

$$
\begin{aligned}
& -\mathrm{A} \\
& -\mathrm{B} \\
& -\mathrm{C}
\end{aligned}
$$$$
\begin{aligned}
& \multimap \mathrm{A} \\
& -\mathrm{B} \\
& -\mathrm{C}
\end{aligned}
$$

(c) Node 11

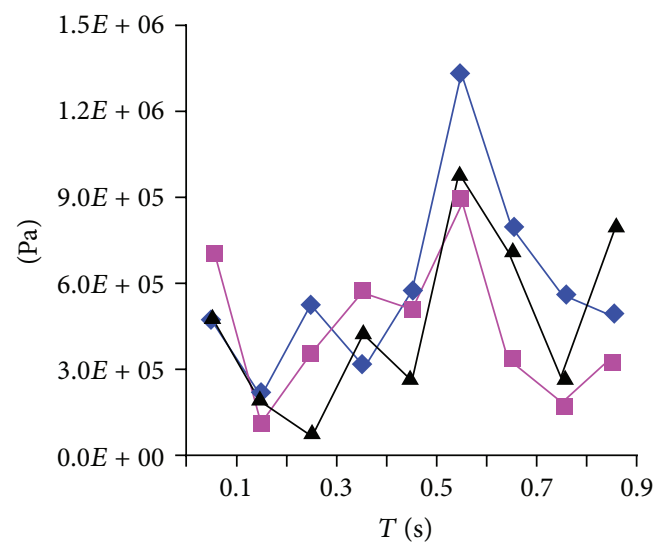

(d) Node 10

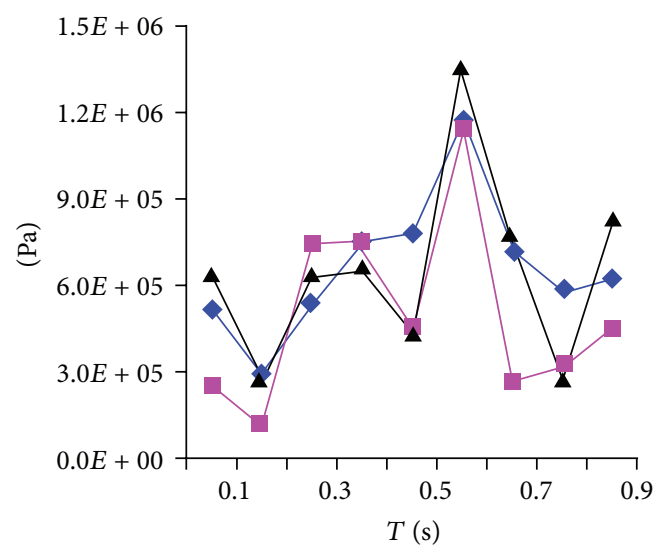

$$
\begin{aligned}
& \multimap \mathrm{A} \\
& -\mathrm{B} \\
& \rightarrow \mathrm{C}
\end{aligned}
$$$$
\begin{aligned}
& \multimap \mathrm{A} \\
& -\mathrm{B} \\
& \leftarrow \mathrm{C}
\end{aligned}
$$

(e) Node 9

(f) Node 8

FIGURE 23: The Von Mises equivalent stress peak-curves of nodes along sideline in models A, B, and C. 

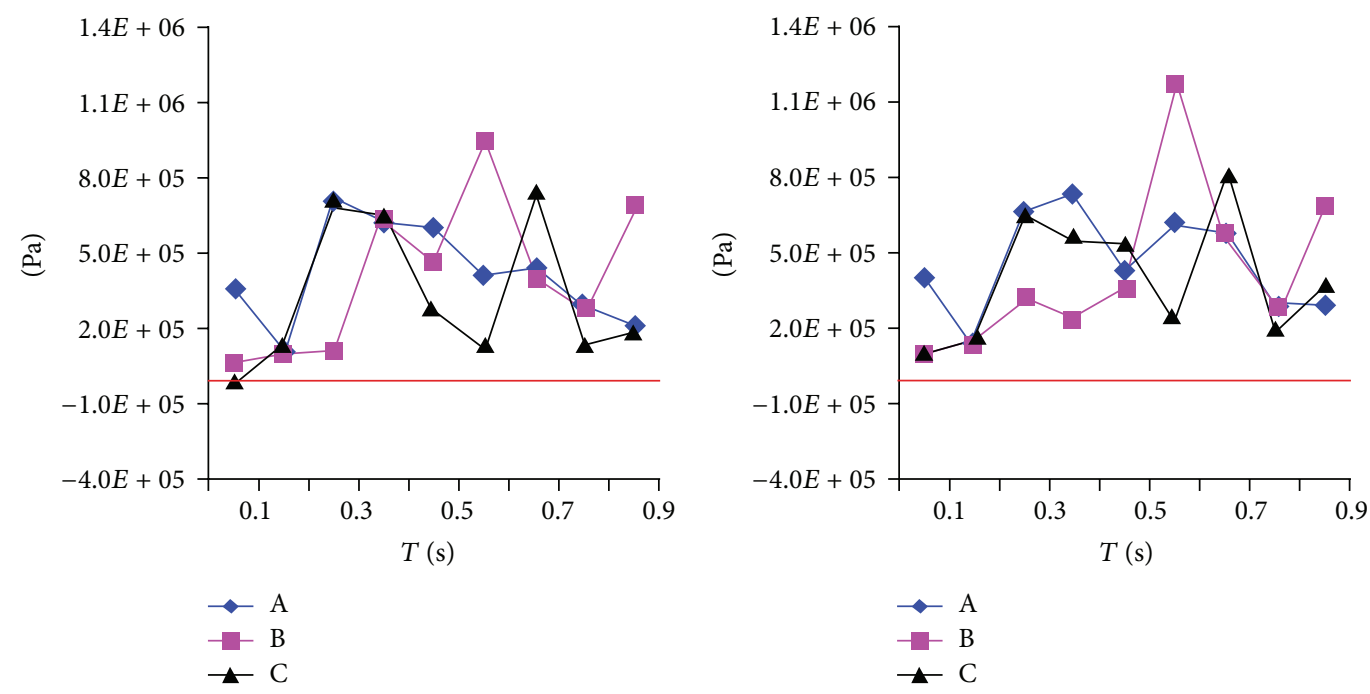

(a) Node 13

(b) Node 12
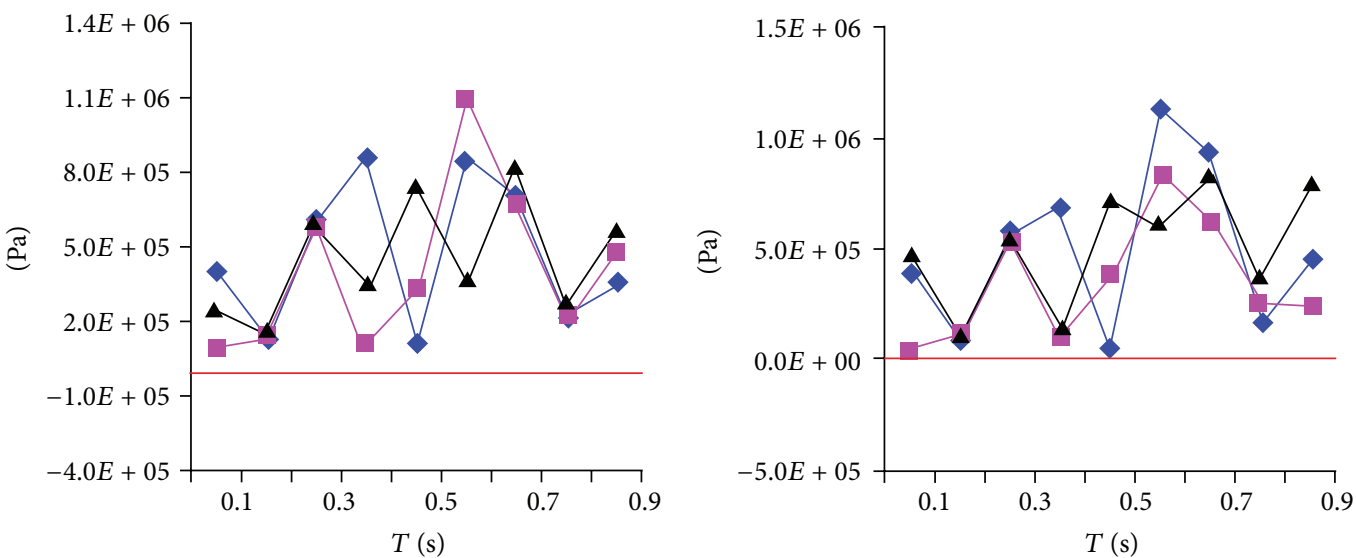

$$
\begin{aligned}
& \longrightarrow \mathrm{A} \\
& -\mathrm{B} \\
& \rightarrow \mathrm{C}
\end{aligned}
$$

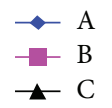

(c) Node 11

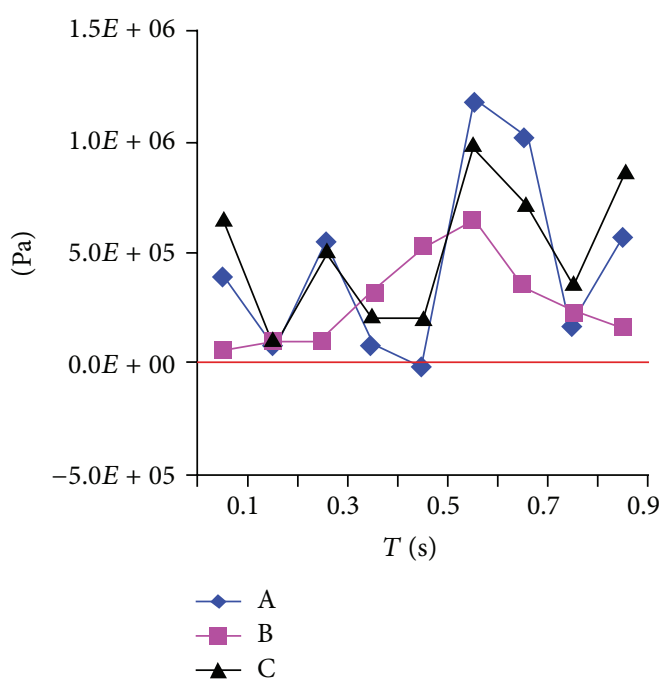

(d) Node 10

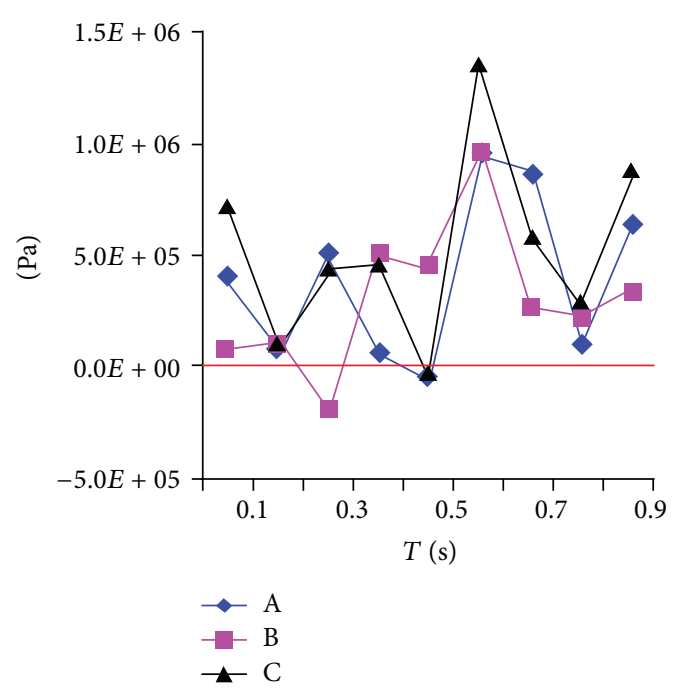

(e) Node 9

(f) Node 8

FIGURE 24: The 1st principal stress peak-curves of nodes along sideline in models A, B, and C. 

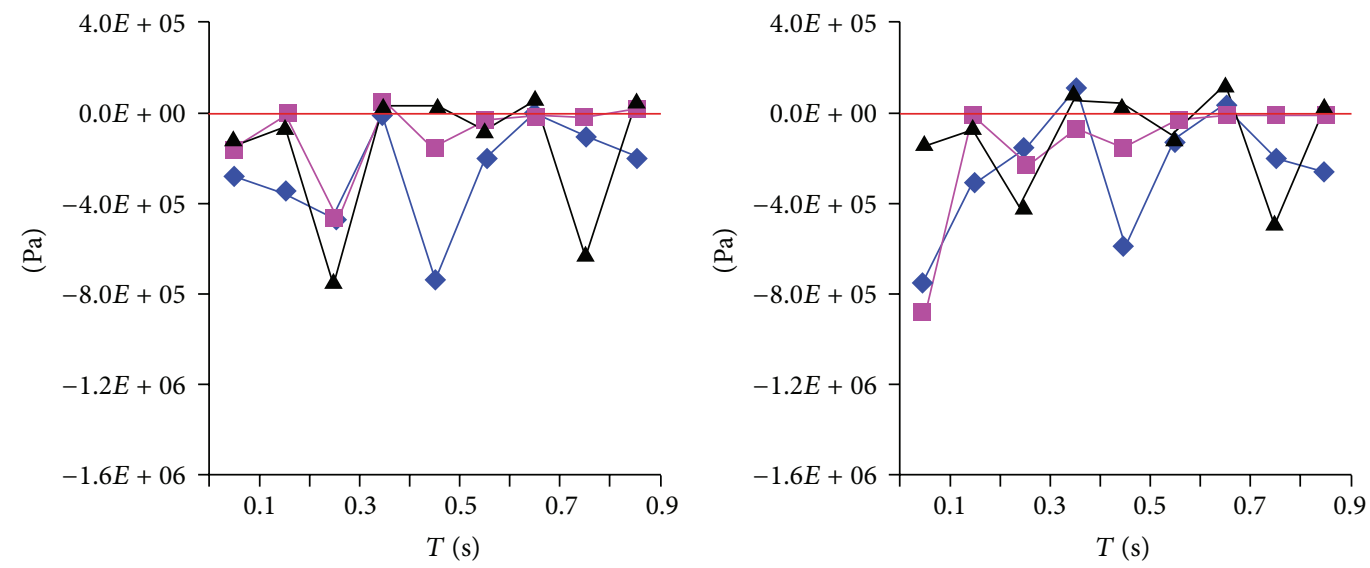

$$
\begin{aligned}
& \multimap \mathrm{A} \\
& -\mathrm{B} \\
& \leftarrow \mathrm{C}
\end{aligned}
$$$$
\begin{aligned}
& \multimap \mathrm{A} \\
& -\mathrm{B} \\
& \leftarrow \mathrm{C}
\end{aligned}
$$

(a) Node 13

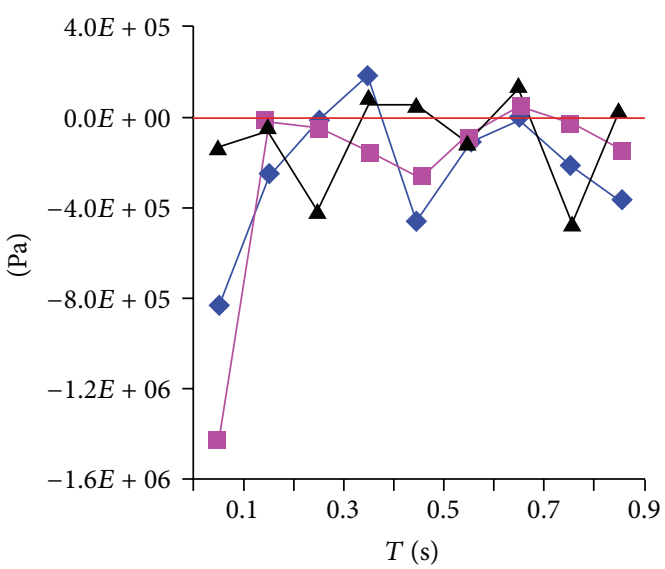

(b) Node 12

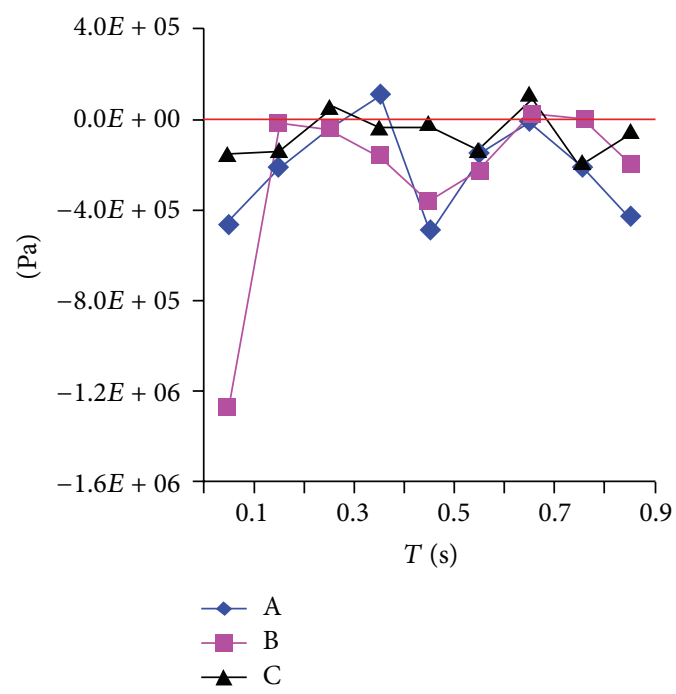

(c) Node 11

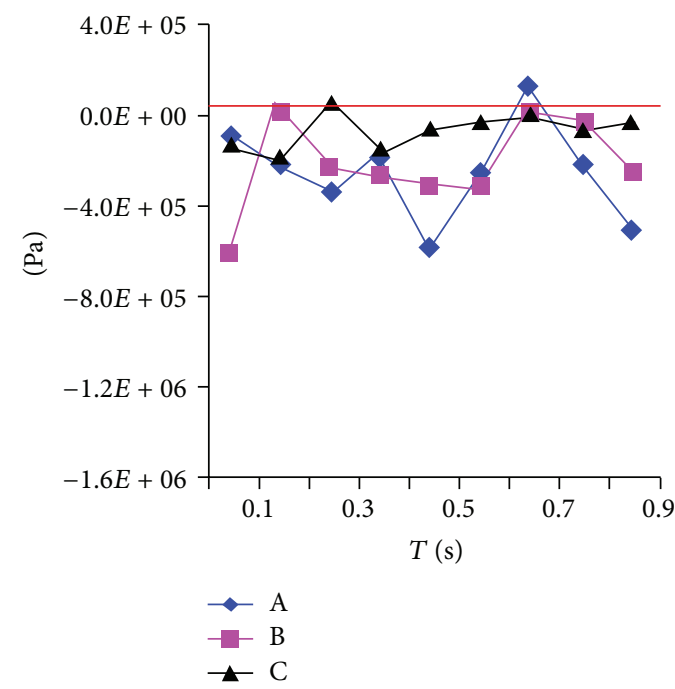

(d) Node 10

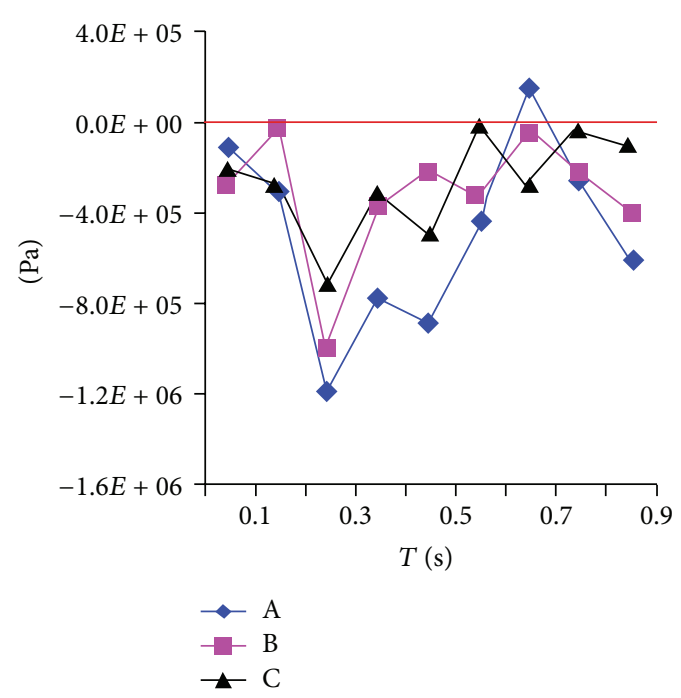

(e) Node 9

(f) Node 8

FIGURE 25: The 3rd principal stress peak-curves of nodes along sideline in models A, B, and C. 

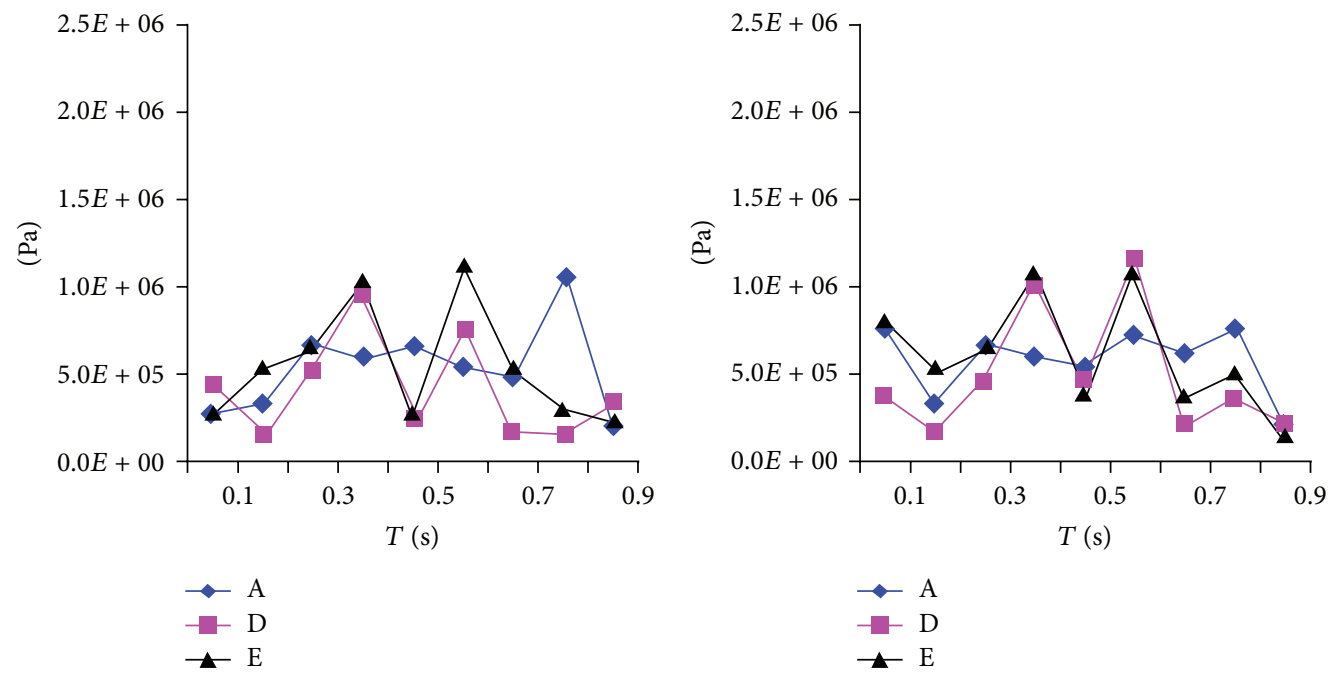

(a) Node 13
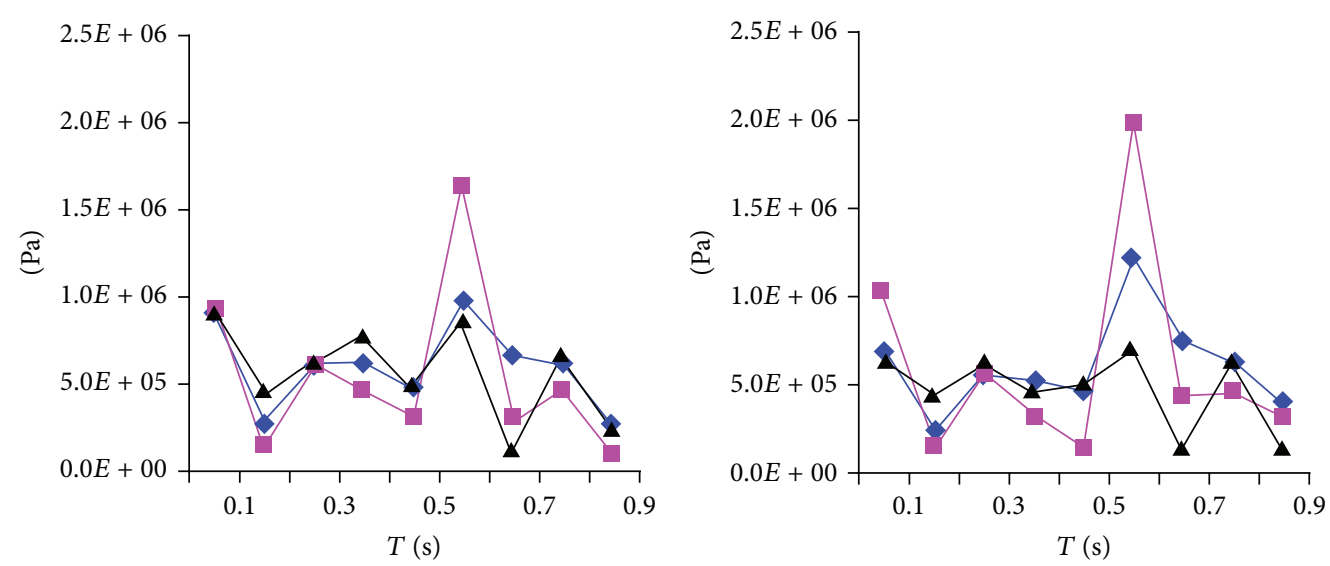

$$
\begin{aligned}
& \rightarrow \mathrm{A} \\
& -\mathrm{D} \\
& \leftarrow \mathrm{E}
\end{aligned}
$$$$
\begin{aligned}
& \multimap \mathrm{A} \\
& -\mathrm{D} \\
& -\mathrm{E}
\end{aligned}
$$

(c) Node 11

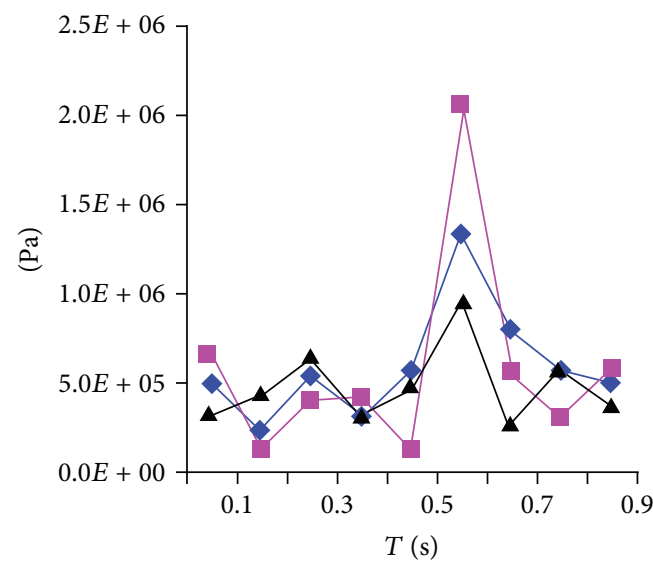

(d) Node 10

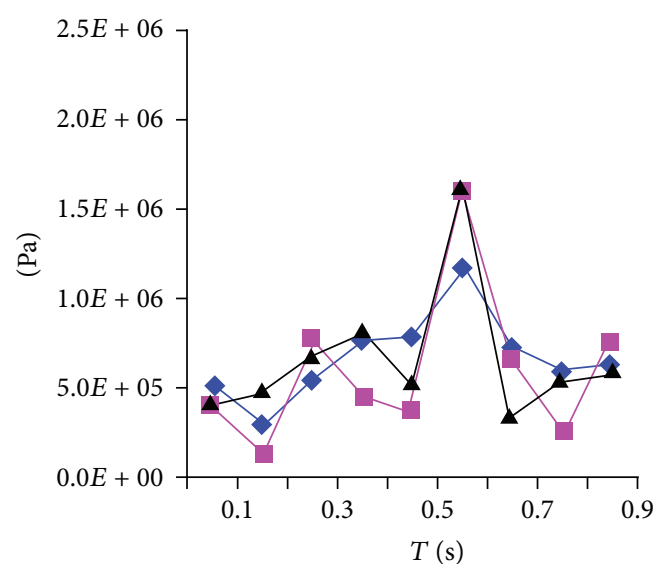

$$
\begin{aligned}
& \longrightarrow \mathrm{A} \\
& -\mathrm{D} \\
& \leftarrow \mathrm{E}
\end{aligned}
$$$$
\begin{aligned}
& \multimap \mathrm{A} \\
& -\mathrm{D} \\
& \leftarrow \mathrm{E}
\end{aligned}
$$

(e) Node 9

(f) Node 8

FIGURE 26: The Von Mises equivalent stress peak-curves of nodes along sideline in models A, D, and E. 

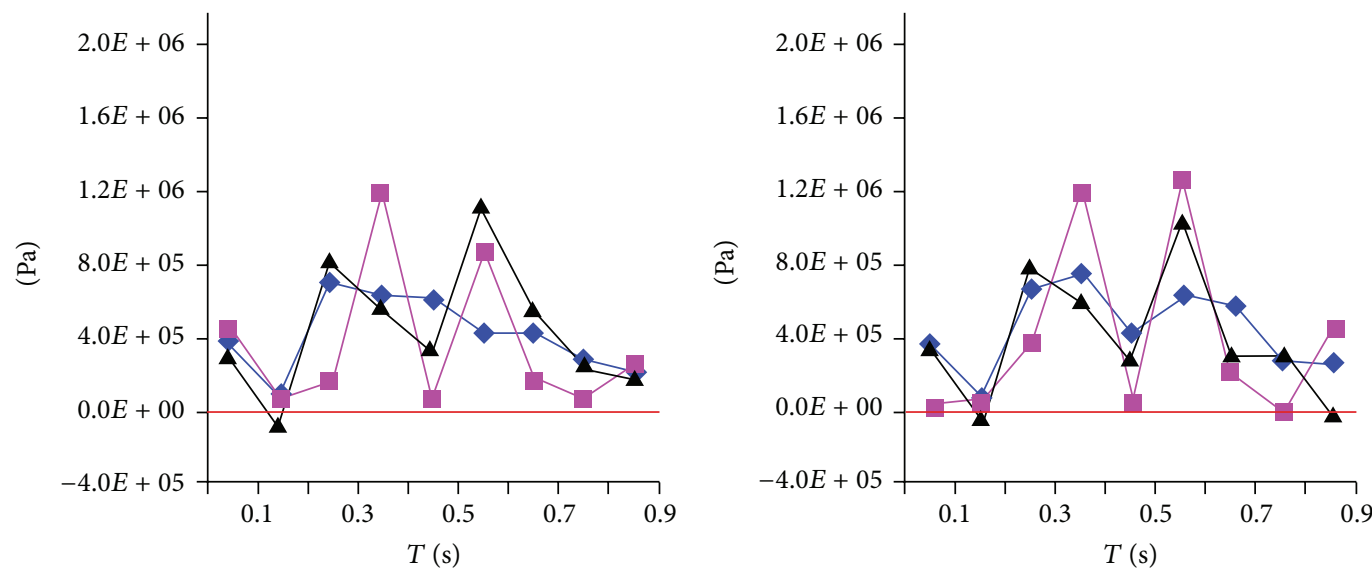

$$
\begin{aligned}
& \rightarrow \mathrm{A} \\
& -\mathrm{D} \\
& \leftarrow \mathrm{E}
\end{aligned}
$$$$
\begin{aligned}
& \multimap \mathrm{A} \\
& -\mathrm{D} \\
& \leftarrow \mathrm{E}
\end{aligned}
$$

(a) Node 13

(b) Node 12
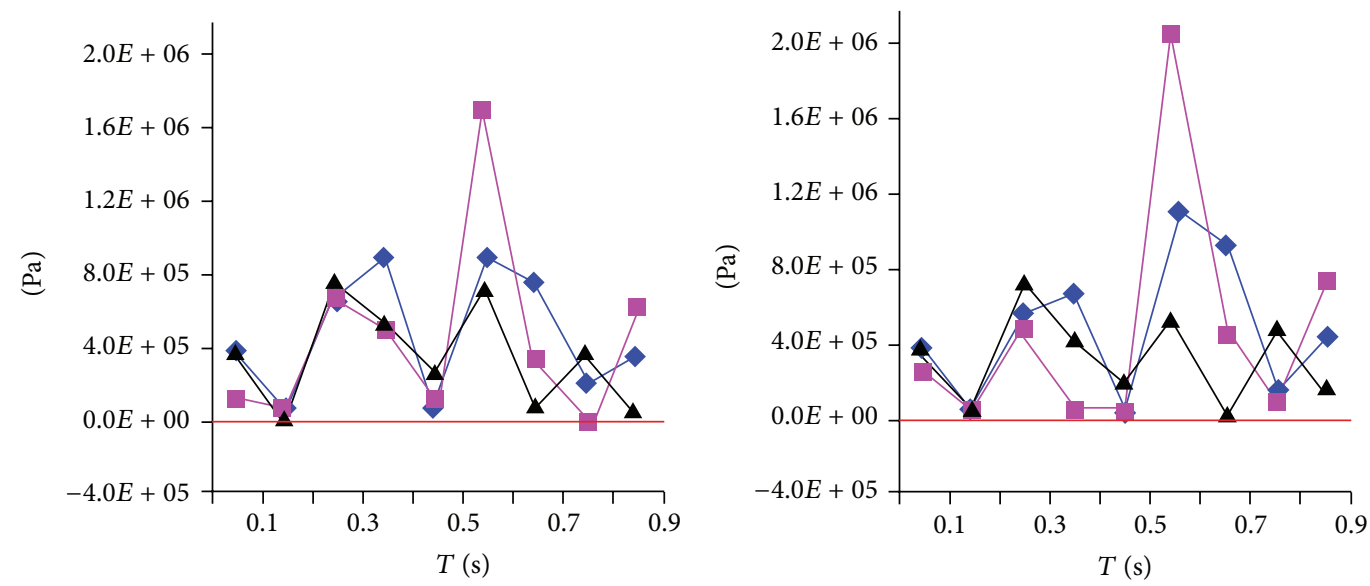

$$
\begin{aligned}
& \rightarrow A \\
& -\mathrm{D} \\
& \leftarrow \mathrm{E}
\end{aligned}
$$$$
\begin{aligned}
& \leftarrow \mathrm{A} \\
& -\mathrm{D} \\
& \leftarrow \mathrm{E}
\end{aligned}
$$

(c) Node 11

(d) Node 10

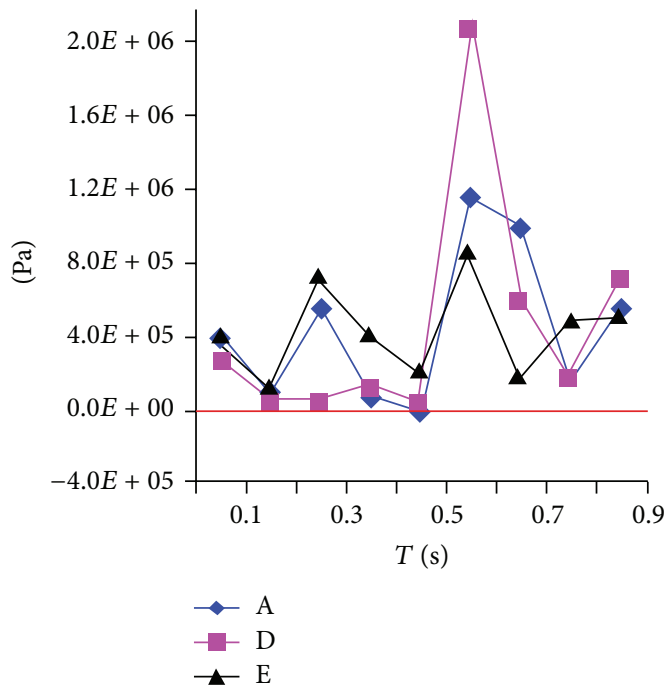

(e) Node 9

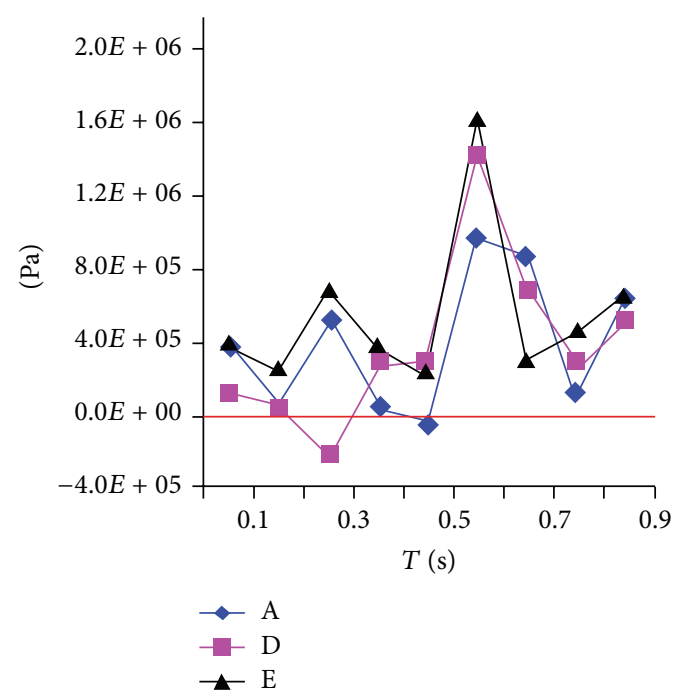

(f) Node 8

FIGURE 27: The 1st principal stress peak-curves of nodes along sideline in models A, D, and E. 

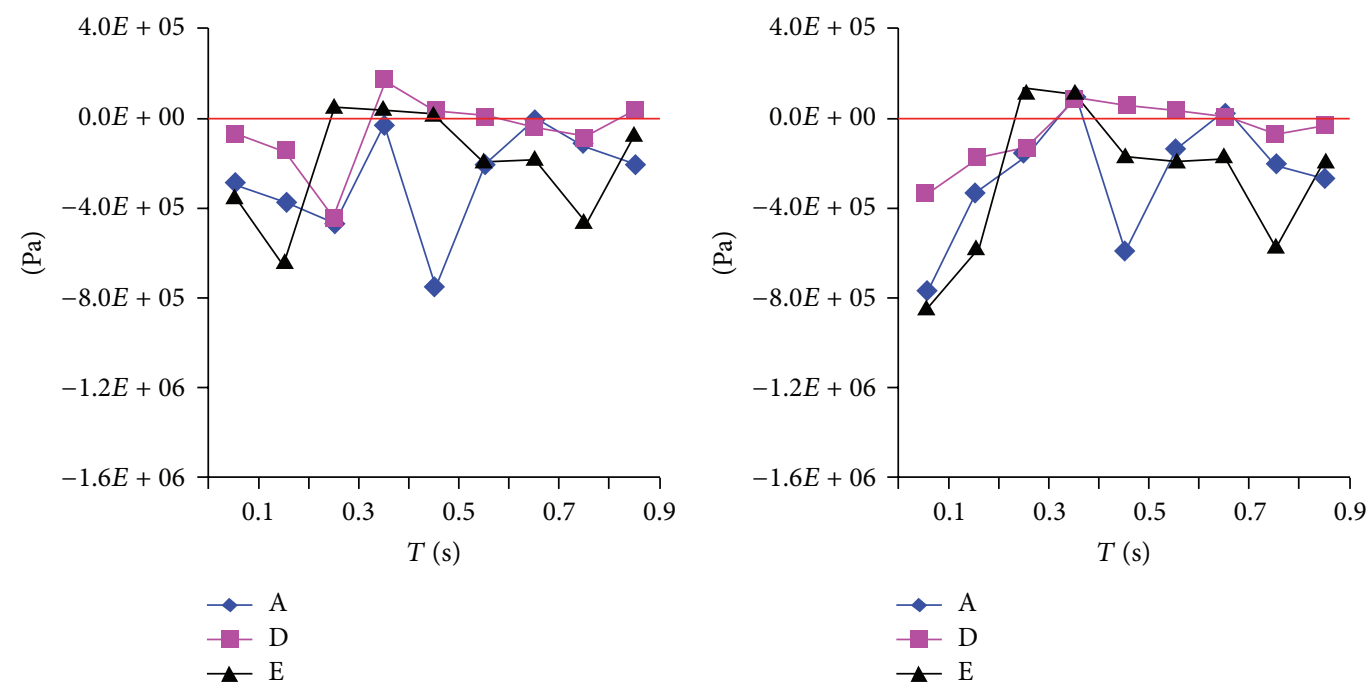

(a) Node 13
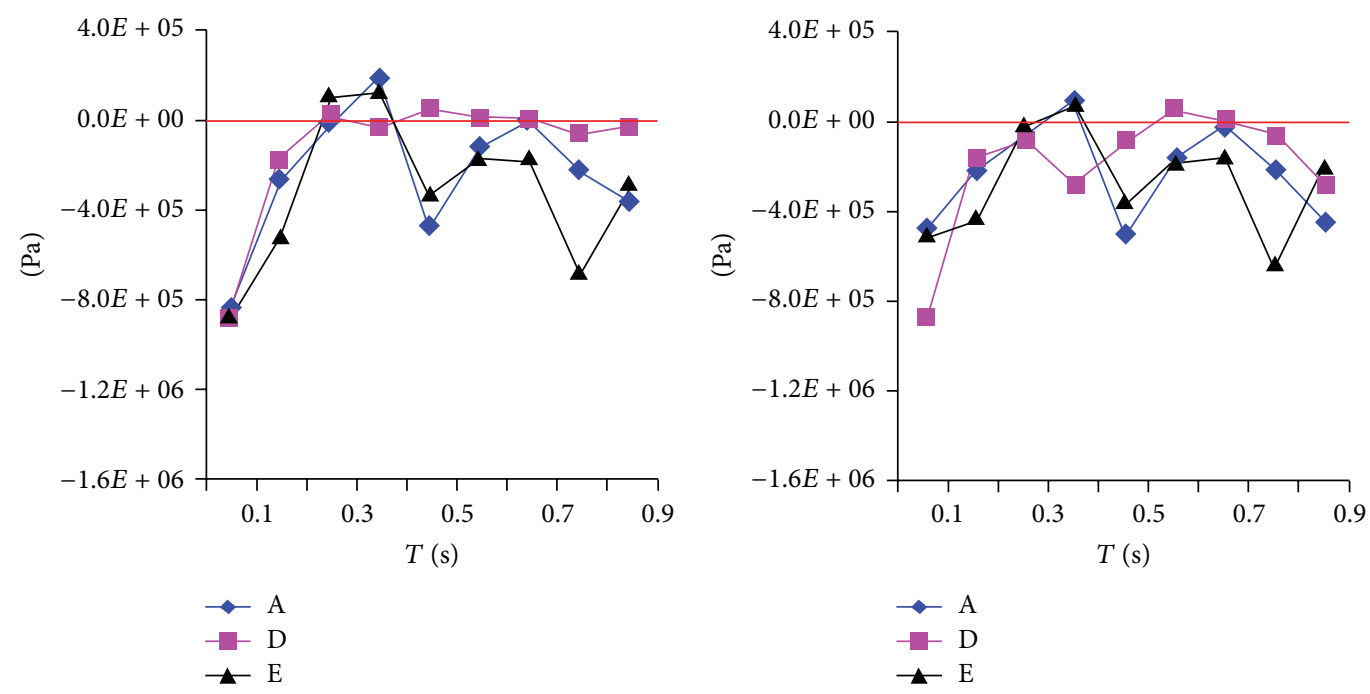

(c) Node 11
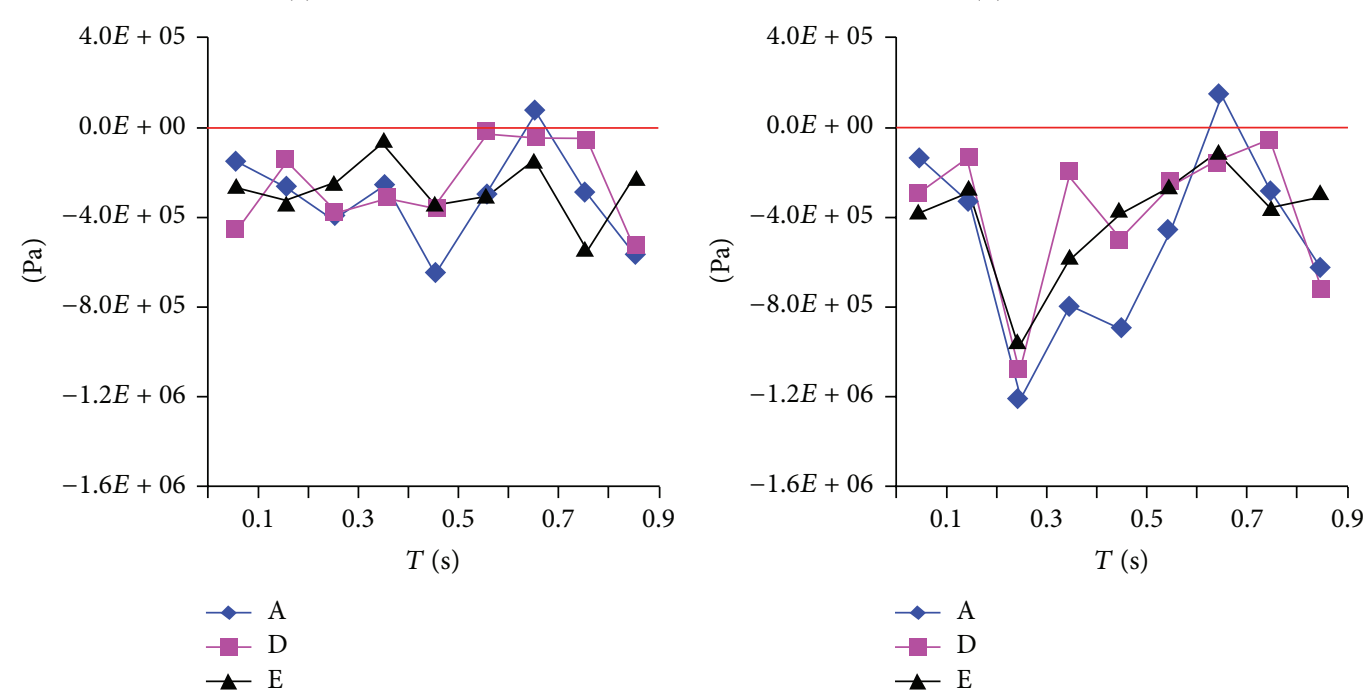

(e) Node 9

(f) Node 8

FIGURE 28: The 3rd principal stress peak-curves of nodes along sideline in models A, D, and E. 


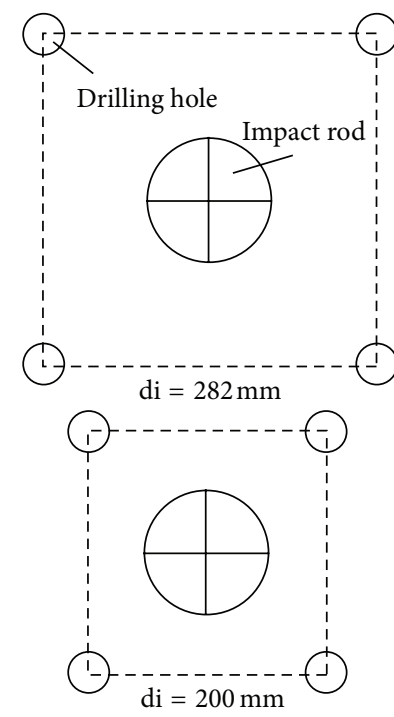

(a) Distribution of drilling holes
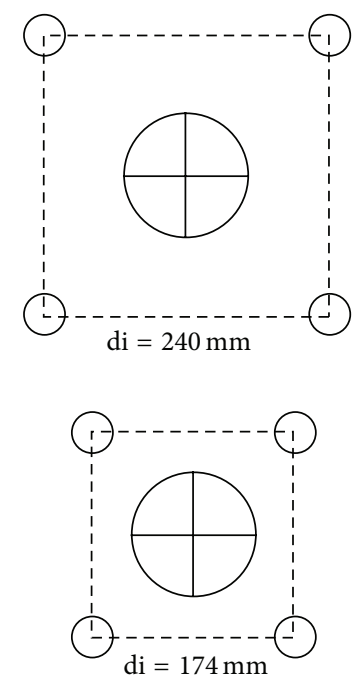

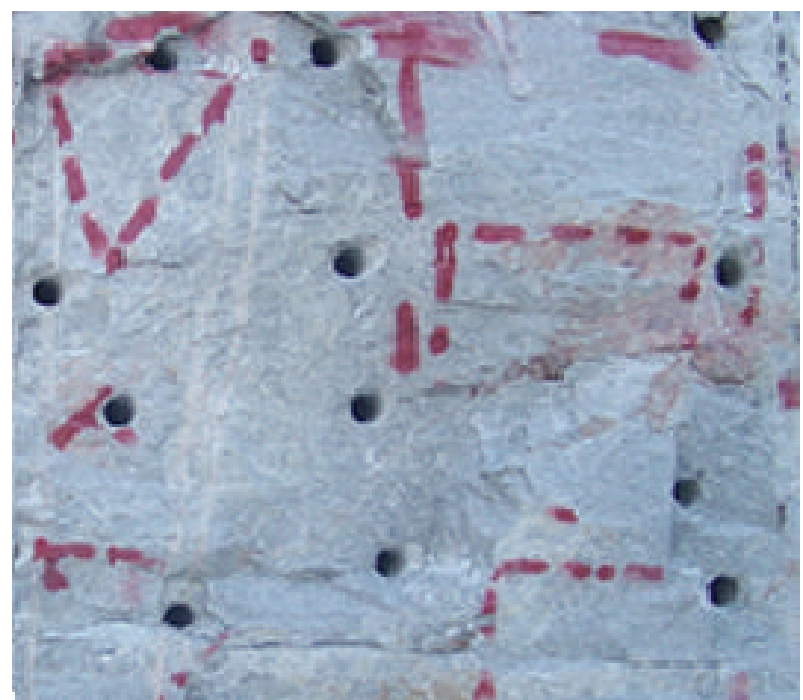

(b) Final working face after drilling

FIgURE 29: Distribution of drilling holes and the final experimental working face.
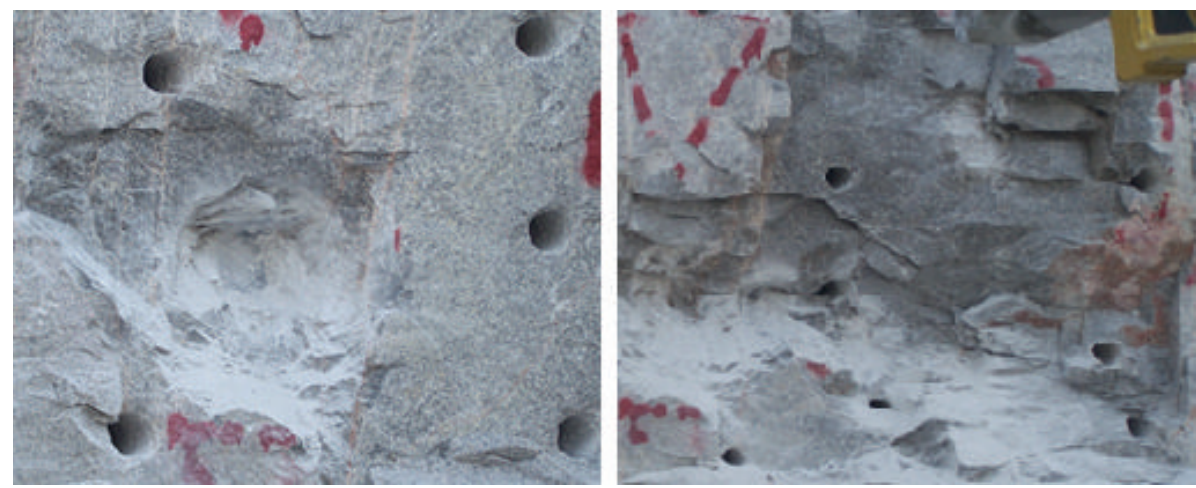

(a) Working face after impact breaking
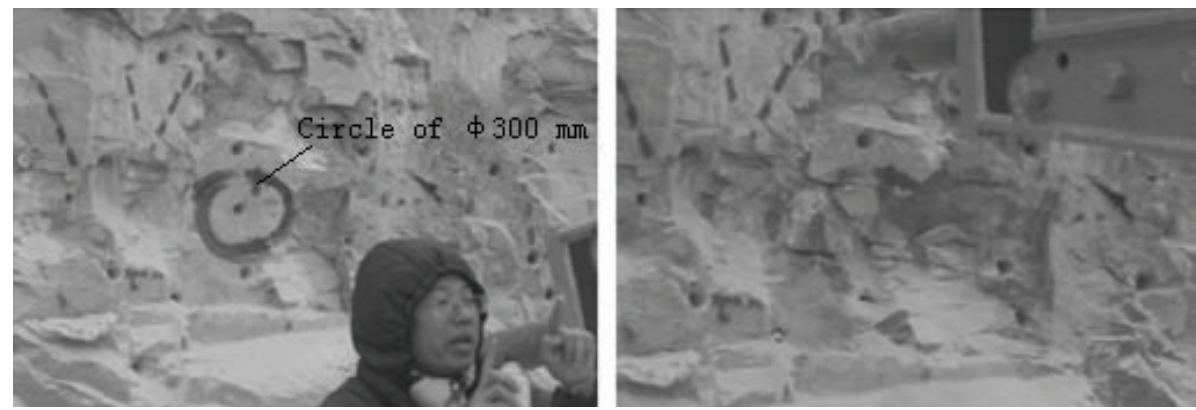

(b) Impact around a circle of $\phi 300 \mathrm{~mm}$

FIgURE 30: Actual breaking conditions in HDIHT field experiments.

$V_{\text {break }}$ : Broken rock volume of each impact $\left(\mathrm{m}^{3}\right)$

$v_{\text {rod }}: \quad$ Velocity of $\operatorname{rod}\left(\mathrm{m} \cdot \mathrm{s}^{-1}\right)$

$h_{\text {pit }}$ : Depth of broken pit $(\mathrm{m})$

$r_{\text {pit }}: \quad$ Radius of broken pit $(\mathrm{m})$

$G$ : Weight of hammer piston $(\mathrm{kg})$

$F$ : $\quad$ Pressing force of hammer (N).

\section{Greek Letters}

$\tau$ : Shear stress per unit length $\left(\mathrm{Pa} \cdot \mathrm{m}^{-1}\right)$

$\theta$ : Half edge angle (rad) $\psi$ : Shear plane angle (rad).

Subscripts

CSW: Chiseling specific work $\left(\mathrm{kg} \cdot \mathrm{m} \cdot \mathrm{cm}^{-3}\right)$. 


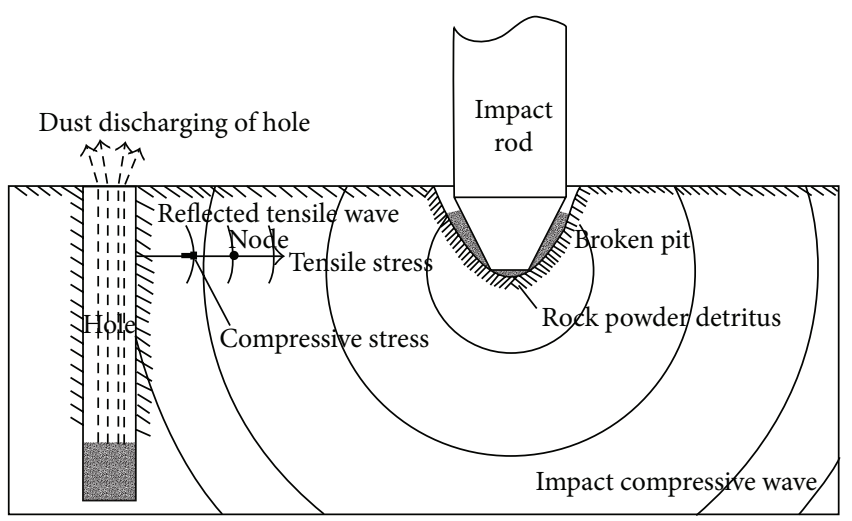

FIGURE 31: Sketch of hard-rock breaking mechanism of HDIHT technology.

\section{Conflict of Interests}

The authors declare that there is no conflict of interests regarding the publication of this paper.

\section{Acknowledgments}

The research is supported by the Staring Project of Youth Team of Taiyuan University of Technology (2013T036), Qualified Personnel Foundation of Taiyuan University of Technology (TYUT-RC201426a), and the 2014 Year in Shanxi CoalBased Key Scientific \& Technological Projects (MJ2014-06). The authors would like to thank the Shanxi Key Laboratory of Fully Mechanized Coal Mining Equipment, Taiyuan, Shanxi, China.

\section{References}

[1] X. H. Xu and J. Yu, Rock Breaking Theory, Chinese Ming Industry Press, Beijing, China, 1984.

[2] Y. R. Liu and H. M. Tang, Rock Mechanics, Chinese University of Geosciences Press, Wuhan, China, 1999.

[3] A. Munjiza, D. R. J. Owen, and N. Bicanic, "A combined finitediscrete element method in transient dynamics of fracturing solids," Engineering Computations, vol. 12, no. 2, pp. 145-174, 1995.

[4] A. Munjiza, T. Bangash, and N. W. M. John, “The combined finite-discrete element method for structural failure and collapse," Engineering Fracture Mechanics, vol. 71, no. 4-6, pp. 469483, 2004.

[5] Y.-J. Zuo, C.-A. Tang, W.-C. Zhu, D.-Y. Li, and S.-C. Li, "Numerical analysis of tunnel reinforcing influences on failure process of surrounding rock under explosive stress waves," Journal of Central South University of Technology, vol. 15, no. 5, pp. 632-638, 2008.

[6] Q. L. Yu, W. C. Zhu, C. A. Tang, and T. H. Yang, "Impact of rock microstructures on failure processes-numerical study based on DIP technique," Geomechanics and Engineering, vol. 7, no. 4, pp. 375-401, 2014.

[7] G. Li and C.-A. Tang, "A statistical meso-damage mechanical method for modeling trans-scale progressive failure process of rock," International Journal of Rock Mechanics and Mining Sciences, vol. 74, pp. 133-150, 2015.

[8] L. Jing, Y. Ma, and Z. Fang, "Modeling of fluid flow and solid deformation for fractured rocks with discontinuous deformation analysis (DDA) method," International Journal of Rock Mechanics and Mining Sciences, vol. 38, no. 3, pp. 343-355, 2001.

[9] X.-L. Zhang, Y.-Y. Jiao, and J. Zhao, "Simulation of failure process of jointed rock," Journal of Central South University of Technology, vol. 15, no. 6, pp. 888-894, 2008.

[10] M. Xia and K.-P. Zhou, "Particle simulation of the failure process of brittle rock under triaxial compression," International Journal of Minerals, Metallurgy and Materials, vol. 17, no. 5, pp. 507-513, 2010.

[11] A. Li, G.-J. Shao, T.-T. Yu, J.-B. Su, and S.-Y. Ding, "Mesoscopic numerical simulation of stratified rock failure using digital image processing," Advances in Mechanical Engineering, vol. 2014, Article ID 106073, 12 pages, 2014.

[12] X. Tan, H. Konietzky, and T. Frühwirt, "Experimental and numerical study on evolution of biot's coefficient during failure process for brittle rocks," Rock Mechanics and Rock Engineering, vol. 48, no. 3, pp. 1289-1296, 2015.

[13] P. K. Kaiser and B.-H. Kim, "Characterization of strength of intact brittle rock considering confinement-dependent failure processes," Rock Mechanics and Rock Engineering, vol. 48, no. 1, pp. 107-119, 2014.

[14] K. B. Min, J. Rutqvist, C.-F. Tsang, and L. Jing, "Stressdependent permeability of fractured rock masses: a numerical study," International Journal of Rock Mechanics and Mining Sciences, vol. 41, no. 7, pp. 1191-1210, 2004.

[15] A. Baghbanan and L. Jing, "Stress effects on permeability in a fractured rock mass with correlated fracture length and aperture," International Journal of Rock Mechanics and Mining Sciences, vol. 45, no. 8, pp. 1320-1334, 2008.

[16] Z. Zhao, L. Jing, I. Neretnieks, and L. Moreno, "Numerical modeling of stress effects on solute transport in fractured rocks," Computers and Geotechnics, vol. 38, no. 2, pp. 113-126, 2011.

[17] M. Genet, W. Y. Yan, and T. Tran-Cong, "Investigation of a hydraulic impact: a technology in rock breaking," Archive of Applied Mechanics, vol. 79, no. 9, pp. 825-841, 2009.

[18] G. V. Basheev, P. A. Martynyuk, and E. N. Sher, "Calculation model for breaking a lump off a rock mass by an impact of a blunt wedge-like tool," Journal of Mining Science, vol. 43, no. 5, pp. 477-488, 2007. 


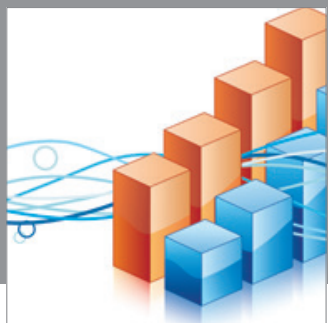

Advances in

Operations Research

mansans

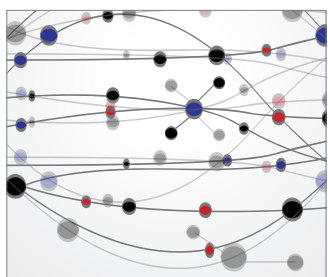

The Scientific World Journal
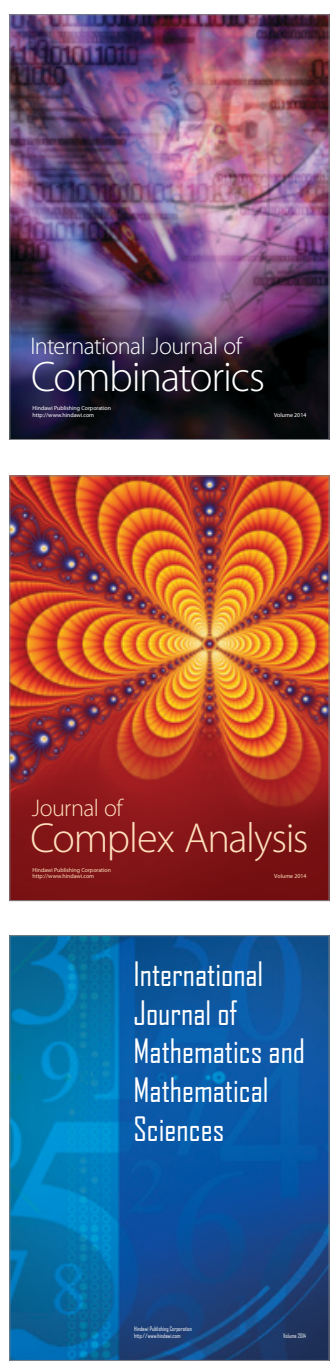
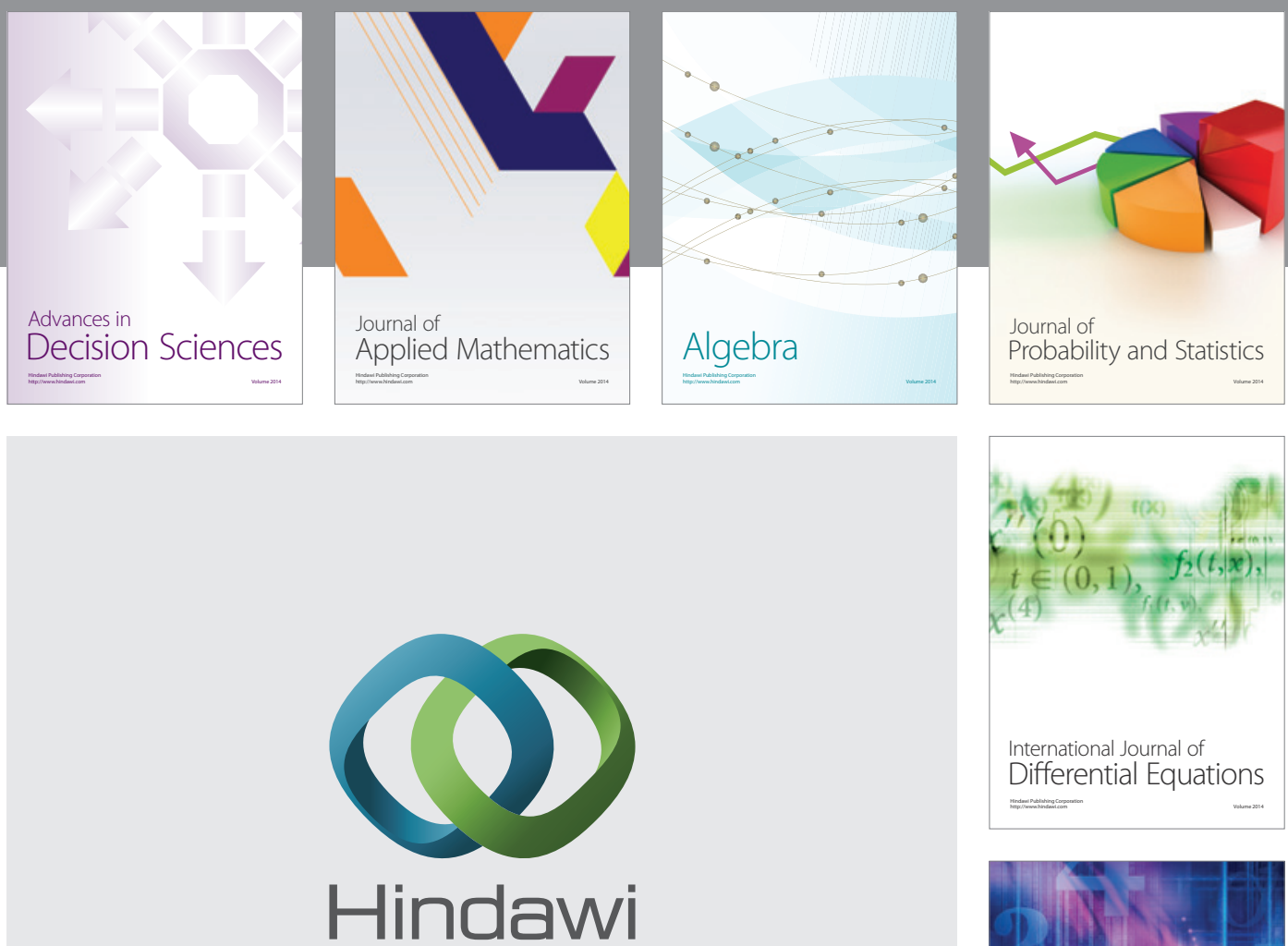

Submit your manuscripts at http://www.hindawi.com
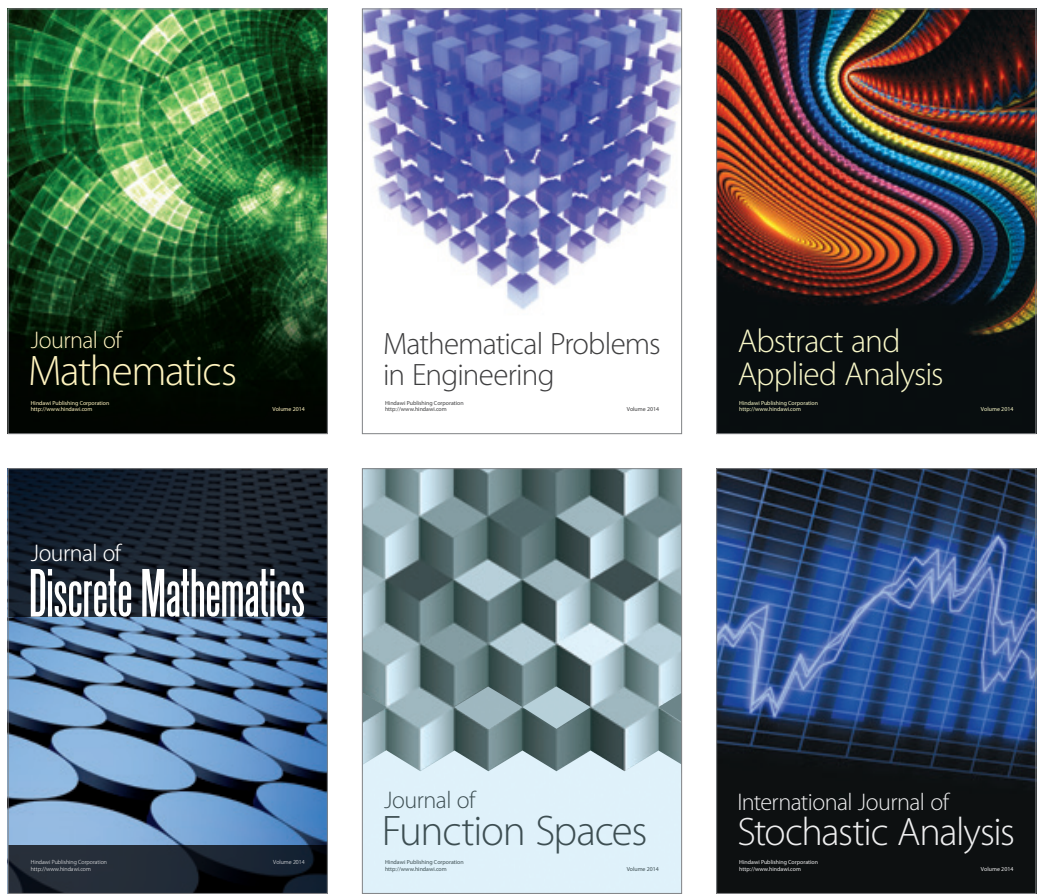

Journal of

Function Spaces

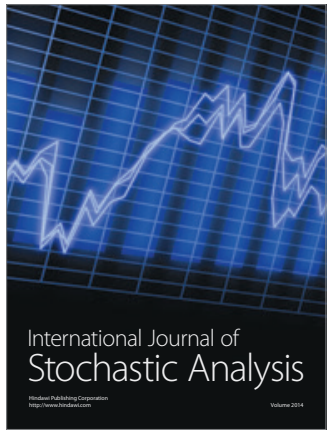

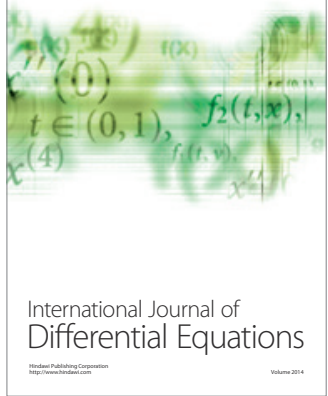
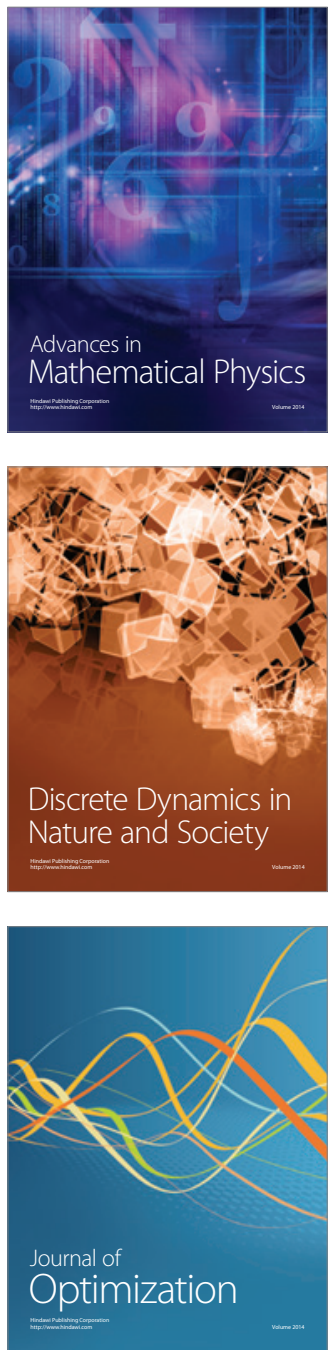